\title{
Propriedades ópticas de aerossóis naturais e de queimadas da Amazônia
}

\author{
Melina Mara de Andrade Paixão \\ Dissertação de mestrado apresentada ao Instituto \\ de Física para obtenção do título de Mestre em \\ Ciências.
}

\author{
Orientador: \\ Prof. Dr. Paulo Eduardo Artaxo Netto

\section{Banca Examinadora:} \\ Prof. Dr. Paulo Eduardo Artaxo Netto (IF/USP) \\ Prof. Dr. Mikiya Muramatsu (IF/USP) \\ Prof. Dr. Eduardo Landulfo (IPEN)
}


FICHA CATALOGRÁFICA

Preparada pelo Serviço de Biblioteca e Informação do Instituto de Física da Universidade de São Paulo

Paixão, Melina Mara de Andrade

Propriedades ópticas de aerossóis naturais e de queimadas da Amazônia. - São Paulo, 2011.

Dissertação (Mestrado) - Universidade de São Paulo. Instituto de Física, Departamento de Física Aplicada.

Orientador: Prof. Dr. Paulo Eduardo Artaxo Netto

Área de Concentração: Física

Unitermos: 1. Física experimental; 2. Aerossóis;

3. Radiação atmosférica; 4. Mudanças climáticas globais. 
À minha querida mãe. 



\section{AGRADECIMENTOS}

Agradeço, primeiramente, ao Prof. Dr. Paulo Artaxo por sua orientação, incentivo e otimismo fantástico, e pela vontade inesgotável de trabalhar que me inspirou nos momentos mais difíceis.

Ao Alexandre Correia, pelas inúmeras conversas, discussões, conselhos, cafés, imprescindíveis ao desenvolvimento do presente trabalho.

Aos técnicos Gilberto Nishioka, Alcides Camargo Ribeiro, Fernando Morais e Ana Lucia Loureiro pelo empenho inestimável em garantir a qualidade das medidas de campo.

Ao Carlos, por sua incrível paciência e determinação.

A todos os integrantes do LFA, pelas conversas animadas e horas de trabalho mais agradáveis.

Ao Joel Schafer, pelo apoio científico e amizade.

Ao Áttila, pela amizade, apoio, incentivo nos momentos críticos, e ajuda nas figuras aqui eternizadas.

Aos meus amigos. Aos meus colegas.

Aos meus pais. 



\section{RESUMO}

Foram analisadas as principais propriedades ópticas do aerossol atmosférico a partir dos radiômetros da rede NASA/AERONET em três regiões de interesse: o Norte da Amazônia, a região do arco do desflorestamento, e a região do cerrado. A metodologia envolveu a obtenção da espessura óptica do aerossol $(\tau)$, distribuição de tamanho, albedo de espalhamento único $\left(\omega_{0}\right)$, e outras propriedades com o uso de radiômetros CIMEL operados pela rede de fotômetros NASA/AERONET.

Foram determinadas propriedades ópticas de aerossóis biogênicos naturais, bem como das emissões de queimadas. Observaram-se profundas modificações nas propriedades do aerossol durante a estação seca, como decorrência de emissões de queimadas. A profundidade óptica do aerossol, $\tau_{500 \mathrm{~nm}}$, aumentou de um valor de background de $0,15 \pm 0,13$ durante a estação chuvosa, para valores médios diários da ordem de 2,5 a 3,5, o que indica uma atmosfera extremamente carregada de aerossóis na região do arco do desflorestamento.

O coeficiente de Ångström, que expressa o tamanho das partículas, aumentou significativamente durante a estação de queimadas para altos valores de $\tau$, indicando a predominância de partículas finas nessa época do ano, aumento esse que também é visto no volume da moda fina da distribuição de tamanho na região do arco do desflorestamento, com um pico no raio de $0,15 \mu \mathrm{m}$. O aerossol biogênico natural está presente durante todo o ano, em todos os locais analisados. da região Amazônica. O aerossol produzido secundariamente na atmosfera, pela oxidação de compostos emitidos pela vegetação, contribui para o volume da moda fina, enquanto que as partículas primárias emitidas pela floresta contribuem para a moda grossa. Das propriedades intrínsecas do aerossol, observou-se que o albedo de espalhamento único do aerossol $\left(\omega_{0}\right)$ tem valor médio de 0,92 $\pm 0,03$ nas estações do arco do desflorestamento. Em Cuiabá foi possível observar duas modas de valores de $\omega_{0}$, uma correspondente ao aerossol natural do cerrado com valor de $0,84 \pm 0,05$, e outra correspondente a queimadas de longa distância com valor de $0,92 \pm 0,03$, compatível com as estações do arco do desflorestamento. O Norte da Amazônia foi

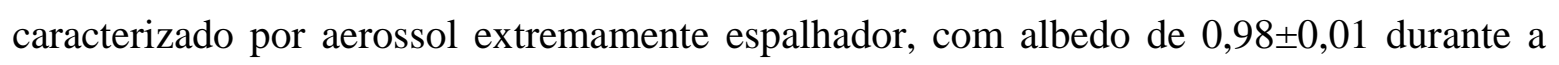
estação chuvosa em Balbina. 
O impacto climático dos aerossóis foi quantificado através das inversões de forçante radiativa direta do aerossol da AERONET. A forçante radiativa instantânea no topo da atmosfera chegou a $-100 \mathrm{~W} \cdot \mathrm{m}^{-2}$ na região do arco de desflorestamento. O valor de eficiência de forçante do aerossol na Amazônia variou entre $-38,6 \mathrm{~W} \cdot \mathrm{m}^{-2} \cdot \tau^{-1}$, em Alta Floresta, a $-50,9 \mathrm{~W} \cdot \mathrm{m}^{-2} \cdot \tau^{-1} \mathrm{em}$ Belterra.

Foi também realizada uma análise entre as medidas integradas na coluna atmosférica com medidas de concentração de aerossóis ao nível do solo. Nesse intuito, estudou-se a relação da profundidade óptica do aerossol obtida pelos radiômetros da AERONET e a concentração de material particulado fino, $\mathrm{MP}_{2,5}$ obtida ao nível do solo. A regressão linear encontrada foi de $\mathrm{MP}_{2,5}=(37 \pm 2) \tau_{500}+(5 \pm 2)$ em unidades de $\left[\mu \mathrm{g} \cdot \mathrm{m}^{-3}\right]$ para a região do arco do desflorestamento, e $\mathrm{MP}_{2,5}=(30,7 \pm 1,3) \tau_{500}+(0,08 \pm 0,40)$ nas mesmas unidades, para a região de Belterra. A validação feita com $\tau$ obtido independentemente pelo sensor MODIS mostrou que a relação é adequada para o arco do desflorestamento e a profundidade óptica do aerossol obtida por ambos os métodos pode ser usada alternativamente para estudos de efeitos de material particulado na saúde humana. 


\section{ABSTRACT}

This work has analyzed the main optical properties of atmospheric aerosol particles in three regions of interest: the Northern Amazon region, the arc of deforestation and the Brazilian cerrado. The methodology involved the measurement of aerosol optical thickness $(\tau)$, size distribution, single scattering albedo $\left(\omega_{0}\right)$, and other properties with the use of CIMEL radiometers that are part of a sun-photometer network operated by AERONET/NASA. It was determined the optical properties of natural biogenic aerosols as well as emissions from biomass burning. We observed large changes in the physical properties of aerosols during the dry season, as a result of emissions from fires. The aerosol optical depth at $500 \mathrm{~nm}, \tau_{500 \mathrm{~nm}}$ increased from a background value of $0.15 \pm 0.13$ during the wet season for the daily average values of 2.5 to 3.5 , indicating a highly loaded atmosphere in the region of the arc of deforestation. The Ångström coefficient, which indicates the particle size, increased significantly during the burning season for high values of $\tau$, indicating the predominance of fine particles in this season. This increase due to biomass burning is also observed in the volume size distribution, with a large peak centered at a radius of $0.15 \mu \mathrm{m}$. The natural biogenic aerosol is present throughout the year in all locations studied in the Amazon region with similar properties. The secondary organic aerosol produced in the atmosphere by oxidation of compounds emitted by the vegetation contributes to the volume of fine mode, while the primary particles emitted by the forest contribute to the coarse mode. The intrinsic properties of the aerosol were also analyzed. It was observed that the single scattering albedo of the aerosol $\left(\omega_{0}\right)$ has an average value of $0.92 \pm 0.03$ in the stations close to the region of the arc of deforestation. In Cuiabá it was possible to observe two modes in the distribution of $\omega_{0}$, corresponding to a natural aerosol from the cerrado with an average value of $0.84 \pm 0.05$, and other mode corresponding to fires from long range transport with a relatively high value of $0.92 \pm 0.03$, consistent with the measurements at the arc of deforestation. The northern Amazon region was characterized by extremely scattering aerosols with albedo of $0.98 \pm 0.01$ during the rainy season in Balbina. 
The climate impact of aerosols was characterized by aerosol direct radiative forcing from inversions calculations by AERONET. The instantaneous radiative forcing at the top of the atmosphere reached a very high $-100 \mathrm{Wm}^{-2}$ in the region of the arc of deforestation. The value of the aerosol forcing efficiency in the Amazon ranged from $-38.6 \mathrm{Wm}^{-2} \cdot \tau^{-1}$ in Alta Floresta, to $-50.9 \mathrm{Wm}^{-2} \cdot \tau^{-1}$ in Belterra, compatible with measurements using other methods. This work also has done an analysis of the comparison between $\tau_{500 \mathrm{~nm}}$ column measurements from AERONET and ground based aerosol concentrations. It was studied in detail the relationship of the aerosol optical depth obtained by the AERONET radiometers with the concentration of fine particulate matter, $\mathrm{PM}_{2.5}$ obtained at ground level in several sites in Amazonia. We found a statistically significant correlation and it was derived a linear regression of $\mathrm{PM}_{2.5}=(37 \pm 2)$ AOD500 $+(5 \pm 2)$ in $\mu \mathrm{g} / \mathrm{m}^{3}$ in the region of the deforestation arc calculated from data in the period of 2001-2006. In addition, estimates from MODIS aerosol optical depth was used to calculate ground based PM2.5 concentrations, with statistically significant agreement. This technique is very useful to assess health effects of aerosols in Amazonia. 


\section{SUMÁRIO}

1 INTRODUÇÃO

$\begin{array}{llr}1.1 & \text { Objetivos } & 20\end{array}$

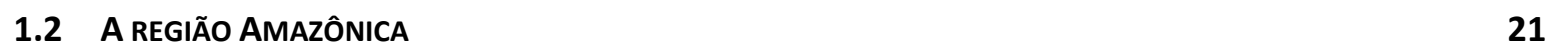

$\begin{array}{lll}1.3 & \text { DESCRIÇÃO DAS ESTAÇõES DA AERONET ESTUDADAS } & 30\end{array}$

1.4 Partículas de aerossol atmosfÉrico e SeU impacto no meIO ambiente 31

2 FUNDAMENTAČ̃̃O TEÓRICA

$\begin{array}{lll}2.1 & \text { RADIAÇÃO DE CORPO NEGRO } & 37\end{array}$

$\begin{array}{lll}2.2 & \text { TRANSFERÊNCIA RAdiativa NA ATMOSFERA } & 40\end{array}$

2.2.1 EQUAÇÃO DE SCHWARZSCHILD

$\begin{array}{lll}\text { 2.2.2 LeI DE LAMBeRt-BeER-BOUguer } & 44\end{array}$

2.3 DESCRIÇÃo DAS PROPRIEDADES DAS PARTíCULAS DE DO AEROSSOL CALCULADAS PELA AERONET 47

2.3.1 FORÇANTE RADIATIVA DO AEROSSOL E EFICIÊNCIA DE FORÇANTE COMO PRODUTOS DA AERONET 53

$\underline{3}$ MATERIAIS E MÉTODOS $\quad 55$

3.1 SENSORIAMENTO REMOTO

3.1.1 AERONET $\quad 55$

$\begin{array}{lll}3.1 .2 \text { MODIS } & 59\end{array}$

3.2 MEDIDAS DE CONCENTRAÇÃO DE MASSA DE AEROSSÓIS IN SITU

$\begin{array}{lll}3.2 .1 & \text { TEOM } & 61\end{array}$

$\begin{array}{lll}3.2 .2 & \text { AFG } & 61\end{array}$

4 RESULTADOS $\quad 63$

4.1 ANÁLISE EXPLORATÓRIA DAS PROPRIEDADES OBTIDAS PELOS RADIÔMETROS DA AERONET 66 
4.1.1 ÁGUA PRECIPITÁVEL NA COLUNA ATMOSFÉRICA 66

$\begin{array}{lll}\text { 4.1.2 PROFUNDIDADE ÓPTICA DO AEROSSOL } & 68\end{array}$

4.1.3 COEFICIENTE DE ÅNGSTRÖM

4.1.4 DETERMINAÇÃO DO ALBEDO DE ESPALHAMENTO ÚNICO 78

4.1.5 A DistRibuIÇÃo de TAMANHO E RAIO EFETIVO do AEROSSOL

4.1.6 FORÇANTE RADIATIVA DIRETA E EFICIÊNCIA DE FORÇANTE INSTANTÂNEAS DO AEROSSOL 87

4.1.7 ESTUDO DE CASO DE INFLUÊNCIA DE POEIRA DO DESERTO DO SAARA 90

4.2 OBTENÇÃo de UMA RELAÇÃo QUANTITATIVA ENTRE A CONCENTRAÇÃo DO MATERIAL PARTICULADO FINO À SUPERFÍCIE E A PROFUNDIDADE ÓPTICA DO AEROSSOL INTEGRADO NA COLUNA ATMOSFÉRICA 95

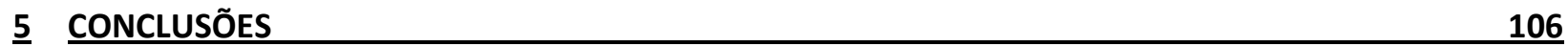

6 RECOMENDAČ̃̃ES PARA TRABALHOS FUTUROS $\quad 109$

\begin{tabular}{llr}
7 & REFERÊNCIAS BIBLIOGRÁFICAS & 110 \\
\hline
\end{tabular}

$\underline{8}$ APÊNDICEI $\quad 120$ 


\section{LISTA DE FIGURAS}

Figura 1. (A) DiREÇÃO E VELOCIDAdE (M/S) DO VENTO À PRESSÃO DE 1000 HPA NA AMÉRICA do SUL NOS SEGUINTES MESES: (A) DEZEMBRO, JANEIRO, FEVEREIRO. (B) JUNHO, JULHO E AGOSTO. A LINHA HORIZONTAL PRETA REPRESENTA A LINHA DO EquAdOR. MÉdIA dOS ANOS DE 1988 - 2007, REANÁLISE do NCEP (NATIONAL CENTER FOR ENVIRONMENTAL PREDICTION). AdAPTAdo de [MARTIN et Al., 2010B].

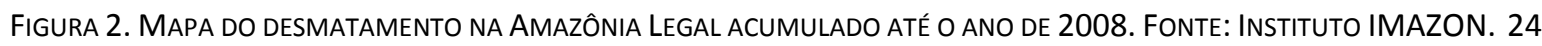

Figura 3. Área total desmatAda ANUALMENTE NA AMAZÔNIA LEGAL DESDE 1988. NOTA-SE QUE O deSMATAMENTO VEM CAINDO CONSISTENTEMENTE DESDE 2004. O VALOR ATRIBUÍDO AO ANO DE 2010 (7200 KM²) É UMA ESTIMATIVA. FONTE: PRODES, INPE.

FIgURA 4. MAPA MENSAL DE FoCOS DE QUEIMA NO BRASIL, DE JANEIRO A DEZEMBRO DE 2010, COM MEDIDAS OBTIDAS ATRAVÉS DO SATÉLITE NOAA15. FONTE: DSA/INPE. 26

FiguRA 5. COMPOSTO dE IMAGENS TRUE COLOR DO SENSOR MODIS A BORDO DO SATÉLITE TERRA NO DIA 16 DE SETEMBRO DE 2004, MOSTRANDO UMA PLUMA DE EMISSÕES DE QUEIMADAS ORIGINADA DA REGIÃO DO ARCO DO DESFLORESTAMENTO E

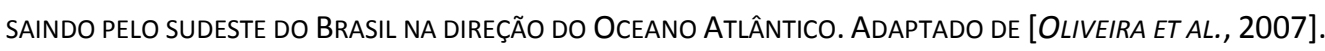
28

Figura 6. Média ANual de desmatamento (DETER - Sistema de DeteCção de Desmatamento em TeMPo ReAL, HTTP://WWW.OBT.INPE.BR/DETER/), FOCOS DE QUEIMADA (SATÉLITES NOAA-12 E NOAA-15, HTTP://WWW.DPI.INPE.BR/PROARCO/BDQUEIMADAS/), E PROFUNDIDADE ÓPTICA DO AEROSSOL DO MODIS/NASA EM TODA A AMAZÔNIA LEGAL. 29

FIGURA 7. MAPA INDICANDO A LOCALIZAÇÃO DAS PRINCIPAIS ESTAÇÕES ESTUDADAS, COM FOCOS DE QUEIMA EM SETEMBRO DE 2010 AO FUNDO. ADAPTADO DE DSA/INPE. 30

FIGURA 8. IMAGENS DE PARTíCULAS OBTIDAS ATRAVÉS DE MICROSCÓPIO ELETRÔNICO DE VARREDURA (SCANNING ELECTRON MicrosCopy, SEM). A) PARTículas BIOGÊNICAS COlETAdAS NA BACIA AMAZÔNICA EM 1999. AdAPTAdo de [MARTIN ET AL., 2010B]. B) IMAGEM TÍPICA DE PARTÍCULAS DE QUEIMADA NA AMAZÔNIA COM ALTA CONCENTRAÇÃO DE BLACK CARBON (BC). SÃO, GERALMENTE, PARTíCULAS NÃO ESFÉRICAS OU PEQUENOS AGLOMERADOS. A ESCALA É DE $1 \mu \mathrm{M}$. AdAPTAdo de [MARTINS ET AL., 1998A]. C) PARTíCULAS ENVELHECIDAS PROVENIENTES DE QUEIMADAS COLETADAS EM CUIABÁ, EM SUA MAIORIA ESFÉRICAS. AdAPTADO dE [MARTINS ET AL., 1998B].

FIGURA 9. DIVERSOS COMPONENTES QUE AFETAM O SISTEMA CLIMÁTICO E SEUS RESPECTIVOS IMPACTOS RADIATIVOS GLOBAIS (FORÇANTE RADIATIVA) EM W.M ${ }^{-2}$, TEMPO DE RESIDÊNCIA, E NÍVEL DE ENTENDIMENTO CIENTÍFICO. (IPCC, 2007)........ 35 
Figura 10. Função de PLANCK PARA um CORPo A TEMPERATURA de 5800K (EM VERMELHO, EIXO VERTICAL À eSQUERDA) E PARA A TEMPERATURA DE 255K (PONTILHADO EM AZUL, EIXO VERTICAL À DIREITA) REPRESENTANDO A EMISSÃO DO SOL E DA TERRA, RESPECTIVAMENTE. A INTENSIDAdE TOTAL EMITIDA PELO SOl É MUITAS ORDENS DE GRANDEZA MAIOR QUE A TERRA.

FIGURA 11. CURVA DE IRRADIÂNCIA SOLAR NO TOPO DA ATMOSFERA E TAMBÉM NA SUPERFÍCIE, PARA ÂNGULO SOLAR ZENITAL IGUAL A $60^{\circ}$ NUMA ATMOSFERA SEM A PRESENÇA DE AEROSSÓIS OU NUVENS. EM CINZA ESTÃO INDICADAS AS ÁREAS DE ESPALHAMENTO E ABSORÇÃO. AdAPTADO DE LIOU, 2002.

FiguRa 12. ILUSTRAÇÃO do CAMINHO ÓPTICO. AdAPTAdO de [LIOU, 2002].

FIGURA 13. SISTEMA DE COORDENADAS UTILIZADO PARA O CASO DE UMA ATMOSFERA PLANO PARALELA. O ÂNGULO $\Theta$ É CHAMADO DE ÂNGULO SOLAR ZENITAL, MEDIDO EM RELAÇÃO À NORMAL; O ÂNGULO AZIMUTAL Ф MEDE A PROJEÇÃO NO PLANO XY; $\boldsymbol{S}$ É O VETOR POSIÇÃO. ADAPTADO DE [LIOU, 2002].

FIGURA 14. DESENHO ESQUEMÁtICO DA RELAÇÃO ENTRE ÂNGULO SOLAR ZENITAL E O COMPRIMENTO DA MASSA DE AR. ... 46

FIGURA 15. ESQUEMA dOS POSICIONAMENTOS do RADIÔMETRO PARA A REALIZAÇÃo de MEDIDAS NO PLANO PRINCIPAL (ACIMA) E ALMUCANTAR (PARTE DE BAIXO), ONDE $\varphi_{0}$ É O ÂNGULO AZIMUTAL DO SOL, $\varphi$ É O ÂNGULO AZIMUTAL do SENSOR, $\theta_{0}$ É O

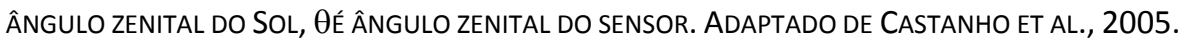
56

Figura 16. Precipitação mensal Climatológica nas Cidades de Rio Branco (AC), Porto Velho (RO), Manaus (AM),

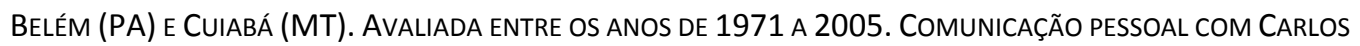
FREDERICO ANGELIS DSA/INPE.

FIGURA 17. SÉRIE TEMPORAL de ÁGUA PRECIPITÁVEL (CM) NA COLUNA ATMOSFÉRICA OBTIDA PELA AERONET. A) NORTE DA AMAZÔNIA. B) REgIÃo do ARCO do deSFLORESTAMENTO. C) CERRAdo.

FIGURA 18. SÉRIE TEMPORAL DE PROFUNDIDADE ÓPTICA dO AEROSSOL EM 440 NM OBTIDA PELA AERONET. A LINHA SE REFERE Às MÉdias diÁRIAS. A) NORTE dA AMAZÔNIA. B) REgIÃo do ARCO do deSFLORESTAMENTO. C) REgIÃo do CERRAdO.... 70

FIGURA 19. SÉRIE TEMPORAL DE PROFUNDIDADE ÓPTICA DO AEROSSOL EM 500 NM, NÍVEL 2.0 PARA TODAS AS ESTAÇÕES DA AMAZÔNIA ESTUDADAS. A SÉRIE EM VERMELHO SE REFERE A TODAS AS MEDIDAS, ENQUANTO QUE A SÉRIE EM PRETO SIGNIFICA MÉDIA DIÁRIA APENAS COM 10 MEDIDAS OU MAIS NO DIA.

FIGURA 20. HISTOGRAMA DA FREQUÊNCIA (NÚMERO DE MEDIDAS NÃO NORMALIZADO) DE T500 DURANTE A ESTAÇÃO SECA E CHUVOSA EM BELTERRA. O SíTIO DE BALBINA APRESENTA COMPORTAMENTO SIMILAR. O RETÂNGULO AZUL INDICA OS 
VALORES DE BACKGROUND, COM T500NM ENTRE 0,06 A 0,30; O RETÂNGULO VERMELHO MOSTRA OS VALORES MAIS ALTOS,

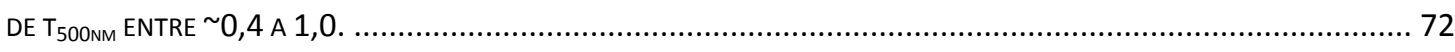

FIGURA 21. HISTOGRAMA DE FREQUÊNCIA DE T500 DURANTE A ESTAÇÃO SECA E CHUVOSA EM ALTA FLORESTA, REPRESENTANDO A REGIÃO DO ARCO DO DESFLORESTAMENTO. O RETÂNGULO AZUL INDICA OS VALORES DE BACKGROUND, COM T500NM ENTRE 0,06 A 0,30; O RETÂNGULO VERMELHO INDICA OS VALORES MAIS ALTOS, DE T500NM ENTRE 0,4 A 1,0 .................. 73

FIGURA 22. HISTOGRAMA DA FREQUÊNCIA DE T500 DURANTE A ESTAÇÃO SECA E CHUVOSA EM CUIABÁ, REPRESENTANDO A REGIÃO DO ARCO DO CERRADO. O RETÂNGULO AZUL INDICA OS VALORES DE BACKGROUND, COM T500NM ENTRE 0,06 A 0,30; 0 RETÂNGULO VERMELHO INDICA OS VALORES MAIS ALTOS, DE T500NM ENTRE 0,4 A 1,0.

FIGURA 23. COEFICIENTE DE ÅNGSTRÖM ENTRE OS COMPRIMENTOS DE ONDA 870-440 NM VERSUS A PROFUNDIDADE ÓPTICA DO AEROSSOL EM 500 NM. OS SÍTIOS DE BELTERRA E BALBINA NÃO APRESENTAM DEPENDÊNCIA SIGNIFICATIVA ENTRE ESSAS DUAS PROPRIEDADES.

Figura 24. SÉRIE TEMPORAL de ALBEDO dE ESPALHAMENTO ÚNICO OBTIDO PELA AERONET PARA NOVE LOCAIS DA AMAZÔNIA.

FIGURA 25. HISTOGRAMA DE FREQUÊNCIA NORMALIZADA (\%) DE MEDIDAS DE ALBEDO DE ESPALHAMENTO ÚNICO EM 673 NM ENTRE MAIO E OUTUBRO PELA AERONET PARA OS VÁRIOS LOCAIS ESTUDADOS.

FIGURA 26. DEPENDÊNCIA ESPECTRAL DO ALBEDO DE ESPALHAMENTO ÚNICO MÉDIO DURANTE A ESTAÇÃO SECA PARA AS DIVERSAS ESTAÇÕES DA AERONET. 83

FIGURA 27. MÉdIA DA DISTRIBUIÇÃO DE TAMANHO DO AEROSSOL DURANTE A ESTAÇÃO CHUVOSA (ACIMA) E ESTAÇÃO SECA (ABAIXO), E O NÚMERO DE OBSERVAÇÕES. DURANTE A ESTAÇÃO SECA O VOLUME DE PARTÍCULAS É BEM MAIOR QUE DURANTE A ESTAÇÃO CHUVOSA, E O PICO DA MODA FINA É BEM PRONUNCIADO. DURANTE A ESTAÇÃO CHUVOSA, É A MODA GROSSA QUE PREDOMINA EM TERMOS DE MASSA. 86

FIGURA 28. À ESQUERDA, RELAÇÃO ENTRE A FORÇANTE RADIATIVA DIRETA INSTANTÂNEA DO AEROSSOL NO TOPO DA ATMOSFERA $\left(F_{\text {TOA }}\right)$ E A PROFUNDIDADE ÓPTICA dO AEROSSOL EM 500 NM. À DIREITA, A MESMA FORÇANTE RADIATIVA DO AEROSSOL VERSUS O RAIO EFETIVO DO MESMO.

FIGURA 29. DEPENDÊNCIA ESPECTRAL DO ALBEDO DE ESPALHAMENTO ÚNICO (441 NM) PARA 4 DIAS SELECIONADOS NO SíTIO DE BALBINA/AM DURANTE A ESTAÇÃO CHUVOSA NA AMAZÔNIA. 90

FIGURA 30. DISTRIBUIÇÃO DE TAMANHO VOLUMÉTRICA DO AEROSSOL PARA OS DIAS SELECIONADOS. 91 
FIGURA 31. RETRO-TRAJETÓRIAS DE 7 DIAS EM BALBINA. 09/FEV./2001

FIGURA 32. RETRO-TRAJETÓRIAS DE 7 DIAS EM BALBINA. 09/FEV./2000

FIgURA 33. RETRO-TRAJETÓRIAS DE 7 DIAS EM BALBINA. 10/FEV./2000 93

FIGURA 34. FORÇANTE RADIATIVA DO AEROSSOL NO TOPO DA ATMOSFERA EM VERMELHO E PROFUNDIDADE ÓPTICA DO AEROSSOL, EM AZUL. A MÉdIA DE TÉ 0,12 \pm 0,01. A BARRA 1 CORRESPONDE AO DIA 9 -FEV-2001, AS BARRAS DE 2 A 4 CORRESPONDEM ÀS OBSERVAÇÕES FEITAS EM 9-FEV-2000, E AS BARRAS 5 E 6 AO DIA 10-FEV-2000. 94

FIGURA 35. HISTOGRAMA NORMALIZADO DE FREQUÊNCIA DOS DADOS DE MP 2,5 NO ANO. MAIS DE 50\% DAS MEDIDAS FORAM TOMADAS DURANTE A ESTAÇÃO SECA. 101

FIGURA 36. GRÁFICO DE REGRESSÃO ENTRE MP 2,5 E PROFUNDIDADE ÓPTICA DO AEROSSOL EM SANTARÉM DURANTE O PERÍODO DE 2000 A 2004. 102

FIGURA 37. GRÁFICO DE REGRESSÃO ENTRE MP ${ }_{2,5}$ E PROFUNDIDADE ÓPTICA DO AEROSSOL EM JI PARANÁ DURANTE O PERÍODO DE SETEMBRO A DEZEMBRO DE 2002 102

FIGURA 38. GRÁFICO DE REGRESSÃO ENTRE MP2,5 E PROFUNDIDADE ÓPTICA DO AEROSSOL DA AERONET EM ALTA FLORESTA. A) COM MP 2,5 MEDIDO PELO AFG, NO PERÍODO DE 1995; 1999-2000: 104

FIgURA 39. COMPARAÇÃo ENTRE MP 2,5 ESTIMAdo PELO T OBTIDO PELO MODIS E MP 2,5 MEdido PELO TEOM EM JI PARANÁ. 105

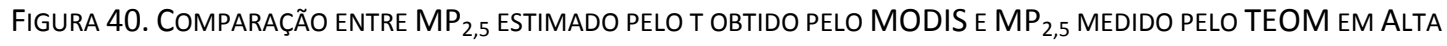
FLORESTA 105 


\section{LISTA DE TABELAS}

TABELA 1. PRINCIPAIS ESTAÇÕES BRASILEIRAS DA REDE AERONET E SEU PERÍODO DE FUNCIONAMENTO.

TABela 2. Período de medidas dos instrumentos de solo na Amazônia

TABELA 3. VALORES MÉDIOS, DESVIO PADRÃO E NÚMERO DE OBSERVAÇÕES DE ALBEDO DE ESPALHAMENTO ÚNICO EM 673 NM PELA AERONET.

TABELA 4. VALORES MÉdIOS E DESVIO PADRÃO dO RAIO EFETIVO DAS PARTíCULAS DE AEROSSOL DE TODA A DISTRIBUIÇÃO DE TAMANHO E TAMBÉM DA MODA FINA E DA MODA GROSSA, SEPARADAMENTE, DURANTE A ESTAÇÃO SECA.

TABELA 5. VALORES MÉDIOS E DESVIO PADRÃO DA LARGURA DA DISTRIBUIÇÃO DE TAMANHO DAS PARTíCULAS DURANTE A ESTAÇÃO SECA

TABELA 6. VALORES MÉdIOS E DESVIO PADRÃO dO RAIO EFETIVO DAS PARTíCULAS DE AEROSSOL DE TODA A DISTRIBUIÇÃO DE TAMANHO E TAMBÉM DA MODA FINA E DA MODA GROSSA, SEPARADAMENTE, DURANTE A ESTAÇÃO CHUVOSA

TABELA 7. VALORES MÉDIOS E DESVIO PADRÃO DA LARGURA DA DISTRIBUIÇÃO DE TAMANHO DAS PARTíCULAS DURANTE A ESTAÇÃO CHUVOSA. 85

TABELA 8. COEFICIENTE ANGULARES E LINEARES DA REGRESSÃO LINEAR ENTRE FORÇANTE RADIATIVA DIRETA DO AEROSSOL E PROFUNDIDADE ÓPTICA DO MESMO.

TABELA 9. CoMPARAÇÃo ENTRE AS REGRESSÕES LINEARES DA LITERATURA. R É O COEFICIENTE DE CORRELAÇÃo LINEAR, N O NÚMERO DE OBSERVAÇÕES E TÉ A PROFUNDIDADE ÓPTICA DO AEROSSOL.

TABELA 10. VALORES TíPICOS DE CONCENTRAÇÃO DE MATERIAL PARTICULADO FINO $\left(\mathrm{MP}_{2.5}\right)$, PROFUNDIDADE ÓPTICA DO AEROSSOL ( $\left.T_{500 N M}\right)$, E COEFICIENTE DE ÅngSTRÖM PARA ALGUNS dOS SítIOS DE MEDIDAS DA AMAZÔNIA. 99

TABELA 11. MÉdia ANUAL DE CONCENTRAÇÃO DE MATERIAL PARTICULADO FINO $\left(\mathrm{MP}_{2,5}\right)$, INALÁVEL (MP 10 ), E NúMERO DE DIAS EM QUE O PADRÃO NACIONAL DE MP 10 DE 50 MG/M³ EM 24H FOI EXCEDIDO NO SÍTIO DE ALTA FLORESTA. 100 


\section{INTRODUÇÃ O}

Vários estudos têm se ocupado em entender o papel da Amazônia como entidade regional e global e de que modo as mudanças de uso da terra influenciam o funcionamento biológico, químico e físico da Amazônia, incluindo seus efeitos regionais na América do Sul e no clima global da Terra.

A questão do balanço radiativo terrestre é chave no entendimento da interação entre o funcionamento dos ecossistemas e na emissão e transporte de partículas de aerossóis atmosféricos [Forster et al., 2007]. Olhando o balanço energético terrestre, observamos que toda a energia que chega à Terra proveniente do Sol deve ser devolvida ao espaço, garantindo o equilíbrio radiativo da Terra. Os processos relevantes são diversos e dependem fortemente do comprimento de onda: seja diretamente refletida pela própria atmosfera terrestre e seus constituintes como gases, partículas, nuvens; refletida pela superfície, ou emitida pela Terra na forma de radiação de onda longa, este equilíbrio define o clima em nosso planeta [Solomon et al., 2009]. No entanto, alguns fatores podem influenciar o clima alterando o equilíbrio radiativo da Terra em particular os gases do efeito estufa, as nuvens e as partículas de aerossol atmosférico. A Amazônia é um delicado ecossistema que vem se modificando principalmente devido a presença humana, com o desflorestamento para uso do solo em agricultura e pastagem, e a queima de biomassa para limpeza do solo. As queimadas na Amazônia emitem não somente gases de efeito estufa, como também partículas de aerossol que afetam, o balanço radiativo na região, espalhando e absorvendo a radiação solar, aquecendo a camada atmosférica em que se encontra, disponibilizando menos radiação na superfície para a fotossíntese, entre outros efeitos [Procópio, 2003b] Além disso, as partículas de aerossol atuam como núcleos de condensação de nuvens, modificando significativamente o ciclo hidrológico [Andreae et al., 2001]. 


\subsection{OBJETIVOS}

O presente trabalho pretende oferecer uma análise detalhada das medidas de propriedades ópticas do aerossol na Amazônia a partir dos radiômetros da rede de fotômetros solares AERONET. A base de dados conta com uma longa série de medidas (até 12 anos) e um novo algoritmo para a obtenção das propriedades ópticas a partir de radiâncias medidas. Estudamos tanto as componentes de aerossol biogênico natural durante a estação chuvosa, quanto a componente de emissões de queimadas durante a estação seca. Também neste estudo foi obtida uma relação quantitativa entre as medidas de profundidade óptica obtidas com os radiômetros da rede AERONET integradas na coluna atmosférica, e medidas da concentração de particulado realizadas no solo, oferecendo uma importante fonte alternativa de índices de poluentes atmosféricos para aplicações ambientais e de impactos de poluentes na saúde. Especificamente, este trabalho tem como objetivos:

1) Caracterizar as propriedades ópticas (espalhamento, absorção e extinção) de aerossóis biogênicos e de queimadas na Amazônia;

2) Determinar o albedo de espalhamento único para as várias localidades e sua sazonalidade.

3) Estudar a distribuição de tamanho derivada das observações de radiância celeste.

4) Determinar a forçante radiativa direta de aerossóis na Amazônia e sua variabilidade espacial e temporal.

5) Determinar o relacionamento entre espessura de aerossol na coluna atmosférica e concentrações de $\mathrm{MP}_{2.5}$ na superfície. 


\subsection{A REGIÃO AMAZÔNICA}

A floresta amazônica é uma das maiores florestas tropicais do mundo, com cerca de 6.600.000 km², estendendo-se do oceano Atlântico às encostas orientais da Cordilheira dos Andes, com uma extensão geográfica englobando diversos países como Colômbia, Equador, Peru, Bolívia, Venezuela, Suriname, Guianas e Brasil. Deste total, cerca de 3,8 milhões de km² encontram-se no Brasil. Em 1966 o governo brasileiro definiu a chamada região da "Amazônia Legal” que abrange os estados do Amazonas, Roraima, Pará, Amapá, Acre, Rondônia, Mato Grosso, Tocantins e parte do Maranhão.

A Floresta Amazônica é de extrema importância para a manutenção do ciclo hidrológico da América do Sul [Artaxo et al., 2009; Marengo, 2004]. Isso porque além das plantas utilizarem a água do subsolo, elas também emitem vapor de água, um processo chamado evapotranspiração que sabe-se hoje é muito importante na formação das chuvas, não só localmente, mas regionalmente. Além disso, a grande extensão da floresta amazônica e sua localização tropical, próxima da na Zona de Convergência Intertropical (chamada em inglês ITCZ) onde os fenômenos convectivos transportam o vapor de água, gases e aerossóis a altos níveis da atmosfera, aumenta a importância dos processos que estão sendo estudados. Os ventos alísios (ventos que sopram de leste para oeste) carregam vapor d'água que vem do oceano Atlântico passa pela região Amazônica, carregam parte da umidade gerada pela floresta e são desviados quando encontram os Andes, distribuindo umidade para toda a região centro-oeste, sudeste e sul do Brasil. A Figura 1 ilustra a direção e velocidade do vento médios na América do Sul [Martin et al., 2010b]. 

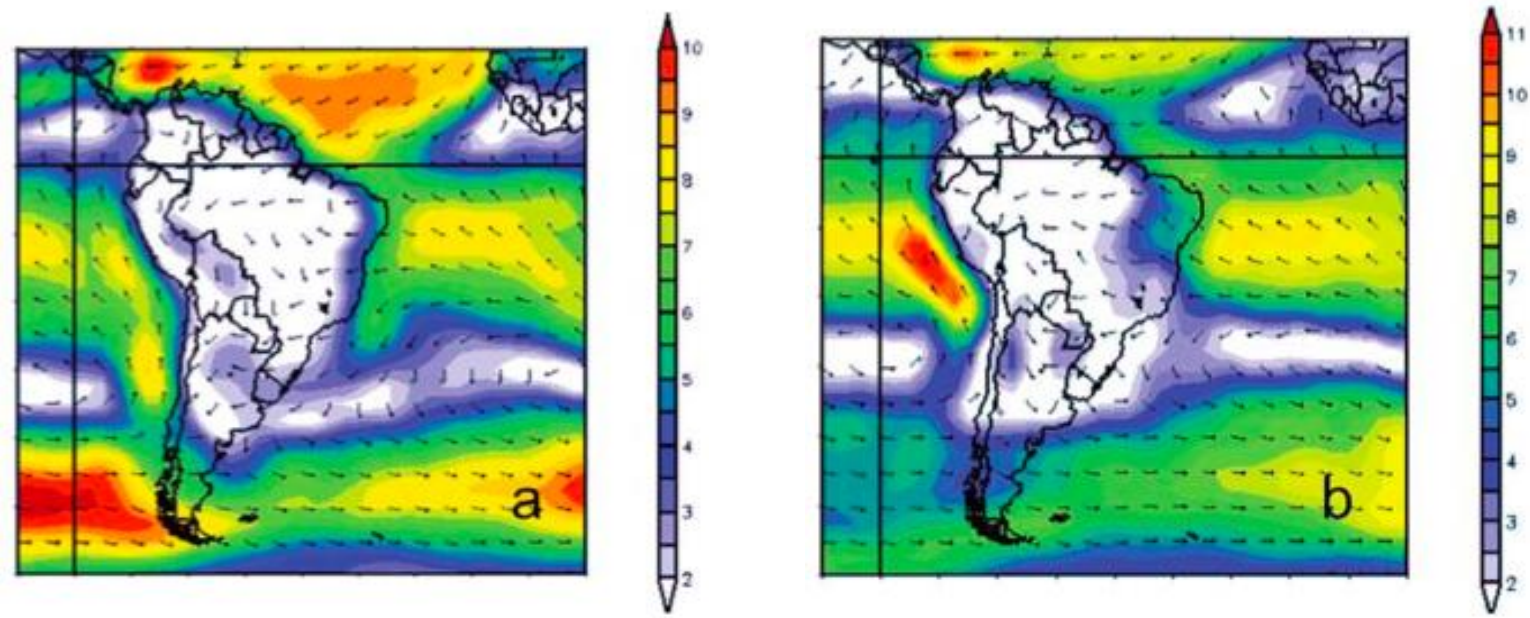

Figura 1. (a) Direção e velocidade (m/s) do vento à pressão de 1000 hPa na América do Sul nos seguintes meses: (a) Dezembro, janeiro, fevereiro. (b) Junho, julho e agosto. A linha horizontal preta representa a linha do Equador. Média dos anos de 1988 - 2007, reanálise do NCEP (National Center for Environmental Prediction). Adaptado de [Martin et al., 2010b].

O desmatamento em grande escala na Amazônia está diretamente ligado à história do modelo de desenvolvimento e do processo de ocupação do interior do Brasil. Três fatores se destacam para a criação de políticas públicas de ocupação do interior nos anos 70: as crescentes dificuldades econômicas do Nordeste devido a recorrentes secas e falta de estratégia econômica para a região, o desenvolvimento econômico do país através da extração de madeira e minerais, e a soberania do país devido ao medo da invasão de estrangeiros [Fearnside, 1986].

Apesar da criação da Superintendência de Desenvolvimento da Amazônia (SUDAM) em 1966, e da Superintendência da Zona Franca de Manaus (SUFRAMA) em 1967, foi só a partir de 1970 com o anúncio do Plano de Integração Nacional (PIN) e da Rodovia Transamazônica que a colonização do interior teve grande impulso. Com o PIN, foi criado o Instituto Nacional de Colonização e Reforma Agrária (INCRA) que estabeleceu diversos programas e recursos destinados ao estabelecimento de pequenas fazendas, e mais tarde para os empreendimentos de grandes corporações, destinados à pecuária em sua maioria, em 1974. 
Com a construção de estradas que pretendiam integrar a Amazônia ao resto do País, acelerando o estabelecimento de grandes pecuaristas e pequenos agricultores na região, veio o desmatamento desenfreado a partir da abertura de ramais vindos das estradas principais, formando desenhos em forma de espinha de peixe. Isso cria regiões com altos índices de desmatamento, com um forte impacto no ecossistema local, enquanto áreas mais distantes das estradas centrais permanecem inalteradas (Figura 2).

O desmatamento começa com a extração madeireira, primeiro as mais nobres sendo o resto utilizado para a construção civil, e então as áreas degradadas são utilizadas para agricultura, principalmente o cultivo da soja e algodão. Como cada fase é administrada por empreendimentos diferentes esse processo pode durar anos. Sendo o solo pobre, migra-se então para o capim e o desenvolvimento da pecuária. O capim e a cobertura florestal remanescente são queimados para a limpeza da área. O capim possui adaptações ao dano causado pelo fogo e brota novamente, o que permite que mais uma vez o gado seja colocado para pastar na área assim degradada. Queimadas subsequentes destroem completamente o que restou da floresta inicial. 


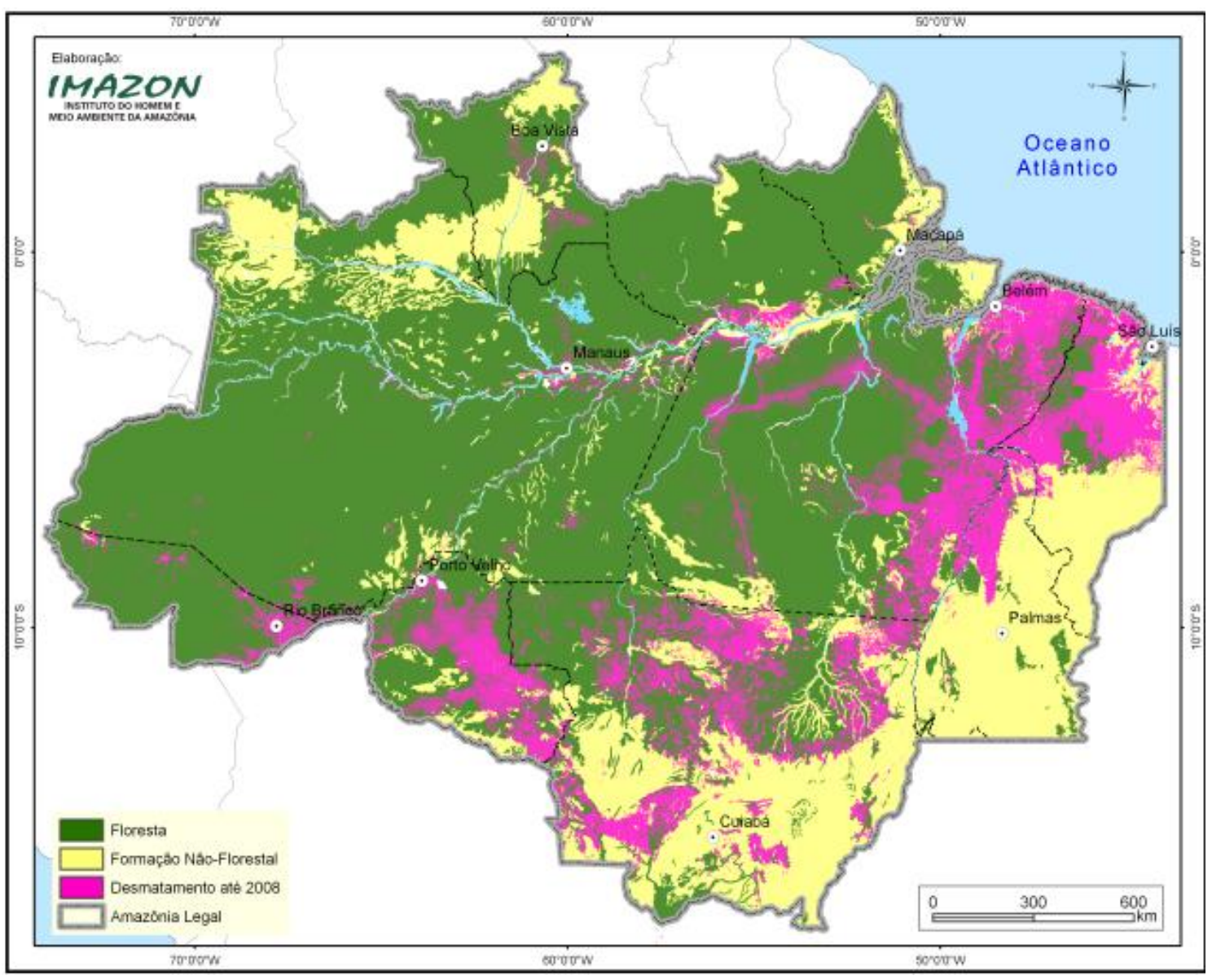

Figura 2. Mapa do desmatamento na Amazônia Legal acumulado até o ano de 2008. Fonte: Instituto IMAZON. 


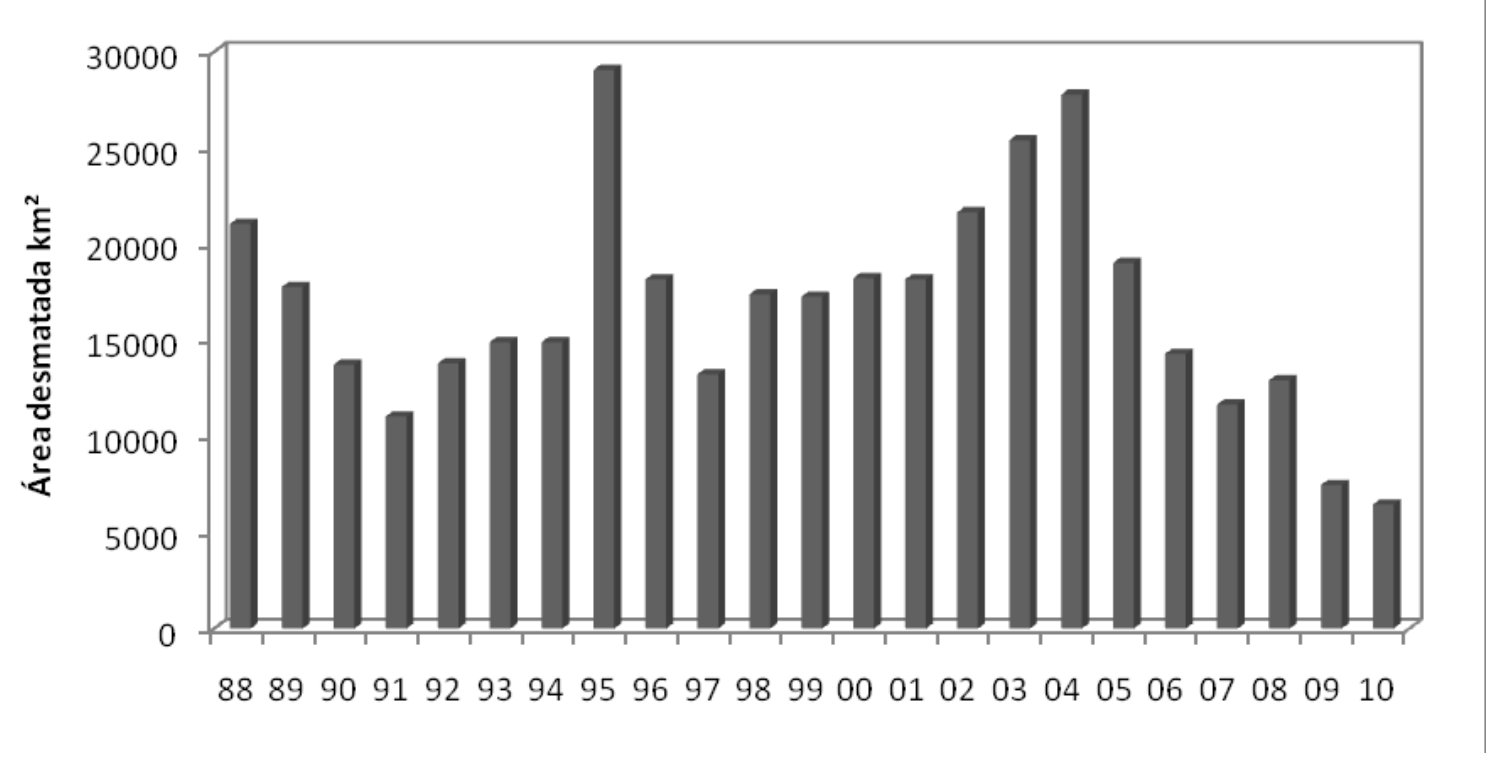

Figura 3. Área total desmatada anualmente na Amazônia Legal desde 1988. Nota-se que o desmatamento vem caindo consistentemente desde 2004. O valor atribuído ao ano de 2010 $\left(7200 \mathrm{~km}^{2}\right)$ é uma estimativa. Fonte: PRODES, INPE.

O desmatamento não é distribuído homogeneamente, e sim concentrado ao longo do denominado "Arco do Desflorestamento", área que se estende do sudeste do estado do Maranhão, ao norte do Tocantins, sul do Pará, norte de Mato Grosso, Rondônia, sul do Amazonas e sudeste do estado do Acre. É também nessa área onde se encontra o maior número de focos de queima de biomassa, como mostrado na Figura 4. 


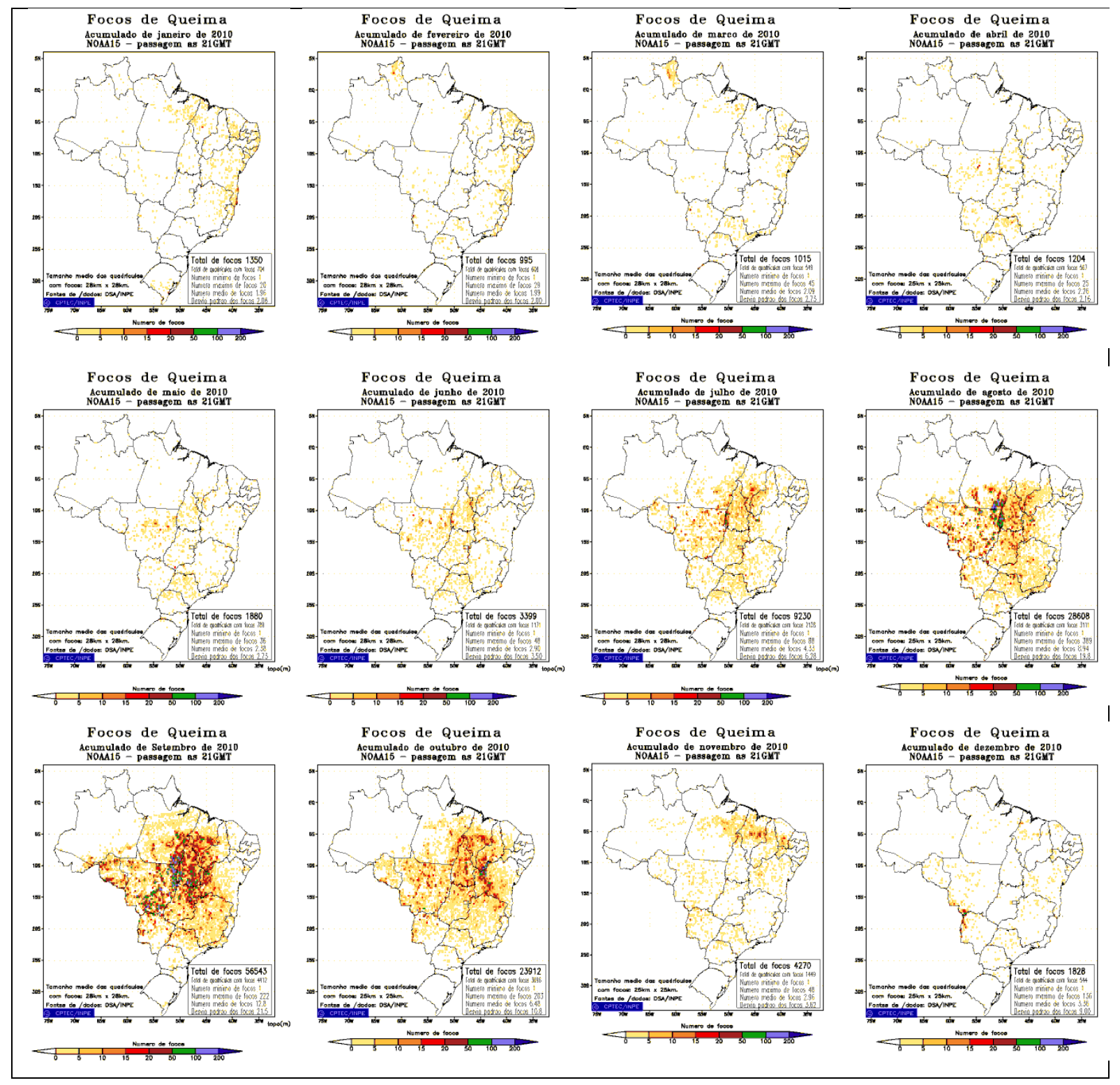

Figura 4. Mapa mensal de focos de queima no Brasil, de janeiro a dezembro de 2010, com medidas obtidas através do satélite NOAA15. Fonte: DSA/INPE.

A evolução de uma queimada pode ser descrita por quatro estágios: ignição, chamas (em inglês, flaming), brasas (em inglês, smoldering), e extinção. No caso da Floresta Amazônia, a quase totalidade das queimadas é antropogênica, e ocorre durante a estação seca. 
O estágio de chamas inicia-se com um processo pirolítico, durante o qual as elevadas temperaturas provocam uma ruptura dos compostos constituintes da biomassa. Componentes de alto peso molecular são decompostos em compostos de peso molecular mais baixo, os quais constituem fonte primária de energia para as chamas, e finalmente em compostos de natureza gasosa. A temperatura pode chegar a $1800 \mathrm{~K}$, produzindo carvão e liberando, principalmente, vapor d'água, $\mathrm{CO}_{2}$ e $\mathrm{CO}$. Com a diminuição das condições necessárias para a manutenção das chamas, a queima entra em um estágio mais 'frio', denominado de fase de brasas. Quando a temperatura no interior da chama está abaixo de $1000 \mathrm{~K}$, reduz-se drasticamente a produção de $\mathrm{CO}_{2}$, há uma grande emissão de compostos não completamente oxidados, como o $\mathrm{CO}$, além de uma maior formação de partículas de natureza orgânicas. Este estágio é o responsável pela emissão da maior parte do material particulado [Ward et al., 1992], embora ele também seja emitido na fase de chamas [Freitas et al., 2005].

As queimadas liberam grandes quantidades de gases e partículas para a atmosfera, sendo uma fonte global significativa de vários gases de efeito estufa como o dióxido de carbono $\left(\mathrm{CO}_{2}\right)$, metano $\left(\mathrm{CH}_{4}\right)$ e óxido nitroso $\left(\mathrm{N}_{2} \mathrm{O}\right)$ [Liousse et al., 2004] A emissão de partículas também é significativa, e experimentos na Amazônia realizados por [Yamasoe, 2000] apontam para emissões de material orgânico, sulfatos, nitratos e outros compostos. Como resultado destas emissões a concentração em massa de partículas de aerossóis em regiões de queimadas, atinge cerca de 300 a $600 \mu \mathrm{g} / \mathrm{m}^{3}$, e o número de partículas sobe para 15.000 a 30.000 partículas por $\mathrm{cm}^{3}$; sendo que na estação chuvosa esse número é da ordem de 10 a $15 \mu \mathrm{g} / \mathrm{m}^{3}$ de concentração em massa e 100 a 300 partículas por $\mathrm{cm}^{3}$ [Yamasoe, 1999]. Os intensos movimentos convectivos na atmosfera, característicos da região tropical, lançam as partículas e gases a grandes altitudes, onde podem ser transportados a longas distâncias [Andreae et al., 2004], como mostrado na Figura 5. 


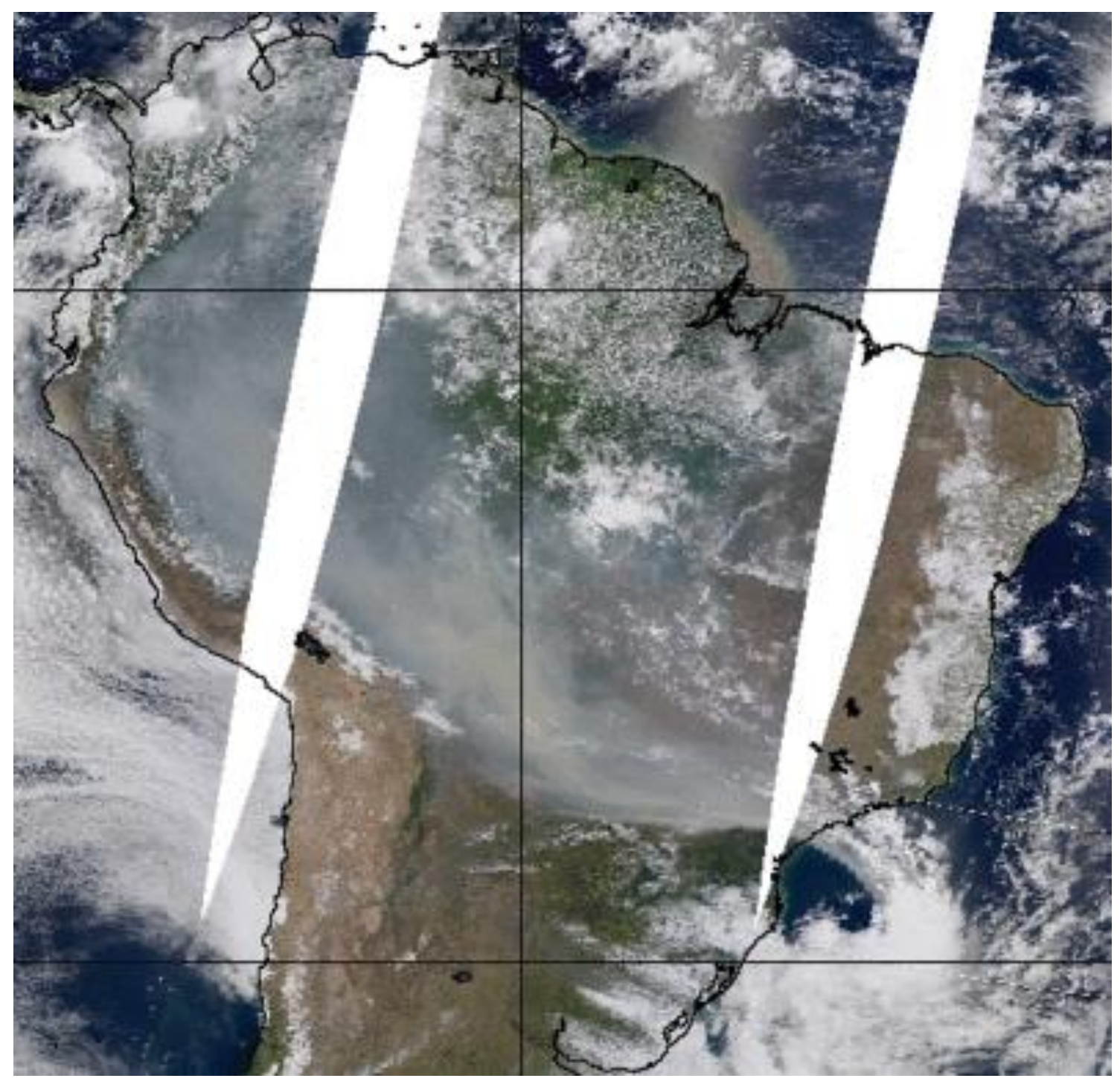

Figura 5. Composto de imagens true color do sensor MODIS a bordo do satélite Terra no dia 16 de setembro de 2004, mostrando uma pluma de emissões de queimadas originada da região do arco do desflorestamento e saindo pelo sudeste do Brasil na direção do Oceano Atlântico. Adaptado de [Oliveira et al., 2007].

Embora o desmatamento tenha diminuído notadamente desde 2004 para níveis da ordem de $7200 \mathrm{Km}^{2}$, o número de focos de queimada não sofreu uma redução tão significativa. Já profundidade óptica do aerossol tem forte correlação com a incidência de focos de queimada [Koren et al., 2007] também mostrado na Figura 6. 


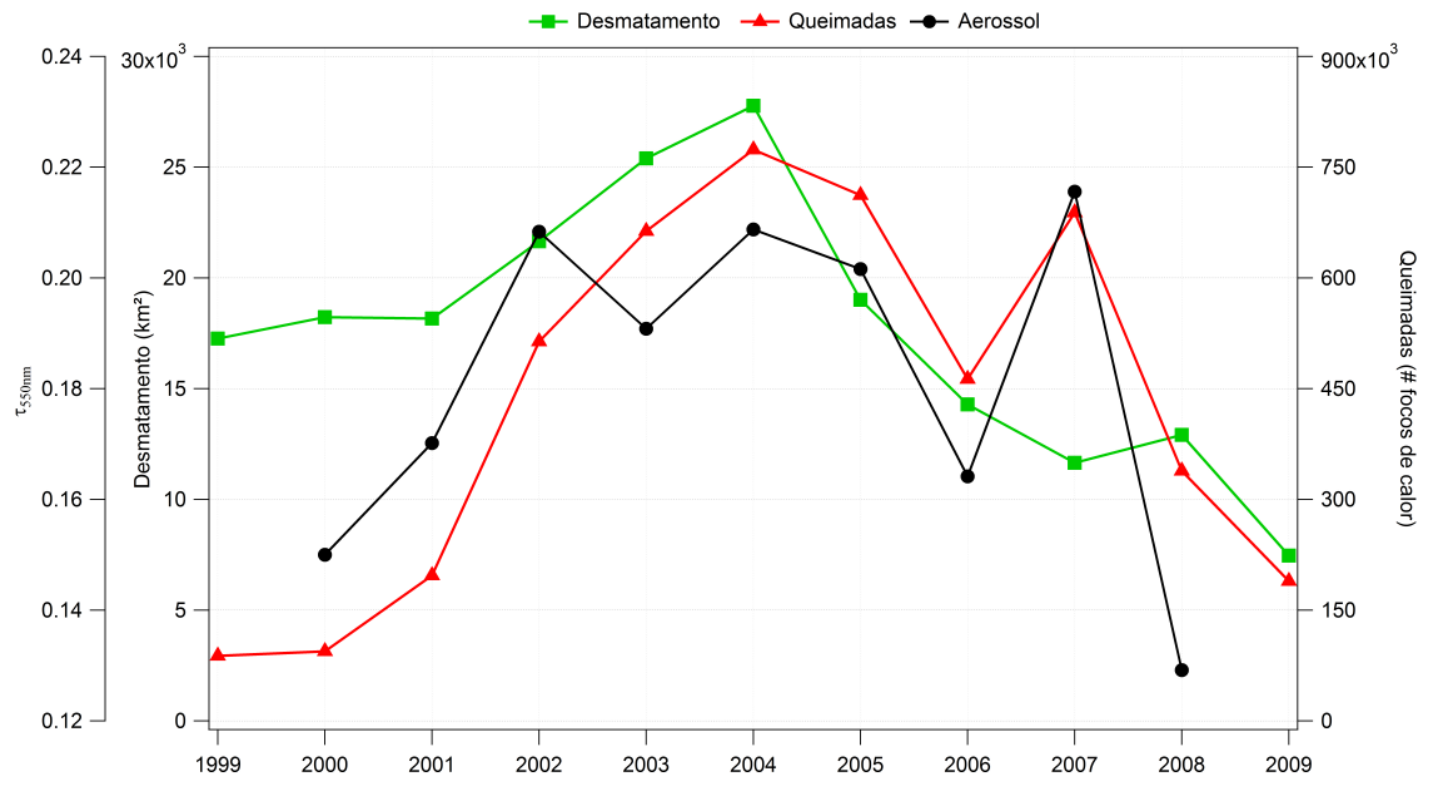

Figura 6. Média anual de desmatamento (DETER - Sistema de Detecção de Desmatamento em Tempo Real, http://www.obt.inpe.br/deter/), focos de queimada (satélites NOAA-12 e NOAA15, http://www.dpi.inpe.br/proarco/bdqueimadas/), e profundidade óptica do aerossol do MODIS/NASA em toda a Amazônia Legal. 


\subsection{DESCRIÇÃO DAS ESTAÇÕES DA AERONET ESTUDADAS}

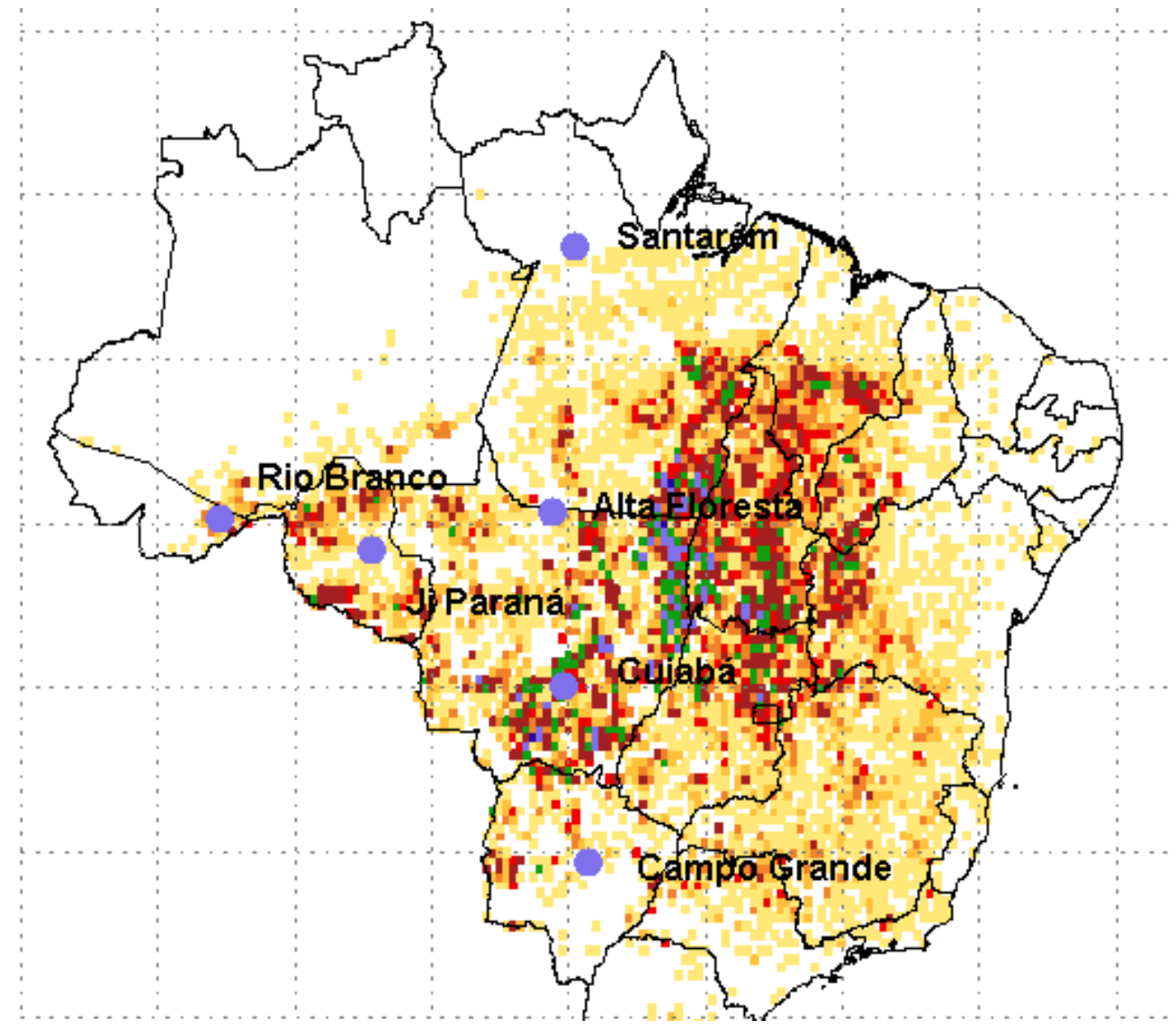

Figura 7. Mapa indicando a localização das principais estações estudadas, com focos de queima em setembro de 2010 ao fundo. Adaptado de DSA/INPE.

O presente estudo se concentrou na análise de medidas coletadas em 6 sítios diferentes, onde localizam-se radiômetros CIMEL da rede AERONET. A região de Santarém no estado do Pará, constituída pelos sítios de Santarém e Belterra (02³9’S, 5457’O), caracterizam o Norte da Amazônia como uma região limpa, muito úmida e próxima da zona de floresta natural, relativamente pouco afetada pelas queimadas. Como ali os ventos sopram predominantemente de Leste, é uma área muito utilizada para o estudo de aerossóis proveniente de transporte de longa distância, como por exemplo, o transporte de areia do Saara para a região Amazônica [Ben-Ami et al., 2010a]. Os meses com maior incidência de chuvas, aqui chamados de estação chuvosa ou úmida, ocorrem de dezembro a maio, enquanto que a estação seca em geral ocorre de junho a novembro. 
Para o estudo da região do Arco do Desflorestamento, foram utilizados os sítios de Alta Floresta - MT (09 $\left.55^{\circ} \mathrm{S}, 56^{\circ} 00^{\prime} \mathrm{O}\right)$, Abracos Hill/Ji Paraná - RO (1045’ S, 62 $\left.21^{\circ} \mathrm{O}\right)$ e Rio Branco - AC (09 $\left.57^{\prime} \mathrm{S}, 67^{\circ} 52^{\prime} \mathrm{O}\right)$, percorrendo toda a extensão do Arco. Inicialmente, quando a estação de Alta Floresta foi instalada, ficava em uma área de transição de floresta/pastagem. As estações Ji Paraná e Abracos Hill distam aproximadamente $60 \mathrm{~km}$ entre si, e estão instaladas em uma região de pastagens. O nome ABRACOS é na verdade uma sigla do projeto Anglo-BRazilian Amazonian Climate Observational Study [Gash e Nobre, 1996] e quando a estação foi desativada, no final de 2005, os instrumentos da rede AERONET e Sol-RadNET foram realocados para a cidade de Ji Paraná. Devido à proximidade geográfica destas estações, neste trabalho as medidas dessas duas localidades estão como uma única, sob o nome de Ji Paraná. Esta região tem uma estação seca bem pronunciada nos meses de maio a outubro, frequentemente com semanas sem nenhuma chuva, e a estação chuvosa é de novembro a abril, sendo novembro um mês de transição.

O cerrado do Brasil central, caracterizado pelo clima seco e vegetação rasteira, também recebe massas de ar vindas da região do arco do desflorestamento, com partículas de aerossol de queimadas já envelhecidas na atmosfera, devido ao transporte a longa distância.

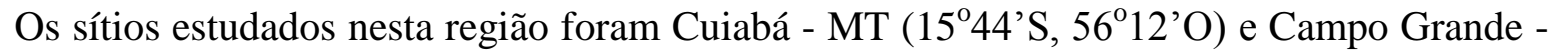
$\operatorname{MT}\left(20^{\circ} 26 ' \mathrm{~S}, 54^{\circ} 32^{\prime} \mathrm{O}\right)$.

\subsection{PARTÍCULAS DE AEROSSOL ATMOSFÉRICO E SEU IMPACTO NO MEIO AMBIENTE}

O chamado "aerossol atmosférico" consiste de partículas sólidas e líquidas em suspensão na atmosfera. As partículas podem ser constituídas por poeira do solo, pólen, material biogênico, fuligem, sal marinho, entre outros. Os aerossóis também podem ser classificados segundo a sua formação: denomina-se de aerossol primário os que são emitidos já na forma de partícula na atmosfera; e de secundário quando gases dão origem ao aerossol por processos de conversão gás-partícula [Seinfeld e Pandis, 2006]. 
O estudo das partículas de aerossol em si pode ser dividido em várias vertentes, entre elas o estudo da composição química e o estudo das propriedades ópticas. A composição química do aerossol é especialmente importante quando o objetivo é estudar processos associados a fontes, processos de transformação do aerossol e também de transporte. Se a massa de ar estudada veio de uma cidade próxima é provável encontrar aerossóis ricos em sulfato, enquanto o aerossol vindo de regiões oceânicas é rico em sal marinho [Kuhn et al., 2010].

Na floresta amazônica, a biosfera é a principal fonte de aerossóis, tanto primários quanto secundários [Artaxo et al., 2009]. A queima de biomassa emite grandes quantidades de partículas durante a estação seca. Uma segunda componente importante de aerossóis na Amazônia está ligada às emissões da própria vegetação. Esta componente denominada biogênica está sempre presente, (Figura 8-a), e consiste na emissão de pólen, esporos de fungos, restos foliares, e também pela formação secundária através da oxidação atmosférica de gases traço e compostos voláteis [Martin et al., 2010b]. A maioria das partículas biogênicas encontra-se na fração grossa, com diâmetros maiores que $2 \mu \mathrm{m}$, enquanto que o particulado fino geralmente é proveniente de emissões de queimadas e de aerossóis secundariamente produzido na atmosfera a partir de gases voláteis emitidos pela vegetação. As queimadas liberam principalmente pequenas partículas não esféricas e pequenos aglomerados (clusters) de material carbônico com forte propriedade de absorção de radiação solar (Figura 8-b) comumente chamado de black carbon (BC). Conforme a pluma de queimada envelhece na atmosfera, são encontradas partículas mais esféricas (Figura 8c), com composição mais homogênea. 
a)
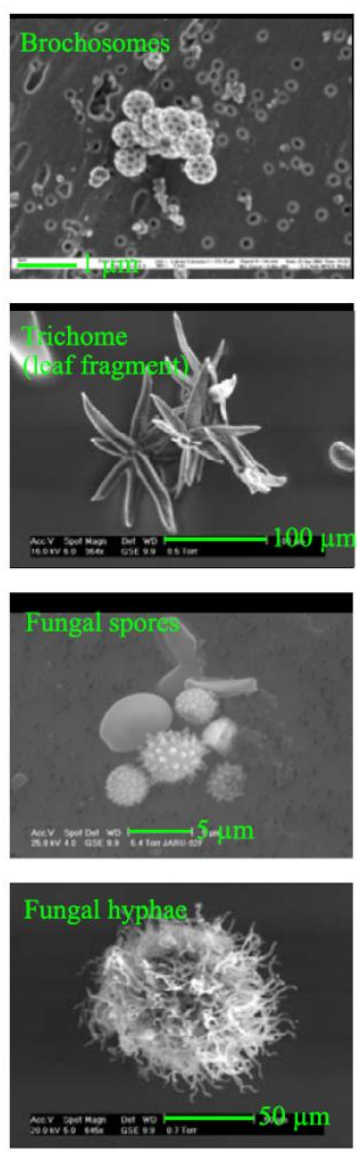

b)
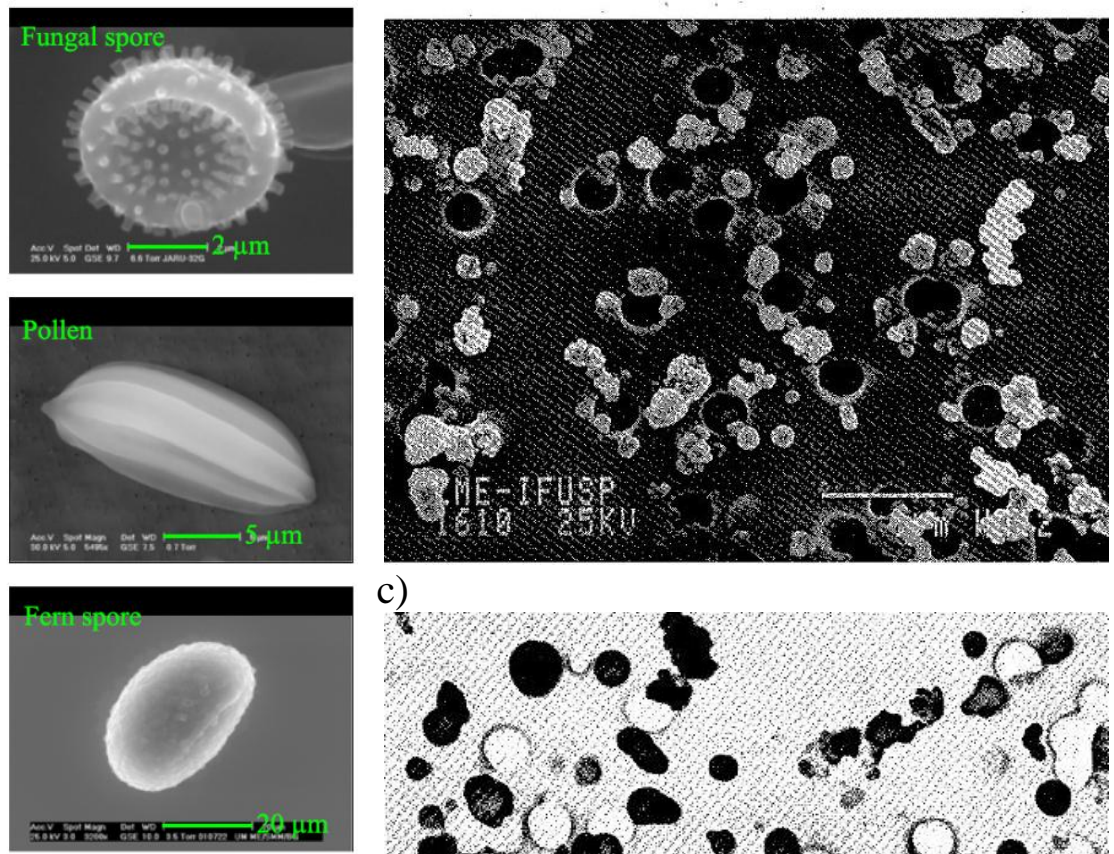

c)

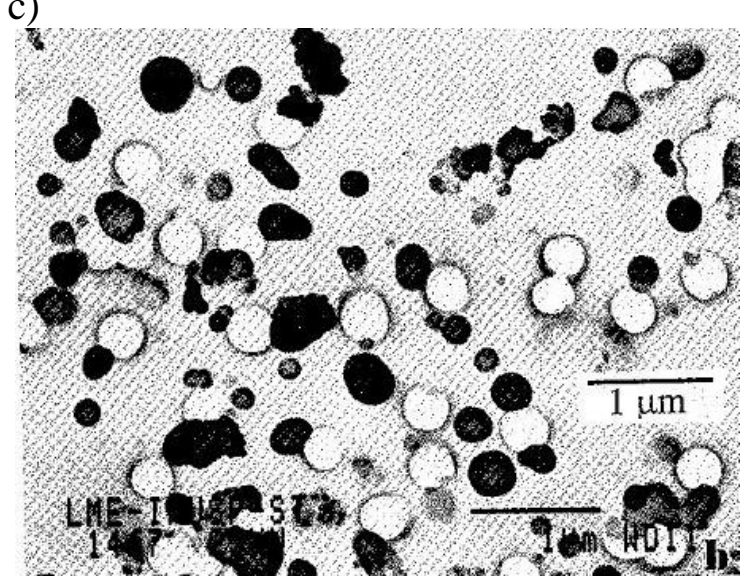

Figura 8. Imagens de partículas obtidas através de microscópio eletrônico de varredura (Scanning Electron Microscopy, SEM). a) Partículas biogênicas coletadas na Bacia Amazônica em 1999. Adaptado de [Martin et al., 2010b]. b) Imagem típica de partículas de queimada na Amazônia com alta concentração de black carbon (BC). São, geralmente, partículas não esféricas ou pequenos aglomerados. A escala é de $1 \mu \mathrm{m}$. Adaptado de [Martins et al., 1998a]. c) Partículas envelhecidas provenientes de queimadas coletadas em Cuiabá, em sua maioria esféricas. Adaptado de [Martins et al., 1998b].

O aerossol atmosférico interage com a luz solar espalhando e absorvendo a radiação e tem um papel importante no balanço radiativo da terrestre. As partículas de aerossol podem tanto ter um efeito de esfriamento como de aquecimento do ar da camada atmosfera em que se encontra, dependendo das suas propriedades ópticas. 
Os efeitos de aquecimento e esfriamento pelo aerossol mudam o perfil termodinâmico da atmosfera favorecendo ou inibindo convecção, por exemplo, o que tem impacto direto na formação de nuvens [Dias, 2002]. Outro fator conhecido, é que as partículas de aerossol funcionam como núcleos de condensação de nuvens (NCN), em outras palavras, as gotas de nuvens se formam pela condensação do vapor d'água em uma partícula de aerossol [Artaxo et al., 2006]. Mudanças na concentração de NCNs afetam a concentração de gotas de nuvem que influenciam a precipitação, pois estas precisam atingir um tamanho limite para precipitar, e também no albedo das nuvens que afeta o balanço radiativo e, portanto, o clima [Andreae et al., 2004].

O impacto dos aerossóis no clima é dividido entre os chamados efeitos direto e indireto [Forster et al., 2007]. O efeito radiativo direto é a interação das partículas com a radiação solar na atmosfera, incluindo o espalhamento e absorção da luz solar incidente. O efeito direto provoca uma diminuição no fluxo radiativo na superfície. Com a redução no fluxo da radiação, a temperatura na superfície é diretamente afetada, com potenciais alterações também na precipitação, na umidade do ar e do solo e na circulação atmosférica. Para quantificar esse impacto, o IPCC (Intergovernmental Panel on Climate Change) definiu a forçante climática dos aerossóis como a mudança na irradiância (solar mais a de onda longa em W.m-2) líquida na tropopausa, entre um estado perturbado e um estado natural. Aerossóis como sulfato, carbono orgânico (OC), resultantes da queima de biomassa e poeira mineral são conhecidos por terem uma componente antropogênica significativa e exercerem uma significante forçante radiativa direta. Os efeitos radiativos indiretos dos aerossóis estão relacionados com a modificação da microfísica de nuvens e, portanto com as propriedades radiativas, quantidade e tempo de vida das nuvens. 


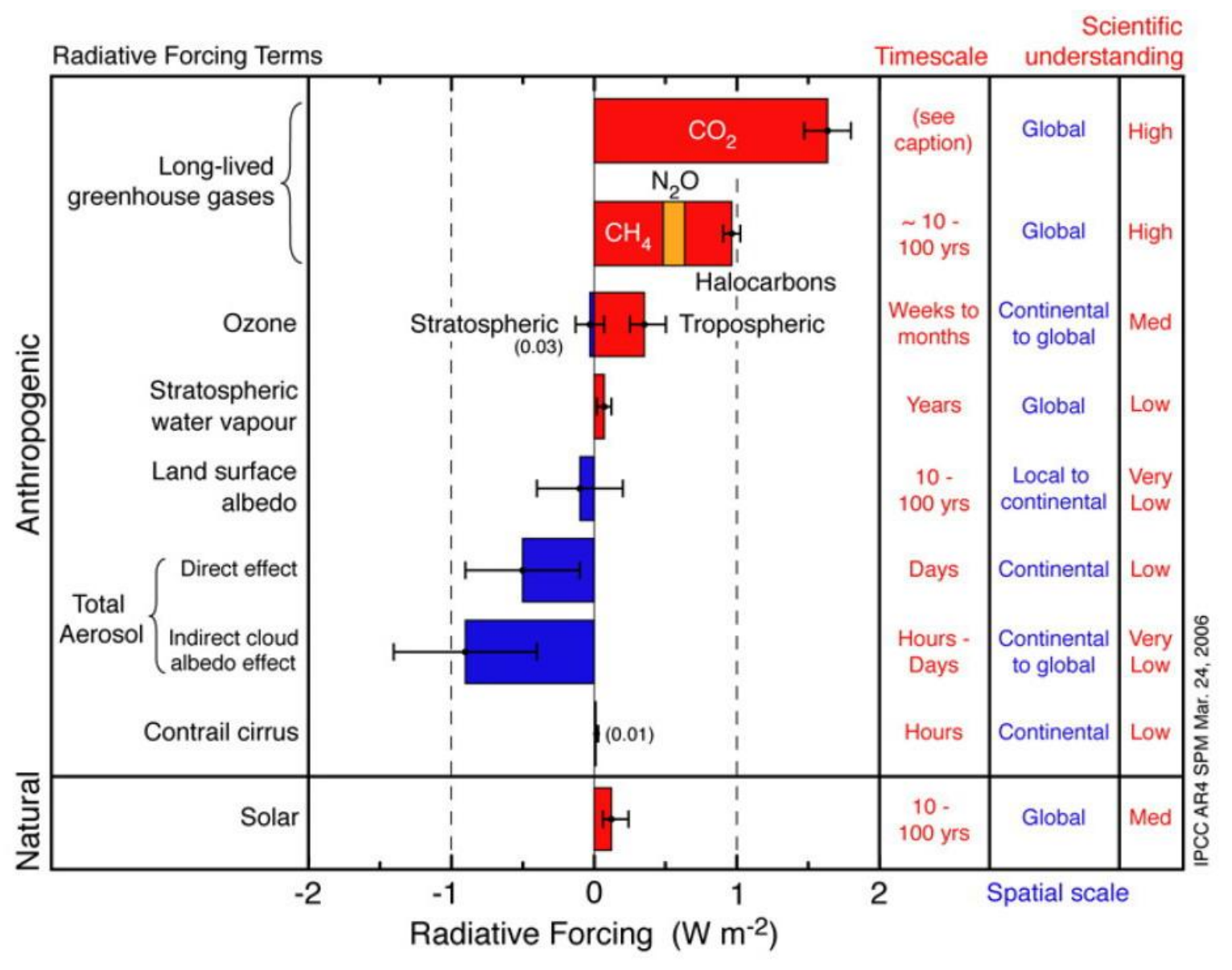

Figura 9. Diversos componentes que afetam o sistema climático e seus respectivos impactos

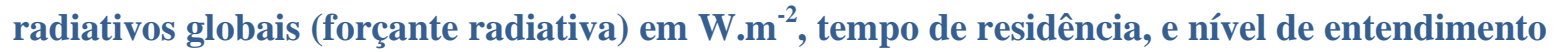
científico. (IPCC, 2007).

A importância da pesquisa nesse campo é demonstrada na Figura 9, revelando que os efeitos direto e indireto dos aerossóis podem causar uma forçante radiativa negativa da mesma ordem de grandeza dos gases estufa, indicando que eles podem minimizar um efeito estufa mais pronunciado. Observa-se que as maiores incertezas são associadas ao papel das partículas de aerossóis no balanço de radiação terrestre. Em parte, este desconhecimento é devido à falta de caracterização das propriedades ópticas de aerossóis em escala regional, ao seu pequeno tempo de residência na atmosfera e aos efeitos indiretos dos aerossóis na formação e desenvolvimento de nuvens. 
As partículas de aerossóis também possuem fortes efeitos na saúde da população, quando em concentrações acima das concentrações naturais [Brunekreef e Holgate, 2002]. As partículas de aerossol podem passar pelo trato respiratório superior e entrar nos brônquios e pulmões, potencialmente causando sérios problemas respiratórios. A fração fina do aerossol, especialmente o material particulado com diâmetro aerodinâmico menor que 2,5 $\mu \mathrm{m}$, também chamada de $\mathrm{MP}_{2.5}$, é a fração que mais causa danos à saúde humana porque pode penetrar no trato respiratório de modo mais profundo, chegando a afetar os alvéolos pulmonares, contribuindo com o aumento da morbidade [Pope et al., 2004].

A resolução CONAMA 03/90 (Conselho Nacional do Meio Ambiente), foi criada em 1990 para regulamentar o padrão nacional de qualidade do ar, incluindo o material particulado inalável (com diâmetro menor que $10 \mu \mathrm{m}$ ), sendo que a média da concentração de MP em 24 horas não deve exceder $150 \mu \mathrm{g} / \mathrm{m}^{3}$, e a média aritmética anual não deve exceder 50 $\mu \mathrm{g} / \mathrm{m}^{3}$. O padrão segue a tendência dos Estados Unidos da América, cuja agência de proteção ambiental EPA (Environmental Protection Agency of United States) estabelece os mesmos valores. Embora a resolução CONAMA 03/90 não contemple a fração fina $\mathrm{MP}_{2.5}$, tanto a agência norte americana EPA, como o conselho europeu de qualidade do ar (European Council or ambient air quality, EC 08) tem como padrão para concentração de MP2.5 a média anual de $15 \mu \mathrm{g} / \mathrm{m}^{3}$ e $17 \mu \mathrm{g} / \mathrm{m}^{3}$, respectivamente. 


\section{FUNDAMENTAÇÃO TEÓRICA}

Neste capítulo são apresentados de maneira sucinta os conceitos básicos de transferência radiativa na atmosfera terrestre, bem como alguns aspectos das hipóteses presumidas no algoritmo da AERONET e no cálculo das propriedades ópticas e de microfísica do aerossol através das medidas do radiômetro Cimel.

\subsection{RADIAÇÃO DE CORPO NEGRO}

A radiação eletromagnética propaga na forma de onda e é caracterizada pelo seu comprimento de onda $(\lambda)$ ou frequência $(v)$, sendo essas duas grandezas conectadas através da relação $\lambda=c / v$, onde c é a velocidade da luz. Planck, em 1901, postulou que os átomos de um corpo se comportam como pequenos osciladores eletromagnéticos e assumem energia que pode ser relacionada com a frequência por $\varepsilon=h v$. Ainda, Planck postulou que esses osciladores emitem energia radiante quando mudam de estado, sendo esses estados de energia quantizados:

$$
\Delta \varepsilon=\Delta n h v=h v
$$

Para se entender os processos de absorção e emissão de energia radiante começamos com as leis de radiação de corpo negro. O termo corpo negro é usado para uma configuração material onde a absorção de radiação seja completa, ou seja, nenhuma radiação é refletida. Podemos visualizar um corpo negro como uma cavidade que possui apenas uma pequeníssima entrada. Toda radiação que entra pela cavidade é refletida inúmeras vezes até ser completamente absorvida pelas paredes. A entrada é tão pequena que a probabilidade da radiação ser refletida para fora da cavidade pode ser considerada nula. Se o corpo estiver em equilíbrio térmico, toda a radiação absorvida tem que ser emitida. A emissão de radiação por corpo negro depende somente de sua temperatura, não dependendo do tipo de material ou forma. 
Rayleigh e Jeans calcularam através da teoria eletromagnética clássica a densidade de energia radiante dentro de uma cavidade, no entanto a teoria prevê que a energia tende a infinito para altas frequências, também conhecido como "catástrofe do ultravioleta". Com a quantização introduzida por Planck, tem-se a função de Planck para a intensidade emitida em unidade de energia/área/tempo/sr/comprimento de onda:

$$
B_{\lambda}(T)=\frac{2 h c^{2}}{\lambda^{5}\left(e^{\frac{h c}{k T \lambda}}-1\right)},
$$

onde h é a constante de Planck e k é a constante de Boltzmann, cujos valores são, 6,626 × $10^{-34}$ J.s e $1,3806 \times 10^{-23} J . K^{-1}$, respectivamente. Para $\lambda \rightarrow \infty$, a função de Planck se comporta como a distribuição de Rayleigh-Jeans, e para $\lambda \rightarrow 0$ como a distribuição de Wien.

A intensidade radiante total emitida por um corpo negro pode ser obtida integrando-se a função de Planck para todo o espectro, para $\lambda$ de zero a $\infty$.

$$
B(T)=\int_{0}^{\infty} B_{\lambda}(T) d \lambda=b T^{4}
$$

onde $b=2 \pi^{4} K^{4} /\left(15 c^{2} h^{3}\right)$. Ainda, por ser isotrópica, temos que o fluxo radiante é:

$$
F=\pi B(T)=\sigma T^{4}
$$

onde $\sigma$ é a constante de Stefan-Boltzmann e tem o valor de 5,671 $\times 10^{-8} \mathrm{Wm}^{-2} \mathrm{~K}^{-4}$. Essa é a chamada lei de Stefan-Boltzmann, que explicita que a radiação de corpo negro depende apenas da temperatura.

Se derivarmos a intensidade total radiante $\mathrm{B}(\mathrm{T})$ em relação a $\lambda$ e igualarmos a zero, obteremos o comprimento de onda em que a função é máxima. Essa relação mostrada abaixo é conhecida como lei do deslocamento Wien. 


$$
\frac{\partial B_{\lambda}(T)}{\partial \lambda}=0 \quad \rightarrow \quad \lambda_{\max }=\frac{\alpha}{T}
$$

onde $\alpha=2,897 \times 10^{-3} \mathrm{~m}$. No caso do Sol sua temperatura é de $\sim 5800 \mathrm{~K}$, e o comprimento de onda de máxima emissão é de $\sim 0,5 \mu \mathrm{m}$. Já a Terra possui uma temperatura de aproximadamente $255 \mathrm{~K}$, e o comprimento de onda máximo é de $\sim 10 \mu m$.

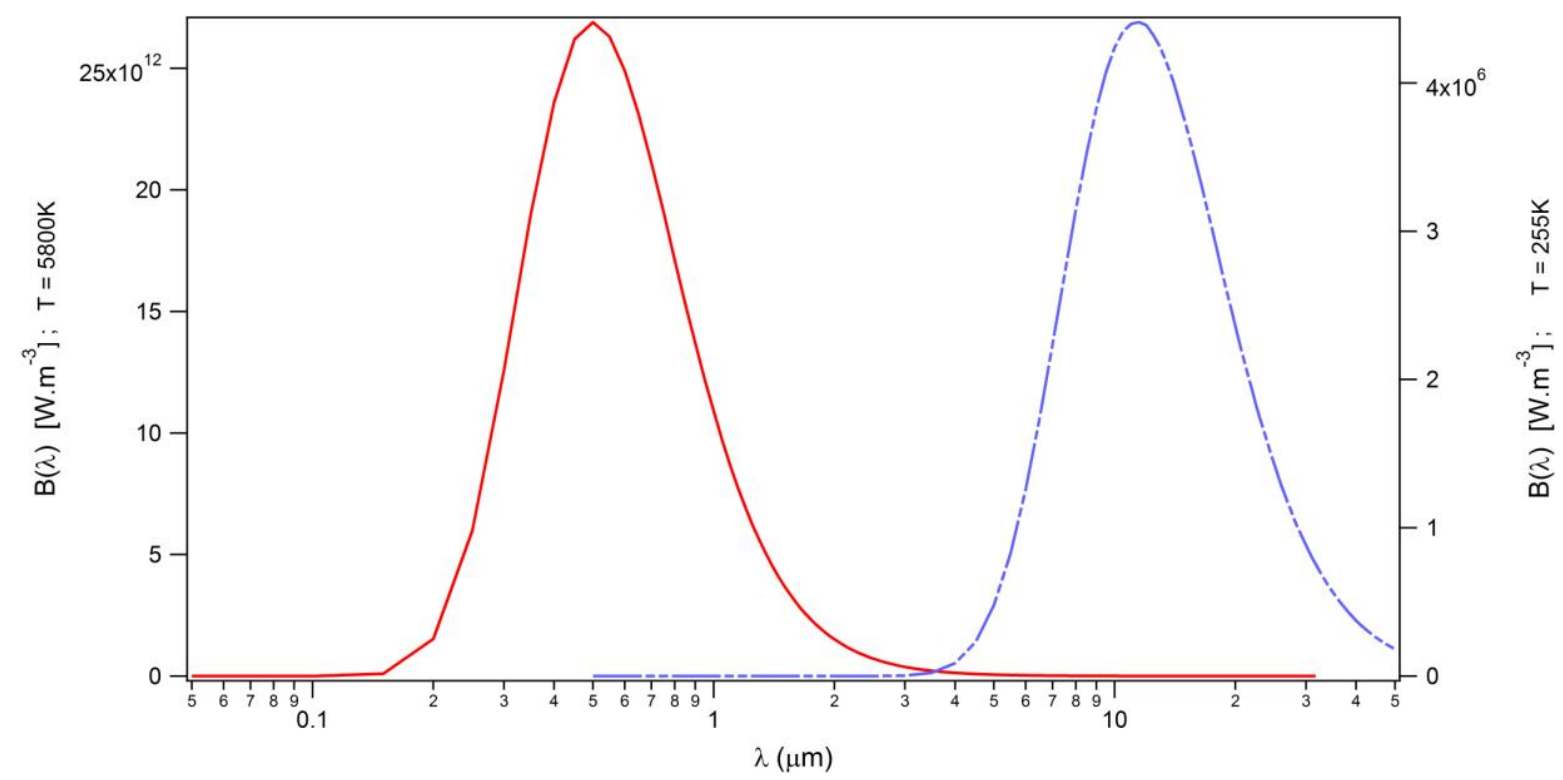

Figura 10. Função de Planck para um corpo a temperatura de $5800 \mathrm{~K}$ (em vermelho, eixo vertical à esquerda) e para a temperatura de $255 \mathrm{~K}$ (pontilhado em azul, eixo vertical à direita) representando a emissão do Sol e da Terra, respectivamente. A intensidade total emitida pelo Sol é muitas ordens de grandeza maior que a Terra.

Sob a condição de equilíbrio termodinâmico, caracterizado por temperatura uniforme e radiação isotrópica, há relação entre a emissividade num dado comprimento de onda, $\varepsilon_{\lambda}$ (definida pela razão entre a intensidade emitida e a função de Planck), e absortância $A_{\lambda}$ (definida como a razão entre a intensidade absorvida e a função de Planck).

$$
\varepsilon_{\lambda}=A_{\lambda}
$$


Essa relação é conhecida como a lei de Kirchhoff para radiação. A Terra como um todo não pode ser considerada estar em equilíbrio termodinâmico, pois sua temperatura varia significativamente, e a radiação não é isotrópica. No entanto, para um volume localizado abaixo dos 60-70 km, com boa aproximação, pode-se aplicar a lei de Kirchhoff [Liou, 2002].

\subsection{TRANSFERÊNCIA RADIATIVA NA ATMOSFERA}

Virtualmente, toda a energia do sistema terra-atmosfera vem do Sol. A interação entre a radiação eletromagnética solar e as moléculas gasosas, partículas de aerossóis e nuvens constituem os principais processos de transferência de energia nesse sistema. O Sol emite radiação em larga faixa do espectro eletromagnético, no entanto a maior parte da energia está concentrada na região do visível entre 400 e 700 nm, mas nem toda essa energia chega à superfície. De cerca de $342 \mathrm{Wm}^{-2}$ do fluxo de energia radiante vinda do Sol que chega ao topo da atmosfera apenas $168 \mathrm{Wm}^{-2}$ é absorvida pela superfície [Seinfeld e Pandis, 2006], efeito devido a atenuação pelos gases da atmosfera, aerossóis, nuvens, e inclusive o albedo de superfície que indica a sua capacidade de reflexão da energia incidente. 


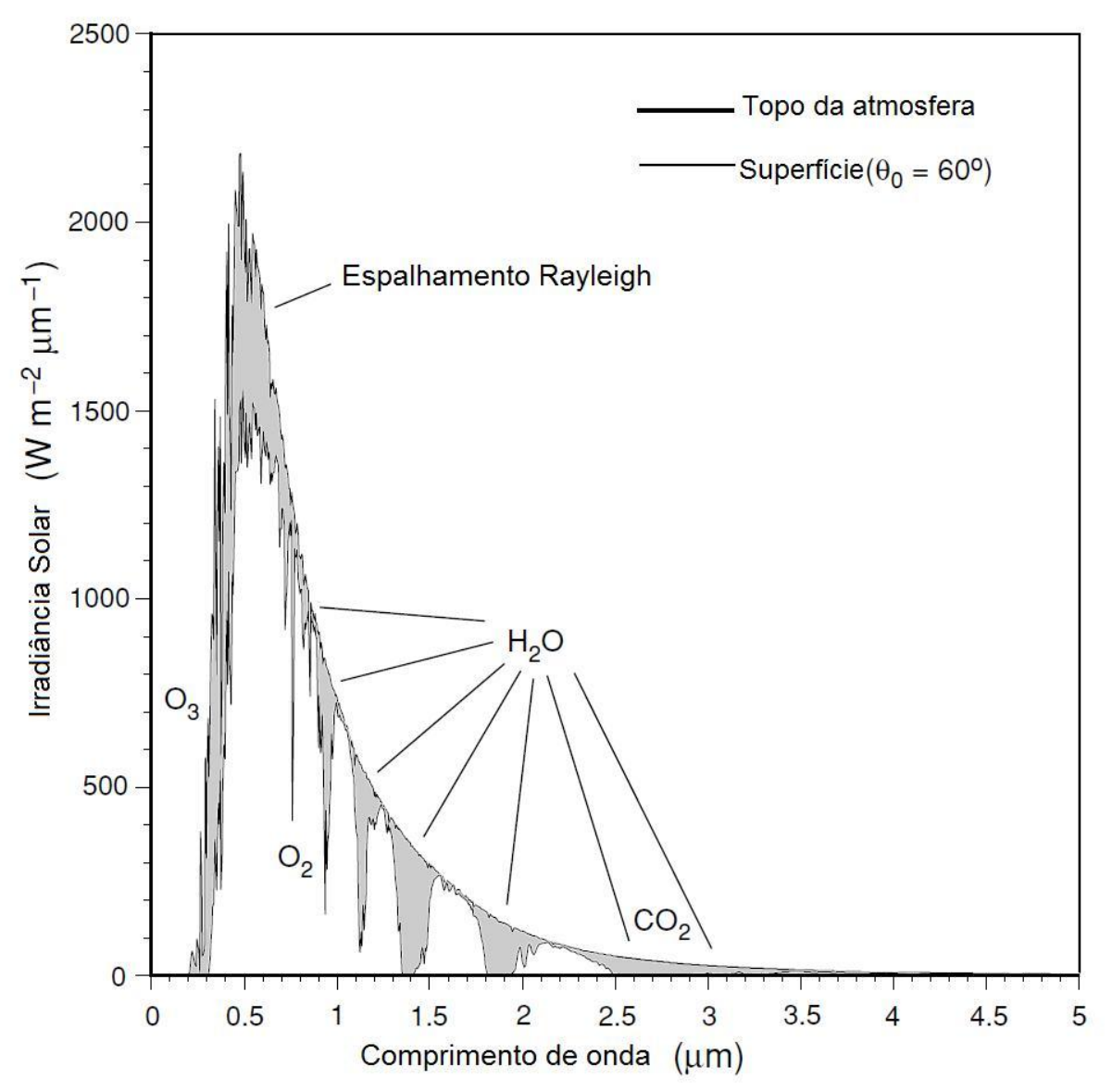

Figura 11. Curva de irradiância solar no topo da atmosfera e também na superfície, para ângulo solar zenital igual a $60^{\circ}$ numa atmosfera sem a presença de aerossóis ou nuvens. Em cinza estão indicadas as áreas de espalhamento e absorção. Adaptado de Liou, 2002.

As equações que regem a transferência de energia radiativa na atmosfera são da maior importância no cômputo da influência dos aerossóis no clima. Como vimos anteriormente, nossa fonte de energia radiativa é o Sol, que atravessa um meio gasoso constituído também por partículas de aerossóis e nuvens até chegar à superfície terrestre.

Considere radiação de certo comprimento de onda $\lambda$ atravessando um meio em uma certa direção. Sua intensidade será diminuída por sua interação com a matéria, devido à absorção e espalhamento pelo material. Sendo a intensidade de radiação $\mathrm{I}_{\lambda}$, ao atravessar um meio de espessura $d s$ na direção de propagação a intensidade será $\mathrm{I}_{\lambda}+\mathrm{dI}_{\lambda}$ tal que:

$$
d I_{\lambda}=-k_{\lambda} \rho I_{\lambda} d s
$$


onde $\rho$ é a densidade do material e $k_{\lambda}$ é a seção de choque de extinção de massa (em unidades de área por massa) para radiação de comprimento de onda $\lambda$.

Por outro lado, a intensidade pode ser aumentada por emissão do meio e também por múltiplo espalhamento de todas as outras direções no mesmo comprimento de onda e direção consideradas. Para tal pode-se definir um coeficiente $\mathrm{j}_{\lambda}$ de uma função fonte $\mathrm{J}_{\lambda}$, tal que o incremento será

$$
d I_{\lambda}=j_{\lambda} \rho d s .
$$

Combinando as duas equações temos:

$$
d I_{\lambda}=-k_{\lambda} I_{\lambda} \rho d s+j_{\lambda} \rho d s .
$$

É conveniente definir a função fonte $\mathrm{J}_{\lambda}$ de modo que $J_{\lambda} \equiv j_{\lambda} / k_{\lambda}$. Então podemos reescrever a equação acima como:

$$
\frac{d I_{\lambda}}{k_{\lambda} \rho d s}=-I_{\lambda}+J_{\lambda} .
$$

Esta é a equação de transferência radiativa mais geral, sem nenhuma imposição de sistemas de coordenadas, fundamental para a discussão dos processos radiativos na atmosfera.

A próxima seção trata da radiação de comprimento de onda curta - espectro do ultravioleta e visível - em que o termo $J_{\lambda}$ da equação acima, que indica a emissão do meio, pode ser negligenciado e a solução da equação diferencial é do tipo exponencial. Já a seção seguinte trata da luz de comprimento de onda longo, caso da emissão terrestre no infravermelho, em que valem os termos de emissão e absorção, e o espalhamento molecular e por partículas pode ser negligenciado. 


\subsubsection{EQUAÇÃO DE SCHWARZSCHILD}

Se considerarmos apenas radiação de onda longa, os principais fenômenos envolvidos na atmosfera serão a emissão da terra no infravermelho e a absorção dessa radiação pelos gases de efeito estufa, sendo que o espalhamento pode ser negligenciado. No equilíbrio termodinâmico local, a função fonte será a função de Planck, e a equação geral de transferência radiativa pode ser escrita como

$$
\frac{d I_{\lambda}}{k_{\lambda} \rho d s}=-I_{\lambda}+B_{\lambda}(T),
$$

onde $\mathrm{k}_{\lambda}$ é agora o coeficiente de absorção. Podemos definir a profundidade óptica do meio entre os pontos $s$ e $s_{1}$ (sendo $s_{1}>s$ e ambos positivos) como

$$
\tau_{\lambda}\left(s_{1}, s\right)=\int_{s}^{s_{1}} k_{\lambda} \rho d s^{\prime},
$$

e notando que

$$
d \tau_{\lambda}\left(s_{1}, s\right)=-k_{\lambda} \rho d s
$$

podemos escrever que

$$
-\frac{d I_{\lambda}(s)}{d \tau_{\lambda}\left(s_{1}, s\right)}=-I_{\lambda}+B_{\lambda}[T(s)] .
$$

Multiplicando toda a equação acima por $e^{-\tau_{\lambda}\left(s_{1}, s\right)}$, e integrando a espessura $d s$ de 0 a $s_{l}$, obtemos

$$
\begin{gathered}
-\int_{0}^{s_{1}} d\left[I_{\lambda}(s) e^{-\tau_{\lambda}\left(s_{1}, s\right)}\right]=\int_{0}^{s_{1}} B_{\lambda}[T(s)] e^{-\tau_{\lambda}\left(s_{1}, s\right)} d \tau_{\lambda}\left(s_{1}, s\right) \\
I_{\lambda}\left(s_{1}\right)=I_{\lambda}(0) e^{-\tau_{\lambda}\left(s_{1}, 0\right)}+\int_{0}^{s_{1}} B_{\lambda}[T(s)] e^{-\tau_{\lambda}\left(s_{1}, s\right)} k_{\lambda} \rho d s .
\end{gathered}
$$


O primeiro termo da solução da equação de Schwarzschild representa a absorção do meio, enquanto que o segundo termo denota a emissão de radiação no caminho entre 0 e $s_{1}$ do meio.

\subsubsection{LEI DE LAMBERT-BEER-BOUGUER}

Se considerarmos apenas a luz do Sol de onda curta, de 0,2 a $5 \mu \mathrm{m}$ por exemplo, podemos negligenciar emissão do sistema terra-atmosfera. Ainda, se pudermos negligenciar contribuições de múltiplo espalhamento na atmosfera, o termo fonte na equação de transferência radiativa vai a zero de modo que podemos escrever:

$$
\frac{d I_{\lambda}}{I_{\lambda}}=-k_{\lambda} \rho d s
$$

Seja a intensidade no começo do caminho $s=0$ igual a $I_{\lambda}(0)$, e após percorrer até $s=s_{1}$ igual a $I_{\lambda}\left(s_{1}\right)$. Então a integral da equação acima, será

$$
I_{\lambda}\left(s_{1}\right)=I_{\lambda}(0) \exp \left(-\int_{0}^{s_{1}} k_{\lambda} \rho d s\right) .
$$

Se o meio for homogêneo de modo que $\mathrm{k}_{\lambda}$ seja independente do caminho, e definindo $u=\int_{0}^{s_{1}} \rho d s$, escrevemos

$$
I_{\lambda}\left(s_{1}\right)=I_{\lambda}(0) e^{-k_{\lambda} u}
$$

Essa equação é conhecida como lei de Beer-Lambert-Bouguer. 


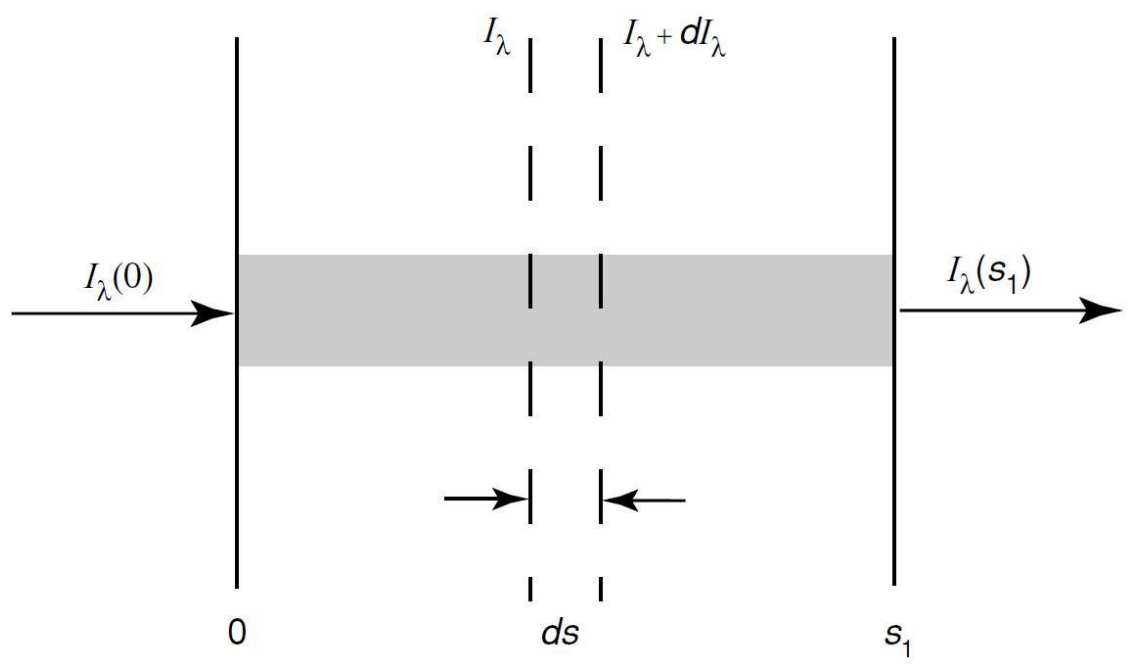

Figura 12. Ilustração do caminho óptico. Adaptado de [Liou, 2002].

Para o cálculo da interação do aerossol atmosférico com a radiação solar, podemos ainda assumir que a atmosfera é plano paralela, ou seja, não há variação horizontal significativa dos parâmetros atmosféricos, somente vertical. Para tais cálculos é conveniente utilizar um sistema de coordenadas em que as distâncias são medidas em relação a normal do plano de estratificação, como na Figura 13.

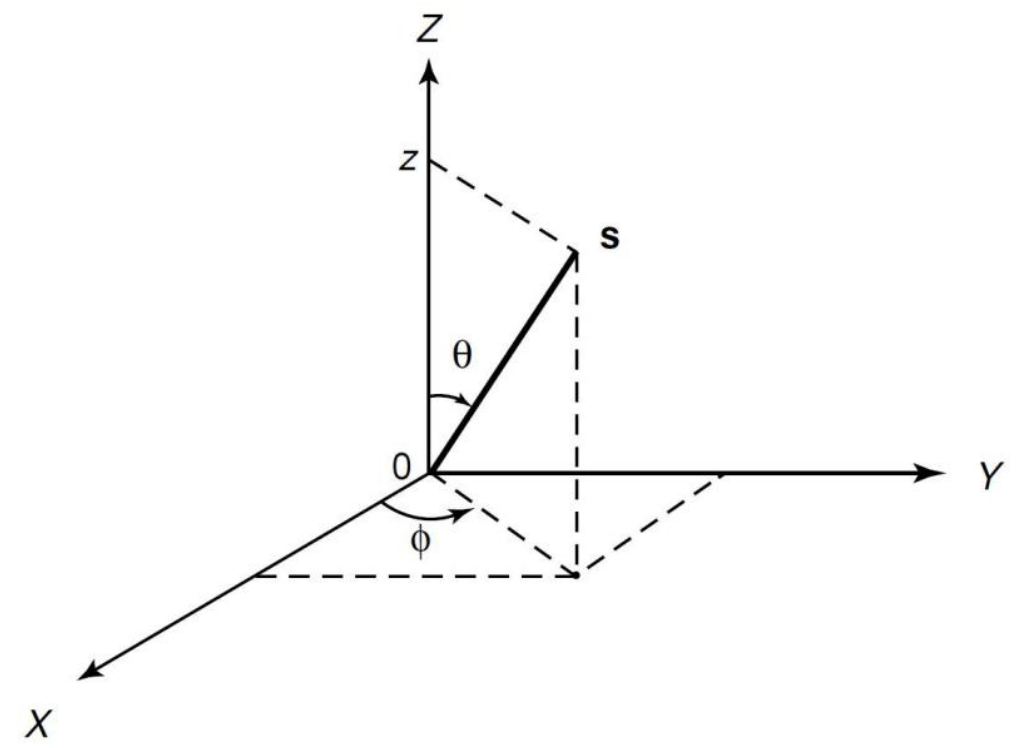

Figura 13. Sistema de coordenadas utilizado para o caso de uma atmosfera plano paralela. $O$ ângulo $\theta$ é chamado de ângulo solar zenital, medido em relação à normal; 0 ângulo azimutal $\phi$ mede a projeção no plano XY; $\overrightarrow{\boldsymbol{s}}$ é o vetor posição. Adaptado de [Liou, 2002]. 
O termo $1 / \cos \theta$ é também chamado de massa de ar no caso específico de atmosfera plana paralela (Figura 14). No caso do sistema Sol-Terra, $\theta$ igual a 0 significa o menor caminho que a radiação solar percorre para chegar à superfície, e a massa de ar correspondente é 1. Quando o ângulo zenital for de $60^{\circ}$, por exemplo, a radiação percorre um caminho duas vezes o tamanho da atmosfera, ou seja, a massa de ar é igual a 2.

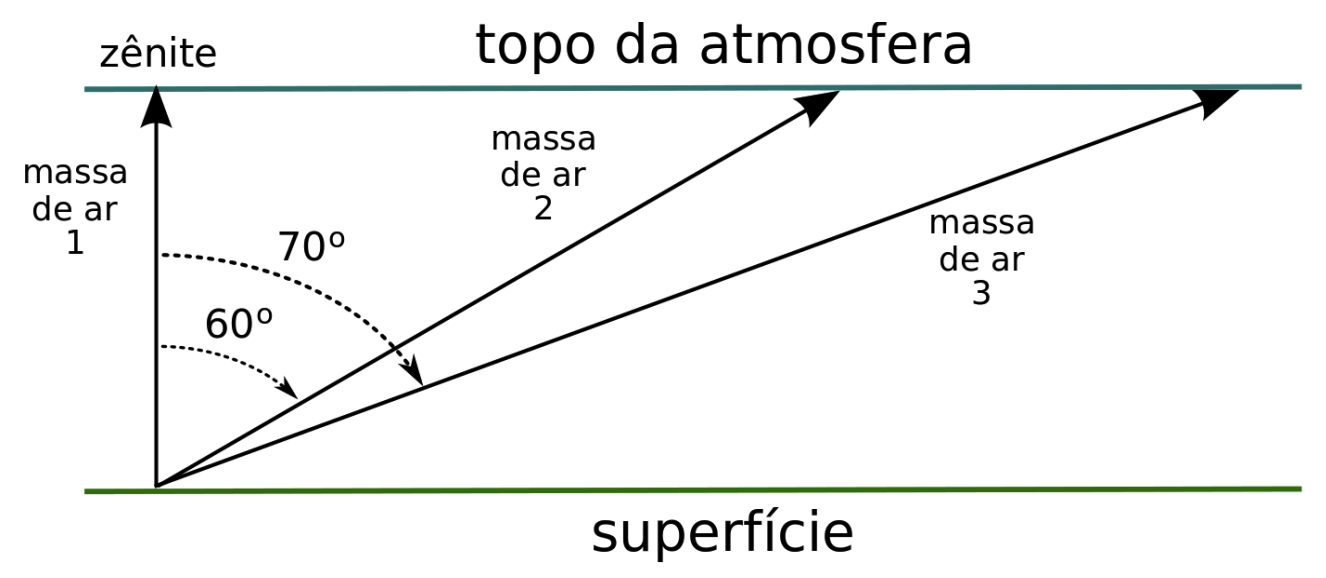

Figura 14. Desenho esquemático da relação entre ângulo solar zenital e o comprimento da massa de ar.

Portanto, no sistema de coordenadas da Figura 13 a distância $d s$ fica agora descrita por $d z / \cos \theta$, e a equação geral de transferência radiativa pode ser escrita da seguinte maneira:

$$
\cos \theta \frac{d I(z ; \theta, \phi)}{k \rho d z}=-I(z ; \theta, \phi)+J(z ; \theta, \phi) .
$$

Introduzindo a profundidade óptica normal a seguir, medida de fora pra dentro ou seja, com os limites da integral trocados,

$$
\tau_{\lambda}=\int_{z}^{\infty} k_{\lambda} \rho d z^{\prime}
$$

temos que

$$
\mu \frac{d I(\tau ; \mu, \phi)}{d \tau}=I(\tau ; \mu, \phi)-J(\tau ; \mu, \phi),
$$


notando que agora o sinal de I e $\mathrm{J}$ foram trocados por causa da definição de profundidade óptica. Por definição, a profundidade óptica é nula no topo da atmosfera, onde $\mathrm{z} \rightarrow \infty$.

Na condição de uma atmosfera sem a presença de nuvens, a profundidade óptica normal de extinção pode ser escrita como a soma da extinção por gases e por aerossóis:

$$
\tau_{\text {ext }}^{\text {total }}(\lambda)=\tau_{\text {ext }}^{\text {aer }}(\lambda)+\tau_{\text {ext }}^{\text {gas }}(\lambda)
$$

\subsection{DESCRIÇÃO DAS PROPRIEDADES DAS PARTÍCULAS DE DO AEROSSOL CALCULADAS PELA AERONET}

Quando um feixe de luz incide sobre uma partícula dois fenômenos podem ocorrer: espalhamento e absorção. Ainda, o espalhamento pode ser divido entre aqueles fenômenos que conservam o comprimento de onda da luz incidente - reflexão, refração e difração - e aqueles que provocam uma mudança, como a fluorescência e o espalhamento Raman, sendo esses últimos fenômenos não tratados aqui por conta da escolha dos instrumentos utilizados no presente trabalho.

O problema de absorção e espalhamento de luz é tratado pela teoria eletromagnética, sendo que sua solução formal para partículas esféricas homogêneas foi desenvolvida em 1908 por Gustav Mie, no intuito de entender a variação de cores no espalhamento e absorção por partículas de outro em uma solução de água. Na realidade, muitos outros trataram do mesmo problema como Debye e Lorenz, mas a teoria é comumente chamada de Teoria Mie, simplesmente, ou teoria Lorenz-Mie. No caso de partículas não-esféricas, importante principalmente no caso de partículas de poeira, por exemplo, a teoria Mie oferece apenas uma aproximação de primeira ordem, no entanto é muito utilizada pelo fato de a solução para partículas esferóides ser de tratamento matemático difícil.

Para partículas muito menores que o comprimento de onda da luz incidente, a solução é dada pela chamada Teoria Rayleigh, utilizada para o caso de gases na atmosfera em se tratando principalmente da luz no espectro visível. Para partículas muito maiores que o comprimento de onda a óptica geométrica é a utilizada. 
Para tanto, é definido um termo físico chamado de parâmetro de tamanho, que indica a relação entre o tamanho da partícula e o comprimento de onda incidente, definido por:

$$
x=\frac{2 \pi r}{\lambda}
$$

onde $r$ é o raio da partícula e $\lambda$ é o comprimento de luz incidente. De maneira geral, quando $\mathrm{x} \ll 1$, o regime de espalhamento é Rayleigh; se $\mathrm{x} 1$, o espalhamento é determinado pela teoria de Mie; e se $x>>1$, o espalhamento é dado pela da óptica geométrica.

No código de inversão utilizado pela rede AERONET, as partículas de aerossol estão particionadas em duas componentes: esféricas e não esféricas. A componente esférica é modelada por um conjunto de esferas polidispersas (que possuem diferentes tamanhos) e homogêneas (é assumido um mesmo índice de refração complexo para todas as partículas de todos os tamanhos). As propriedades são calculadas pela teoria Mie pelo método de ordenadas discretas descrito em Nakajima et al., 1988, e Stamnes et al., 1998.

A componente não esférica é tratada como uma mistura de partículas esferoides (ou esferoidais) polidispersas, homogêneas, orientadas aleatoriamente. O método utilizado para calcular essas partículas é baseado no modelo de mistura de formatos de esferóides polidispersos aleatoriamente orientados descrito em detalhes por [Dubovik et al., 2002; 2006a].

O cálculo das propriedades ópticas e de microfísica de partículas de aerossol pela AERONET passou por diversas mudanças ao longo dos anos. A última versão do algoritmo foi lançada em 2006 e é chamada de Versão 2.0. As principais características do novo algoritmo são:

— a atmosfera é presumida com geometria plano paralela;

— a distribuição vertical de aerossóis é assumida homogênea para as inversões do almucantar, e dupla camada para as inversões de plano principal;

- A distribuição da razão dos esferoides é foi obtida em um trabalho experimental descrito em [Dubovik et al., 2006a]. 
- a refletância de superfície é aproximada por BRDF (Bidirectional Reflectance Distribution Function): modelo Cox-Munk [COX e MUNK, 1954] sobre a água e modelo Lie-Ross [Pokrovsky, 2003] sobre a terra. Os parâmetros BRDF para localidades na terra foram adotados de "MODIS ecotype generic BRDF models". A importância de se usar acuradas propriedades de refletância de superfície na inversão e possíveis melhoramentos no cálculo de propriedades do aerossol é descrita por [Sinyuk et al., 2007].

- Os cálculos por Cox-Munk usam os cálculos de velocidade do vento pelas reanálises do NCEP/NCAR (National Center for Environmental Prediction /National Center for Atmospheric Research).

As propriedades do aerossol derivadas e calculadas pelos algoritmos da AERONET podem ser dividas em dois blocos: medidas diretas e medidas indiretas, também chamadas de inversões. As propriedades diretas são as obtidas onde o valor de entrada é a radiância direta, medida com o colimador do radiômetro apontando para o disco solar. As propriedades então calculadas são a profundidade óptica do aerossol, a quantidade de água precipitável na coluna atmosférica, e o coeficiente de Ångström.

A profundidade óptica do aerossol, dada pelas Equações (19) e (21), é calculada pela lei de Lambert-Beer-Bouguer da atenuação exponencial da intensidade ao passar pela atmosfera (Equação (16)). A intensidade inicial $\mathrm{I}_{0}$, que o radiômetro mediria antes de a luz atravessar a atmosfera, é obtida pelo método de Langley [Eck et al., 1999]. A profundidade óptica dos gases atmosféricos é levada em conta na escolha cuidadosa das bandas espectrais medidas pelo radiômetro, sendo que as concentrações dos gases $\mathrm{O}_{3}$ e $\mathrm{NO}_{2}$ são avaliadas pela climatologia ${ }^{1}$, e $\mathrm{H}_{2} \mathrm{O}$ é medido separadamente no canal $940 \mathrm{~nm}$ pelo próprio radiômetro.

1 Os detalhes do algoritmo e referências pertinentes estão disponíveis no website da AERONET http://aeronet.gsfc.nasa.gov/new_web/publications.html 
A profundidade óptica do aerossol é considerada neste trabalho a soma dos efeitos de espalhamento e absorção pela partícula de aerossol, também chamada de profundidade óptica de extinção:

$$
\tau_{\text {ext }}(\lambda)=\tau_{\text {esp }}(\lambda)+\tau_{a b s}(\lambda)
$$

O coeficiente de Ångström, também chamado de expoente $\alpha$, representa a dependência espectral da profundidade óptica. Em 1929, Ångström apresentou a expressão empírica

$$
\tau^{a e r}=\beta \lambda^{-\alpha}
$$

onde $\lambda$ é o comprimento de onda em $[\mu \mathrm{m}]$ correspondente a profundidade óptica do aerossol, e $\beta$ é o coeficiente de turbidade que iguala a $\tau^{\text {aer }}$ para $\lambda=1 \mu \mathrm{m}$ [Ångström, 1929].

Fazendo-se a razão da Equação (24) entre dois comprimentos de onda $\lambda_{1}$ e $\lambda_{2}$ e aplicando o logaritmo em ambas as partes da expressão, o coeficiente de Ångström pode ser escrito como

$$
\alpha=\frac{d \ln \tau^{\text {aer }}}{d \ln \lambda}=-\frac{\ln \left(\frac{\tau_{\lambda_{1}}}{\tau_{\lambda_{2}}}\right)}{\ln \left(\frac{\lambda_{1}}{\lambda_{2}}\right)}
$$

Os valores típicos de $\alpha$ variam de quase zero para uma população de aerossóis dominados pela fração grossa, como por exemplo, poeira do deserto do Saara [Holben et al., 1991], maior que 2,0 para aerossóis dominados por partículas da moda fina (também chamada de moda de acumulação) tais como aerossóis de queimada [Kauffman et al., 1994], e entre 3 e 4 no regime Rayleigh [Seinfeld e Pandis, 2006]. Desse modo, o coeficiente de Ångström também é utilizado para indicar o tamanho das partículas de aerossol.

A quantidade de água precipitável na coluna é calculada através do método de absorção diferencial utilizando o canal de 0,94 $\mu \mathrm{m}$ [Schmid et al., 2001] e como o próprio nome sugere se refere a quantidade de vapor d'água que pode vir a precipitar em toda a coluna atmosférica, expressa em [cm]. 
As inversões são calculadas através das medidas do Cimel de radiância difusa de almucantar e plano principal (ver Seção 3.1.1 para maiores detalhes). Produtos derivados incluem a distribuição de tamanho em volume, função de fase do espalhamento, parte real e imaginária do índice de refração, raio efetivo, e albedo de espalhamento único. A distribuição angular de radiâncias do céu é obtida usando o método de Nakajima et al. [1983; 1996], sendo que esse método leva em conta adequadamente o efeito de espalhamento múltiplo em todo o intervalo dos ângulos de espalhamento. A AERONET também realiza o cálculo simultâneo da distribuição de tamanho e índice de refração via ajuste simultâneo de todas as radiâncias medidas em todo o intervalo angular e espectral disponível.

A distribuição de tamanho obtida desse modo é apresentada em termos de volume de partícula por área de atmosfera, e se relaciona com a distribuição numérica de partículas da seguinte maneira:

$$
\frac{d V(r)}{d \ln r}=V(r) \frac{d N(r)}{d \ln r}=\frac{4}{3} \pi r^{3} \frac{d N(r)}{d \ln r} \quad\left[\mu m^{3} / \mu m^{2}\right]
$$

e o raio efetivo da distribuição de tamanho é dado por

$$
r_{e f f}=\frac{\int_{r_{\min }}^{r_{\max }} r^{3} \frac{d N(r)}{d \ln r} d \ln r}{\int_{r_{\min }}^{r_{\max }} r^{2} \frac{d N(r)}{d \ln r} d \ln r}
$$

O índice de refração complexo do aerossol, em termos da componente de espalhamento $\mathrm{n}(\lambda)$ e de absorção $\mathrm{k}(\lambda)$, tem a forma de

$$
m(\lambda)=n(\lambda)-i k(\lambda)
$$

A partir desses parâmetros microfísicos são modelados todos os parâmetros ópticos segundo [Dubovik e King, 2000]. 
A função de fase de espalhamento, $P(\Theta ; \lambda)$ [adimensional], fornece a distribuição angular da intensidade espalhada $F(\Theta)$ nos 83 ângulos possíveis de espalhamento das medidas de almucantar realizadas pelo radiômetro.

$$
P(\Theta ; \lambda)=\frac{F(\Theta)}{\int_{0}^{\pi} F(\Theta) \operatorname{sen} \Theta d \Theta}
$$

O parâmetro de assimetria, $g(\lambda)$, é obtido calculando-se a média ponderada dos cossenos dos ângulos de espalhamento pelas radiâncias, dado a seguir

$$
\begin{aligned}
g(\lambda)=<\cos \Theta & >=\frac{1}{2} \frac{\int_{0}^{\pi} \cos \Theta F(\Theta) \operatorname{sen} \Theta d \Theta}{\int_{0}^{\pi} F(\Theta) \operatorname{sen} \Theta d \Theta} \\
= & \frac{1}{2} \int_{0}^{\pi} \cos \Theta P(\Theta) \operatorname{sen} \Theta d \Theta
\end{aligned}
$$

O fator $\frac{1}{2}$ garante $\mathrm{g}=1$ para espalhamento totalmente frontal, ou seja, toda intensidade que incide sobre a partícula é espalhada para frente $(\Theta=0), \mathrm{e} g=1$ para retroespalhamento $(\Theta$ $\left.=180^{\circ}\right)$. Se o espalhamento da luz é isotrópico, ou seja, simétrico, tem-se $\mathrm{g}=0$. Dessa maneira definido, g é positivo se a maior parte do espalhamento for frontal, negativo se for maior o retroespalhamento. $\mathrm{O}$ fator de assimetria é importante na avaliação da contribuição das partículas de aerossol no processo de transferência radiativa na atmosfera.

O albedo de espalhamento único, $\omega_{0}(\lambda)$, é a razão entre o coeficiente de espalhamento e o coeficiente de extinção, e é definido pela AERONET como a razão entre a profundidade óptica de espalhamento do aerossol e de extinção:

$$
\omega_{0}(\lambda)=\frac{\tau_{e s p}(\lambda)}{\tau_{e x t}(\lambda)}
$$


De posse das propriedades ópticas e de microfísica do aerossol ainda são calculados os fluxos radiativos ascendentes e descendentes no topo da atmosfera e na superfície, a forçante radiativa e a eficiência de forçante do aerossol, descritos em mais detalhes na próxima seção.

\subsubsection{FORÇANTE RADIATIVA DO AEROSSOL E EFICIÊNCIA DE FORÇANTE COMO PRODUTOS DA AERONET}

O algoritmo da AERONET calcula a forçante radiativa direta do aerossol como sendo a diferença entre a irradiância (ou fluxo) global integrada em todo o espectro, com e sem a presença de aerossol, computados no topo da atmosfera (TOA, do inglês Top of Atmosphere) e na superfície (BOA, Bottom of Atmosphere).

$$
\begin{gathered}
\Delta F_{B O A}=F_{B O A}^{\downarrow}-F_{B O A}^{\downarrow 0} \\
\Delta F_{T O A}=-\left(F_{T O A}^{\uparrow}-F_{T O A}^{\uparrow 0}\right)
\end{gathered}
$$

onde $\mathrm{F}$ e $\mathrm{F}^{0}$ são as irradiâncias com e sem aerossol, e as setas para cima $\uparrow$ indicam fluxo ascendente, e para baixo $\downarrow$ indicam fluxo descendente. Essa escolha dos sinais implica que valores negativos estão associados a efeito de esfriamento e valores negativos ao aquecimento, tanto na superfície (BOA) quanto no topo da atmosfera (TOA).

A partir dessa definição segue que a eficiência de forçante do aerossol é a razão entre a própria forçante por unidade de profundidade óptica do aerossol em $550 \mathrm{~nm}$, também calculada na superfície e no topo da atmosfera:

$$
\Delta F_{B O A / T O A}^{e f f}=\frac{\Delta F_{B O A / T O A}}{\tau_{550 n m}}
$$

A eficiência de forçante é importante, pois caracteriza o impacto direto radiativo do aerossol de uma região normalizado pela sua profundidade óptica. 
Nesse ponto é importante uma breve descrição do código de transferência radiativa usado pela AERONET para calcular os fluxos solar e a forçante radiativa, descrito em detalhes em [García et al., 2008a].

Os fluxos são calculados espectralmente entre 0,3 a $2,8 \mu \mathrm{m}$ utilizando mais de 200 subintervalos. $\mathrm{O}$ índice de refração foi interpolado/extrapolado a partir dos comprimentos de onda medidos pelo radiômetro para todo o intervalo solar, e da mesma maneira a dependência espectral da refletância de superfície. A integração dos efeitos de absorção gasosa e espalhamento molecular segue o código GAME (Global Atmospheric Model) [Dubuisson et al., 1996; Roger et al., 2006].

A validação do produto foi feita comparando os fluxos calculados com medidas de solo de piranômetros em todo o globo por [García et al., 2008a], e foi obtida uma excelente correlação em todos os casos, porém com uma superestimação de $6 \pm 13 \mathrm{~W} \cdot \mathrm{m}^{-2}$ na região da Amazônia brasileira. 


\section{MATERIAIS E MÉTODOS}

Nesta seção são descritos brevemente os métodos utilizados neste trabalho de medida de propriedades físicas de partículas de aerossóis. As propriedades ópticas foram obtidas através de sensoriamento remoto, tanto por satélite através do sensor MODIS, quanto do solo com a rede de radiômetros da AERONET. Para as medidas de concentração de material particulado, foram utilizados métodos gravimétricos como a análise de filtros no amostrador de particulado fino e grosso (AFG) e também o método de microbalança oscilante (TEOM - Tapered Element Oscilating Microbalance).

\subsection{SENSORIAMENTO REMOTO}

\subsubsection{AERONET}

A AERONET, do inglês AErosol RObotic NETwork, é uma rede de sensoriamento remoto de aerossóis a partir do solo, estabelecida pela NASA e expandida por colaboradores de agências nacionais, pesquisadores, e parceiros como o Instituto de Física da Universidade de São Paulo. A rede é composta por mais de 200 fotômetros solares espalhados pelo globo em lugares estratégicos para medir as propriedades ópticas, radiativas e de microfísica do aerossol integrados na coluna atmosférica. Criada inicialmente com o intuito de validar medidas de aerossol por sensoriamento remoto com satélites, a rede AERONET atualmente provê séries de longo prazo, em alguns lugares com mais de 10 anos de medidas em tempo quase real e com grande cobertura espacial.

O aparato instrumental consiste em um radiômetro automático, tipo CIMEL 318A, que mede a radiância em bandas espectrais centradas nos comprimentos de onda 340, 380, 440, $500,675,870,940$, e $1020 \mathrm{~nm}$. A largura a meia altura do filtro é de $2 \mathrm{~nm}$ para os canais 340 e $380 \mathrm{~nm}$, e $10 \mathrm{~nm}$ para os demais canais. O instrumento é equipado com dois colimadores e filtros de baixo e alto ganho para medidas de radiância direta, apontando para o disco solar, e radiância difusa em ângulos de espalhamento específicos, apontando para o céu. 
As medidas de radiância difusa são feitas em 4 comprimentos de onda $(440,670,870$ e $1020 \mathrm{~nm}$ ) ao longo do plano principal solar e almucantar, detalhado na Figura 15. O plano principal é definido como o plano vertical com ângulo azimutal $(\varphi)$ fixo no Sol, variando o ângulo zenital $(\theta)$, sendo zero na direção do Sol, positivo para cima e negativo para baixo. O almucantar é feito fixando o ângulo solar zenital e variando o ângulo azimutal. Como é assumido que o aerossol se encontra homogeneamente distribuído na atmosfera, o ângulo zero, na direção do Sol, mede o espalhamento frontal, indo até $180^{\circ}$ para espalhamento traseiro. Em sentido horário os ângulos são positivos, e no sentido anti-horário os ângulos são negativos.

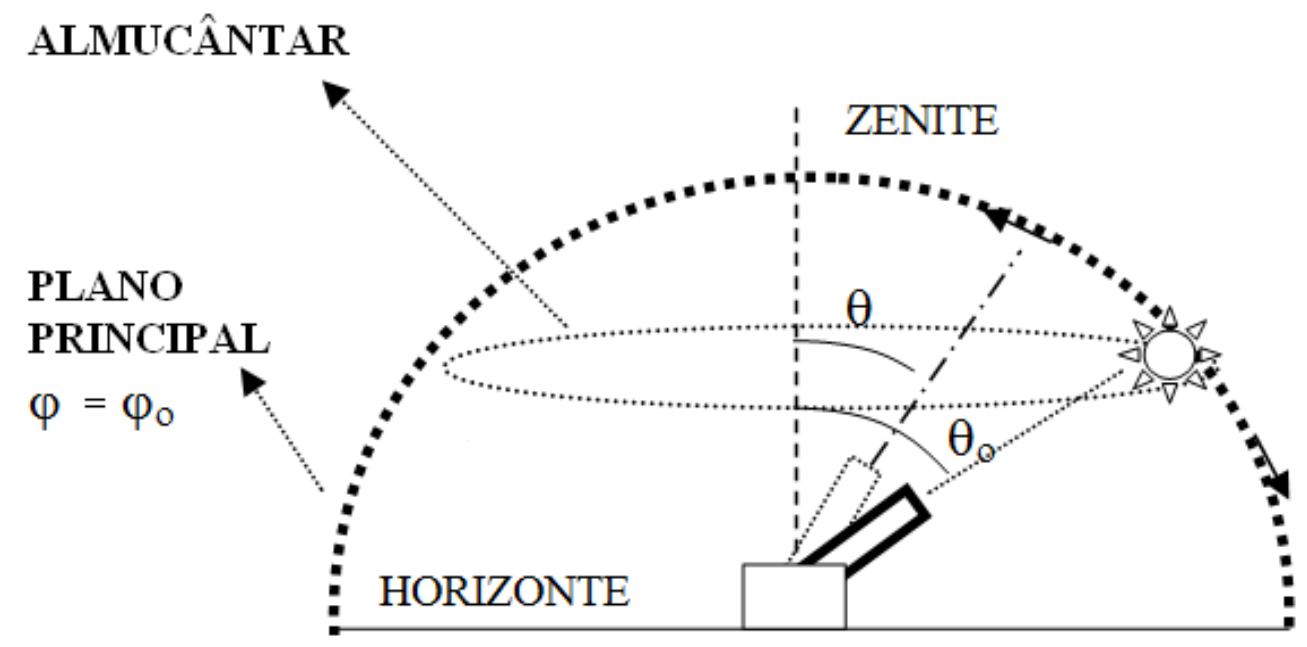

Figura 15. Esquema dos posicionamentos do radiômetro para a realização de medidas no Plano Principal (acima) e Almucantar (parte de baixo), onde $\varphi_{0}$ é o ângulo azimutal do Sol, $\varphi$ é o ângulo azimutal do sensor, $\theta_{0}$ é o ângulo zenital do Sol, $\theta$ é ângulo zenital do sensor. Adaptado de Castanho et al., 2005. 
O instrumento faz medidas automáticas pré-programadas começando com massa de ar igual a 7 pela manhã (ver Capítulo 2 Fundamentação Teórica, Figura 14), até massa de ar igual a 7 no final da tarde. A menor massa de ar possível tem valor igual a 1 e equivale ao comprimento total da atmosfera. Essa é a massa de ar ao meio dia num local na linha do Equador, por exemplo. Durante períodos de massa de ar grande, as medidas diretas são feitas a intervalos de 0,25 de massa de ar, enquanto que para massa de ar pequena o intervalo é tipicamente de 15 minutos. As medidas de almucantar são tomadas a cada $0,5^{\circ}$ de ângulo azimutal perto do Sol (dentro de $6^{\circ}$ ) e aumenta para cada $2-10^{\circ}$. São possíveis até 9 medidas de plano principal por dia e 8 de almucantar.

Estes dados estão disponíveis em três níveis de processamento: o nível 1.0 é chamado de medidas básicas, em que o sinal da tensão no radiômetro é convertido em irradiância e são calculadas todas as propriedades ópticas do aerossol no primeiro nível da medida. O nível 1.5 é o chamado cloud screened, ou seja, as medidas básicas passam por um procedimento para a retirada dos dados contaminados pela presença de nuvens na atmosfera. O nível final 2.0, quality assured, é avaliado quando o radiômetro volta para a NASA para recalibração dos dados, geralmente uma vez por ano, e são submetidos a uma série de critérios para serem considerados para ter a qualidade assegurada descrito em [Holben et al., 2006]. Os principais critérios são:

- Avaliação das ocorrências de falha do instrumento e determinação das possíveis causas como, por exemplo, água na lente, teia de aranha dentro do colimador, problemas no ajuste fino do robô, etc.;

- Verificação de anomalias no sensor de temperatura que afetam a correção de temperatura para o canal de $1020 \mathrm{~nm}$;

- Determina se houve degradação do filtro ou mudanças não lineares nas constantes de calibração durante o período em que o instrumento permaneceu em campo;

- Inspeciona as observações de profundidade óptica do aerossol para ver se há dependência espectral anômala devido a vazamentos ou degradação dos filtros ou problemas eletrônicos; e também para possíveis contaminações por nuvens; 
- Checa a consistência dos dados usando informações adicionais como imagens do MODIS, medidas de lidar, retro-trajetórias de massa de ar, etc.;

- Avalia o impacto dos novos dados coletados na climatologia existente.

Das medidas diretas, do disco solar, são calculadas a profundidade óptica do aerossol nos sete comprimentos de onda, o coeficiente de Ångström entre dois comprimentos de onda, e quantidade de vapor d'água na coluna atmosférica derivada da medida do canal $940 \mathrm{~nm}$.

Das medidas de almucantar e plano principal são calculadas as propriedades de espalhamento das partículas como a própria função de fase e o fator de assimetria, e ainda a distribuição volumétrica de tamanho, albedo de espalhamento único $(\omega)$ e o índice de refração complexo do aerossol $(m=n+i k)$. De posse das propriedades ópticas do aerossol, são ainda calculados os fluxos ascendentes e descendentes no topo da atmosfera, na superfície, e a forçante radiativa e eficiência de forçante do aerossol.

Se por um lado a obtenção da profundidade óptica do aerossol é direta, aplicando-se a lei de Lambert-Beer-Bouguer ao sinal de irradiância medido pelo sensor, o cálculo das propriedades derivadas de medidas de almucantar e plano principal envolve muitas aproximações e vem sendo alvo de constante aprimoramento. O primeiro código da AERONET, RAD.PAK (1993), calculava apenas a distribuição de tamanho e função de fase, segundo Nakajima et al., 1996. No ano de 2000 foi implementada a versão de (Dubovik e King 2000), que passou a ser completamente operacional a partir de 2003 e é chamada de Versão 1.0 do algoritmo. Em 2006 foi lançada a Versão 2.0, atual, descrita detalhadamente em [Holben et al., 2006], cujas principais mudanças foram a parametrização do grau de não esfericidade [Dubovik et al., 2006b], importante para as partículas de poeira; a utilização do produto de albedo de superfície do MODIS; e significativa melhora na qualidade dos dados de nível 2.0, com menos perda de observações. 
A incerteza na medida da profundidade óptica do aerossol é de aproximadamente 0,010 0,021, sendo devida principalmente aos erros de calibração do instrumento e é espectralmente dependente, com erros maiores no ultravioleta [Eck et al., 1999]. A técnica de inversão do índice de refração é mais precisa quando $\tau$ em $440 \mathrm{~nm}$ é maior que 0,4 [Dubovik et al., 2000], o ângulo solar zenital é maior que $50^{\circ}$, e o erro na radiância difusa é menor que $5-10 \%$, dependendo de $\tau$ [Holben et al., 2006]. Nessas condições, a incerteza é de 0,03 ou menos, sendo que quanto maior o valor de $\tau$, menor o erro.

No Brasil diversas estações da AERONET funcionaram por pequenos períodos, e cerca de 7 continuam a operar continuamente. As principais estações de medidas utilizadas nesse estudo são mostradas na tabela abaixo.

Tabela 1. Principais estações brasileiras da rede AERONET e seu período de funcionamento.

\begin{tabular}{|c|c|c|c|c|c|c|c|c|c|c|c|c|c|}
\hline & 1995 & 1999 & 2000 & 2001 & 2002 & 2003 & 2004 & 2005 & 2006 & 2007 & 2008 & 2009 & 2010 \\
\hline \multicolumn{14}{|l|}{ Balbina/AM } \\
\hline \multicolumn{14}{|l|}{ Santarém/PA } \\
\hline \multicolumn{14}{|l|}{ Belterra/PA } \\
\hline \multicolumn{14}{|l|}{ Campo Grande/MS } \\
\hline \multicolumn{14}{|l|}{ Cuiaba MirandaMT } \\
\hline \multicolumn{14}{|l|}{ Abracos Hill/RO } \\
\hline \multicolumn{14}{|l|}{ Ji Parana SE/RO } \\
\hline \multicolumn{14}{|l|}{ Rio Branco/AC } \\
\hline \multicolumn{14}{|l|}{ Alta Floresta/MT } \\
\hline & & & & & & & & & & & & & \\
\hline & & Esta & ções d & esativ & adas & & & Estaç & cões a & tivas & & & \\
\hline
\end{tabular}

\subsubsection{MODIS}

O sensoriamento remoto de aerossóis por satélite data do final da década de 70, com instrumentos mais antigos como o AVHRR e TOMS, e mais recentemente MODIS, MISR, CALIOP entre outros. Os primeiros sensores eram desenhados para os campos da meteorologia e monitoramento da superfície, mas também obtinham informação sobre aerossóis primeiramente sobre os oceanos, por serem superfícies escuras e homogêneas (R. Martin 2008). O lançamento do satélite Terra, em dezembro de 1999, marca o começo de uma série de instrumentos específicos para o monitoramento de aerossóis [Remer, 2002]. 
O sensor MODIS (MODerate-resolution Imaging Spectroradiometers) é uma combinação única de resolução espectral, com 36 bandas de comprimento de onda cobrindo o intervalo de $0,415 \mu \mathrm{m}$ até $14,5 \mu \mathrm{m}$, e resolução espacial de $1 \mathrm{~km}, 0,5 \mathrm{~km}$, ou 0,25 km, dependendo do comprimento de onda. Atualmente está a bordo de dois satélites da NASA: Terra (2000) e Aqua (2002). Sendo de órbita polar, tem cobertura quase global a cada 2 dias, e passa exatamente pelo mesmo ponto da Terra a cada 16 dias.

Neste trabalho foi utilizado o produto de profundidade óptica do aerossol sobre continente, do conjunto de dados "Level 2" do produto de aerossóis. A resolução espacial padrão desse produto é de 10 x $10 \mathrm{~km}$. O erro de calibração é aproximadamente entre 2-3\% [Levy et al., 2010] Nos sítios estudados, a hora da passagem dos satélites Terra e Aqua é de aproximadamente 14:30 e 17:30 UTC, respectivamente.

Para comparar as medidas de aerossol do MODIS com as medidas em solo de material particulado foram utilizadas as recomendações de [Ichoku, 2003] se fazendo a media de $\tau$ em caixas de 50 x $50 \mathrm{~km}$ centrado no sítio de amostragem. Como a resolução padrão é de 10 x $10 \mathrm{~km}$, a caixa média terá um máximo de 25 pixels, sendo que para o cálculo foram utilizadas apenas as que tinham 5 pixels ou mais. Ainda, foi utilizada a informação do expoente de Ångström 440 - 670 nm para estimar a profundidade óptica em 500 nm, mesmo canal utilizado pela rede AERONET, sendo que o sensor MODIS mede em $550 \mathrm{~nm}$. 


\subsection{MEDIDAS DE CONCENTRAÇÃO DE MASSA DE AEROSSÓIS IN SITU}

\subsubsection{TEOM}

O TEOM (Tapered Element Oscillating Microbalance) é um sistema de medida direta de massa em tempo real muito utilizado em estações de monitoramento da qualidade do ar como as da Cetesb e da EPA. O ar é aspirado através de um tubo cônico (balança de inércia), sendo o fluxo de ar mantido a volume constante. Um sistema eletrônico mantém o tubo em oscilação e mede continuamente a sua frequência. À medida que as partículas vão se depositando no filtro, a massa do oscilador se modifica e como resultado a frequência de oscilação se altera, sendo diretamente proporcional à massa acumulada no filtro. O instrumento foi adaptado com uma entrada (inlet) que seleciona partículas com diâmetro aerodinâmico menor que 2,5 $\mu \mathrm{m}$. As medidas foram tomadas a cada 30 minutos.

\subsubsection{AFG}

O Amostrador Fino e Grosso (AFG) tem dois estágios para coleta de partículas finas e grossas, e é equipado com dois filtros Nuclepore de $47 \mathrm{~mm}$ de diâmetro. As partículas grossas com diâmetro entre 2,5 - $15 \mu \mathrm{m}$ são coletadas no filtro superior, enquanto que a fração restante $\left(\mathrm{MP}_{2,5}\right)$ é coletada no filtro do segundo estágio. Os filtros são pesados numa microbalança eletrônica com $1 \mu \mathrm{g}$ de precisão [Artaxo et al., 1994], e o volume de ar amostrado é registrado por um medidor de fluxo da marca Hastings. O intervalo de troca dos filtros varia entre 1 dia até 1 semana. A medida de aerossóis utilizando AFG tem boa reprodutibilidade e boa comparação com outros métodos de medida [Hopke et al., 1997]. 
Tabela 2. Período de medidas dos instrumentos de solo na Amazônia.

\begin{tabular}{lll}
\hline Local & Instrumento & Período de amostragem \\
\hline Alta Floresta & AFG & $1992-2005$ \\
\cline { 2 - 3 } & TEOM & Setembro a Novembro de 2006. \\
\hline Ji Paraná & TEOM & Setembro a Novembro de 2002. \\
\hline Santarém & AFG & $2000-2004$ \\
\hline
\end{tabular}

Para comparar as medidas de ambos os instrumentos, AFG e TEOM, com os radiômetros da AERONET, foram feitas médias temporais de $\tau_{\text {AERONET }}$.

Foram feitas médias durante todo o período em que o AFG foi amostrado, sendo que sempre que fosse amostrado por mais de um dia foi imposto que houvesse pelo menos uma média diária de $\tau$ para cada dia de AFG.

No caso das medidas de TEOM, foram feitas médias horárias centradas na hora cheia, e foi requerido que a variação na concentração do aerossol não variasse mais que $10 \%$ em 1 hora. Isso para não dar peso às emissões estritamente locais. 


\section{RESULTADOS}

Neste capítulo são apresentados e discutidos os resultados básicos obtidos com as medidas realizadas, tais como as séries temporais de medidas diretas da AERONET, como a profundidade óptica do aerossol $(\tau)$ e a quantidade de vapor d'água na coluna atmosférica. São também apresentados e discutidos os resultados das inversões da AERONET como distribuição de tamanho em volume de partículas e raio efetivo, albedo de espalhamento único $\left(\omega_{0}\right)$, e o índice de refração complexo do aerossol. Também realizamos um estudo pioneiro entre o material particulado fino medido à superfície (a concentração atmosférica do aerossol) e a profundidade óptica medida pela AERONET. Caracterizado o aerossol, tanto as propriedades intrínsecas como a profundidade óptica foi possível estudar a relação entre forçante radiativa direta e sua eficiência com as propriedades intrínsecas do aerossol. Todas as medidas da AERONET aqui reportadas são de nível 2.0 de qualidade, exceto quando explicitado o contrário.

Neste estudo dividiram-se os sítios em três regiões distintas de acordo com a incidência de emissões de queimadas:

- Norte da Amazônia, compreendendo os estados do Amazonas e Pará, que contem os sítios de Manaus (AM), Balbina (AM), Santarém (PA), e Belterra (PA). Estes sítios representam a atmosfera com pouca influência de queimadas, e serão utilizados como referência para propriedades de aerossóis de regiões remotas. Ao Norte da Amazônia, como em Manaus e Belém, a estação seca começa tardiamente em relação à região do arco do desflorestamento, em junho e se estende até dezembro. A precipitação média mensal varia entre 80 e 270 mm em Manaus, e entre 60 e 400 mm em Belém, conforme Figura 16. 
- Região do arco do desflorestamento, compreendendo os estados do Acre, Rondônia, e norte do Mato Grosso, que compreende os sítios de Rio Branco (AC), Ji Paraná (RO) e Alta Floresta (MT), representam a expansão da fronteira agrícola, caracterizando-se por forte influência de queimadas e intensas atividades de mudanças de uso do solo. Porto Velho e Rio Branco tem uma estação seca bem pronunciada de maio a outubro, com períodos onde por algumas semanas sem ocorrência de precipitação. A precipitação durante a estação seca nesta região varia entre 75 e $150 \mathrm{~mm}$ mensais.

- Região do cerrado, correspondentes aos sítios de Cuiabá (MT) e Campo Grande (MS), que são afetados ocasionalmente por queimadas locais (em geral menos extensas que as observadas no arco do desflorestamento) e, principalmente, por transporte a longa distância de aerossóis de queimadas emitidas na região do arco do desmatamento. $\mathrm{O}$ aerossol de queimadas observado nestes locais é caracterizado pelo chamado "envelhecimento", onde as propriedades correspondem ao aerossol depois de alguns dias de transporte. As chuvas são inconstantes durante todo o ano, e a estação seca pode ser definida entre os meses de abril e setembro, caracterizando uma antecipação de cerca de um mês em relação à região do arco do desflorestamento. 

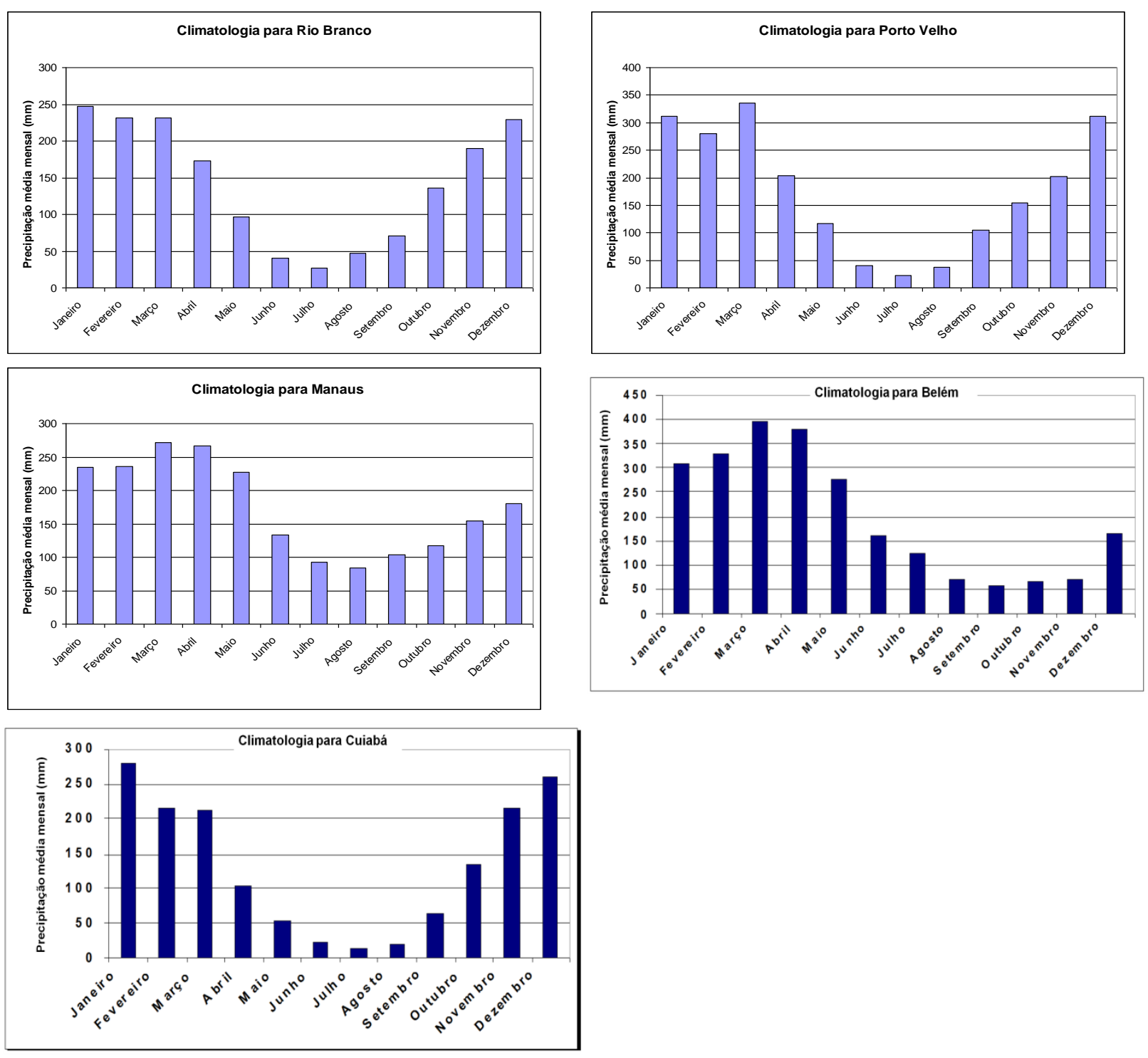

Figura 16. Precipitação mensal climatológica nas cidades de Rio Branco (AC), Porto Velho (RO), Manaus (AM), Belém (PA) e Cuiabá (MT). Avaliada entre os anos de 1971 a 2005. Comunicação pessoal com Carlos Frederico Angelis DSA/INPE. 


\subsection{ANÁLISE EXPLORATÓRIA DAS PROPRIEDADES OBTIDAS PELOS RADIÔMETROS DA AERONET}

4.1.1 ÁGUA PRECIPITÁVEL NA COLUNA ATMOSFÉRICA

A climatologia da concentração do vapor de água na Amazônia é importante, pois o regime de precipitação é critico para a incidência de queimadas. Através das medidas dos radiômetros da AERONET pode-se obter uma série temporal de água precipitável em diversas regiões. Os sítios de Balbina, Manaus, Belterra e Santarém apresentam comportamento similar na variabilidade anual de água precipitável (Figura 17-a). Pode-se distinguir uma estação seca no meio do ano, entre junho e novembro, acompanhando a sazonalidade da precipitação, com valores variando entre $3-5 \mathrm{~cm}$, e uma estação chuvosa entre dezembro e maio, com valores variando entre 4-6 cm. Esses sítios no Norte do Brasil são caracterizados pela alta umidade relativa ao longo de praticamente todo o ano, e nota-se a ausência de valores baixos de água precipitável comparado com as demais localidades estudadas.

Os sítios localizados no arco do desflorestamento também apresentam uma sazonalidade marcante que acompanha o ciclo de chuvas No entanto a variabilidade da coluna de vapor de água é muito maior, com valores no intervalo de $1,5-5,5 \mathrm{~cm}$.

Por fim, no cerrado os valores de água precipitável são fortemente sazonais, com valores variando entre menores que $1 \mathrm{~cm}$, para $5,5 \mathrm{~cm}$ na estação chuvosa, valores que são típicos dos demais sites na Amazônia. 

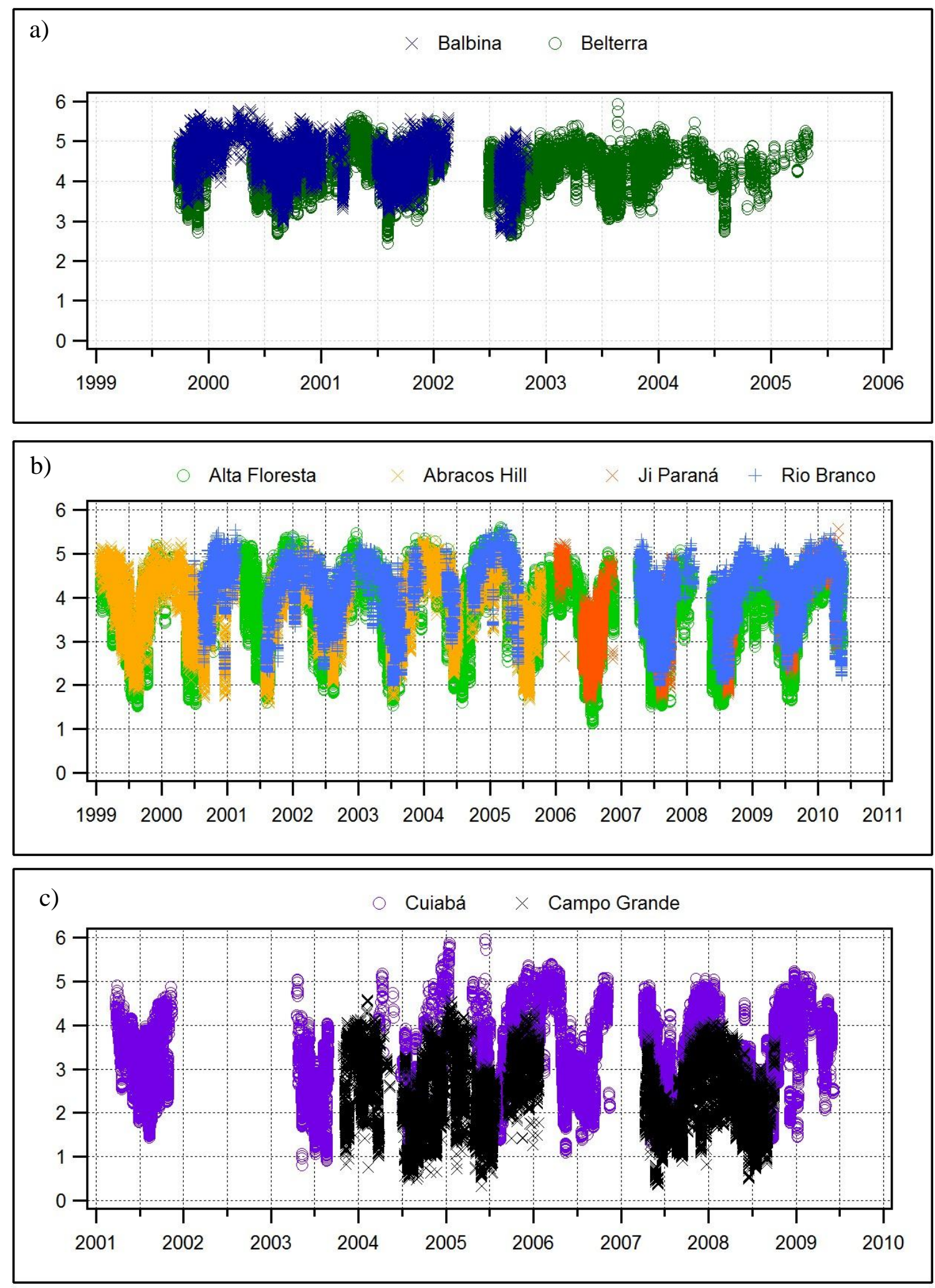

Figura 17. Série temporal de água precipitável $(\mathrm{cm})$ na coluna atmosférica obtida pela AERONET. a) Norte da Amazônia. b) Região do arco do desflorestamento. c) Cerrado. 


\subsubsection{PROFUNDIDADE ÓPTICA DO AEROSSOL}

A profundidade óptica do aerossol $(\tau)$ está relacionada com a quantidade de matéria opticamente ativa na coluna atmosférica e é importante na caracterização da carga de aerossóis das regiões estudadas, e na forçante radiativa direta nestes locais. As propriedades intrínsecas do aerossol como coeficiente de Ångström, distribuição de tamanho das partículas, albedo de espalhamento único e outras propriedades são discutidas na sequência. A Figura 19 apresenta a série temporal de profundidade óptica do aerossol em $440 \mathrm{~nm}$ obtida nos vários sites da AERONET na Amazônia. Os resultados são apresentados agregados para três regiões: a) Norte da Amazônia. b) Região do arco do desflorestamento. c) Região do cerrado. O coeficiente de Ångström, que será apresentado na próxima seção, indica a dependência espectral da profundidade óptica do aerossol e seu relacionamento com o tamanho da partícula, e pode ser utilizado para obtenção de $\tau$ em outros comprimentos de onda.

O Norte da região Amazônica apresenta propriedades ópticas do aerossol muito diferentes da região do arco do desflorestamento - impactado por queimadas -, com aerossol dominado por emissões biogênicas, sendo estes emitidos diretamente na forma de partículas pela vegetação ou formados secundariamente na atmosfera [Schneider et al., 2011]. Na Figura 18-a observa-se que tanto Belterra quanto Balbina, que são cidades da região do Norte da Amazônia, tem um comportamento de profundidade óptica do aerossol muito similar entre si, atingindo seus valores máximos de outubro a dezembro, e permanecendo com valores de $\tau_{440}$ abaixo de 0,2 no restante do ano. Esporadicamente são observados picos em $\tau_{440}$ no período entre março e abril, como em 2001 e 2003 mostrados na Figura 18-a, originados da entrada de poeira do deserto do Saara na região Norte da Amazônia [Ansmann et al., 2009; Ben-Ami et al., 2010b].

Na Figura 18-b com os locais da região do arco do desmatamento, notam-se valores pronunciados de $\tau_{440}$ durante a estação de queimadas. Embora os sítios estejam muito distantes entre si, compreendendo 3 estados - Acre, Mato Grosso e Rondônia - a sazonalidade de $\tau$ é a mesma devido à estação de queimadas, atingindo seu máximo no mês de setembro. A uniformidade desses valores também indica um impacto regional das 
concentrações. Esses resultados estão de acordo com o trabalho de [Hoelzemann et al., 2009a], que mostrou que a correlação entre medidas em sítios da AERONET no Brasil tem representatividade em escalas regionais. Observa-se que as médias diárias acompanham os picos de $\tau_{500}$, mostrando a persistência da ocorrência de altos valores de $\tau_{500}$, muitas vezes por vários dias consecutivos (Figura 19).

As medidas da AERONET para os sítios da região do cerrado, ilustrados na Figura 18-c, também mostram valores mais elevados de $\tau$ durante a estação de queimadas. Todavia, observa-se que em geral os valores não são tão altos como no arco do desflorestamento, exceto pelos anos de 2005 e 2007. Os valores máximos são tipicamente perto de 2,0 a 2,5. Isso indica que os picos de $\tau$ no cerrado são resultado de transporte de longa distância de aerossol de queimada do arco do desflorestamento, que podem exercer influência em escalas de distâncias de milhares de quilômetros de acordo com sua dispersão e transporte por massas de ar [Hoelzemann et al., 2009b; Procópio, 2003a]. 

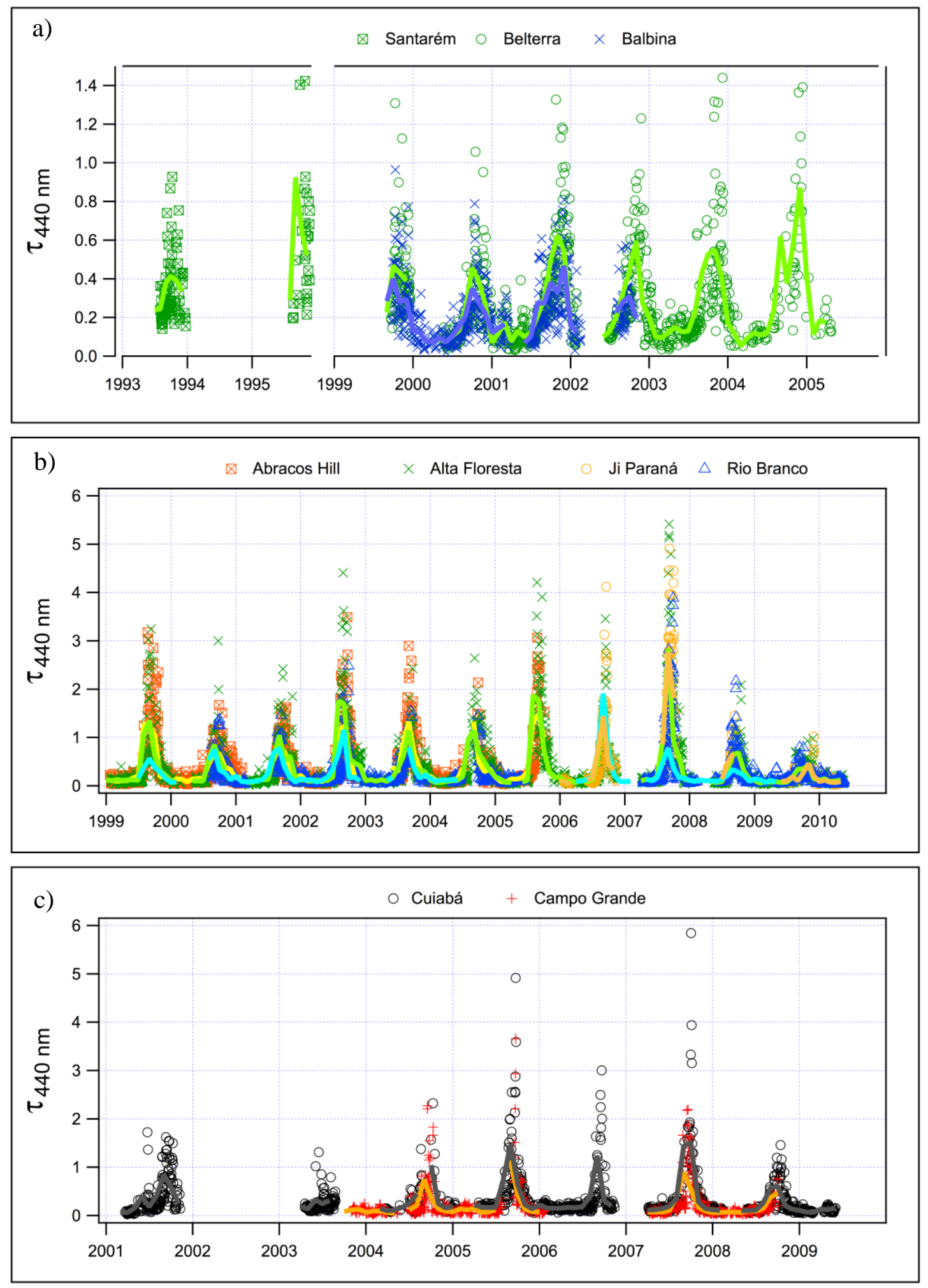

Figura 18. Série temporal de profundidade óptica do aerossol em $440 \mathrm{~nm}$ obtida pela AERONET. A linha se refere às médias diárias. a) Norte da Amazônia. b) Região do arco do desflorestamento. c) Região do cerrado. 


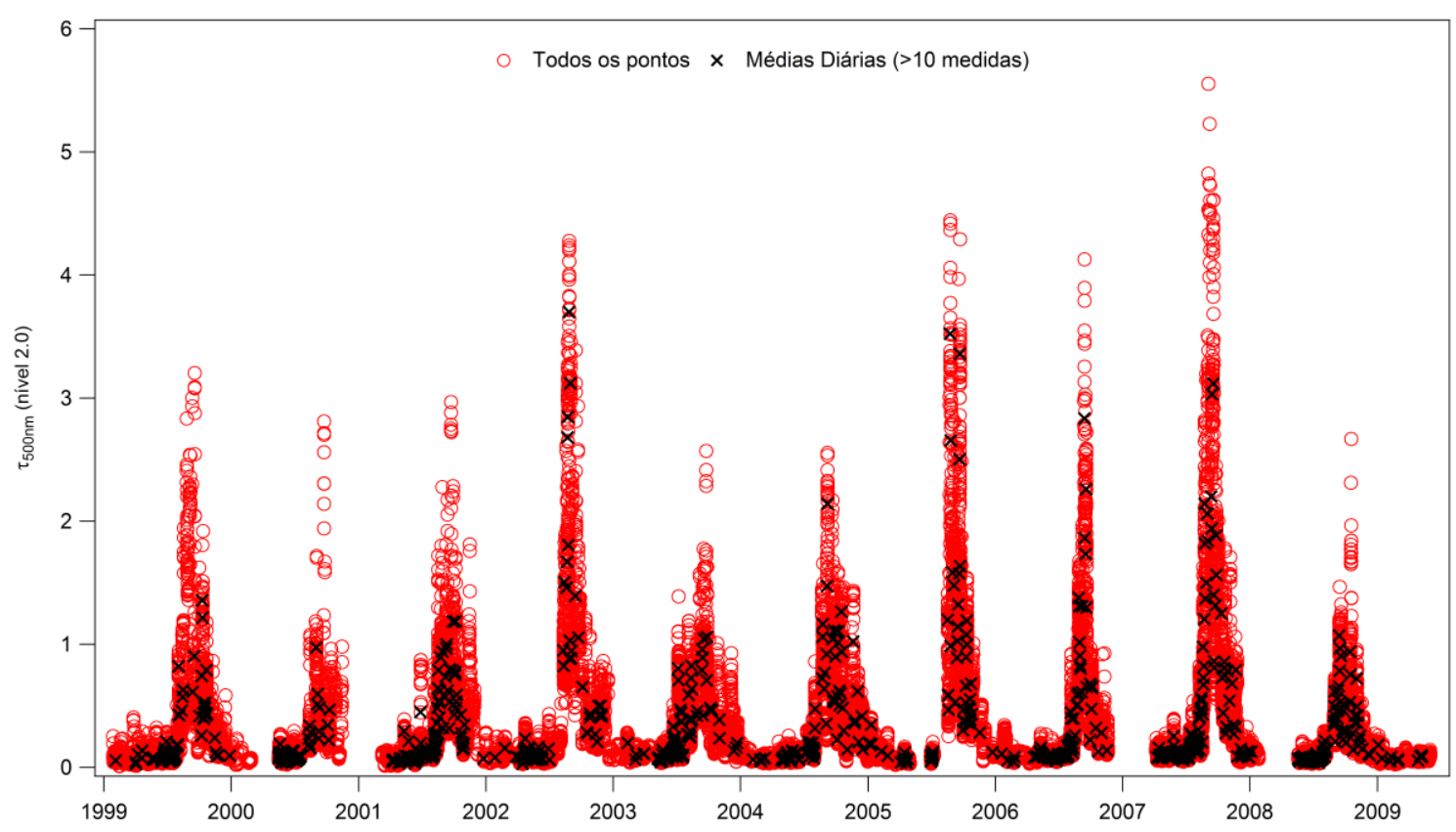

Figura 19. Série temporal de profundidade óptica do aerossol em $500 \mathrm{~nm}$, nível 2.0 para todas as estações da Amazônia estudadas. A série em vermelho se refere a todas as medidas, enquanto que a série em preto significa média diária apenas com 10 medidas ou mais no dia.

Os histogramas das observações de $\tau_{500}$, mostrados na Figura 20, Figura 21 e Figura 22 ilustram a frequência dos aerossóis naturais biogênicos durante a estação chuvosa e seca em Belterra, Alta Floresta e Cuiabá. Observa-se que os histogramas têm distribuição aproximadamente normal em espaço logaritmo, sendo alguns deles monomodais e outros bimodais. Em todos os sítios há sempre presente uma moda correspondente aos valores menores de $\tau$, tanto durante a estação chuvosa como durante a estação seca, devido à emissão de aerossóis de fundo (também chamado de aerossóis de background) característicos da localidade, como aerossóis biogênicos emitidos pela floresta no caso de sítios da região do arco do desflorestamento e do Norte da Amazônia. Na época das queimadas, sobrepõe-se à distribuição de fundo um pico de $\tau$ elevado, correspondente às emissões de aerossóis de queimadas. Embora o Norte da Amazônia, representado pelo sítio de Belterra, tenha menor impacto de emissões de queimadas, observa-se uma pequena moda de $\tau_{500}$ maior que 0,7 no histograma das observações durante a estação seca devido principalmente a emissões locais. Em Alta Floresta e Cuiabá essa moda é bem pronunciada, embora também presente durante a estação chuvosa, pois algumas queimadas de resíduos 
agrícolas e manutenção de pastos também ocorrem nestas regiões durante a estação chuvosa.

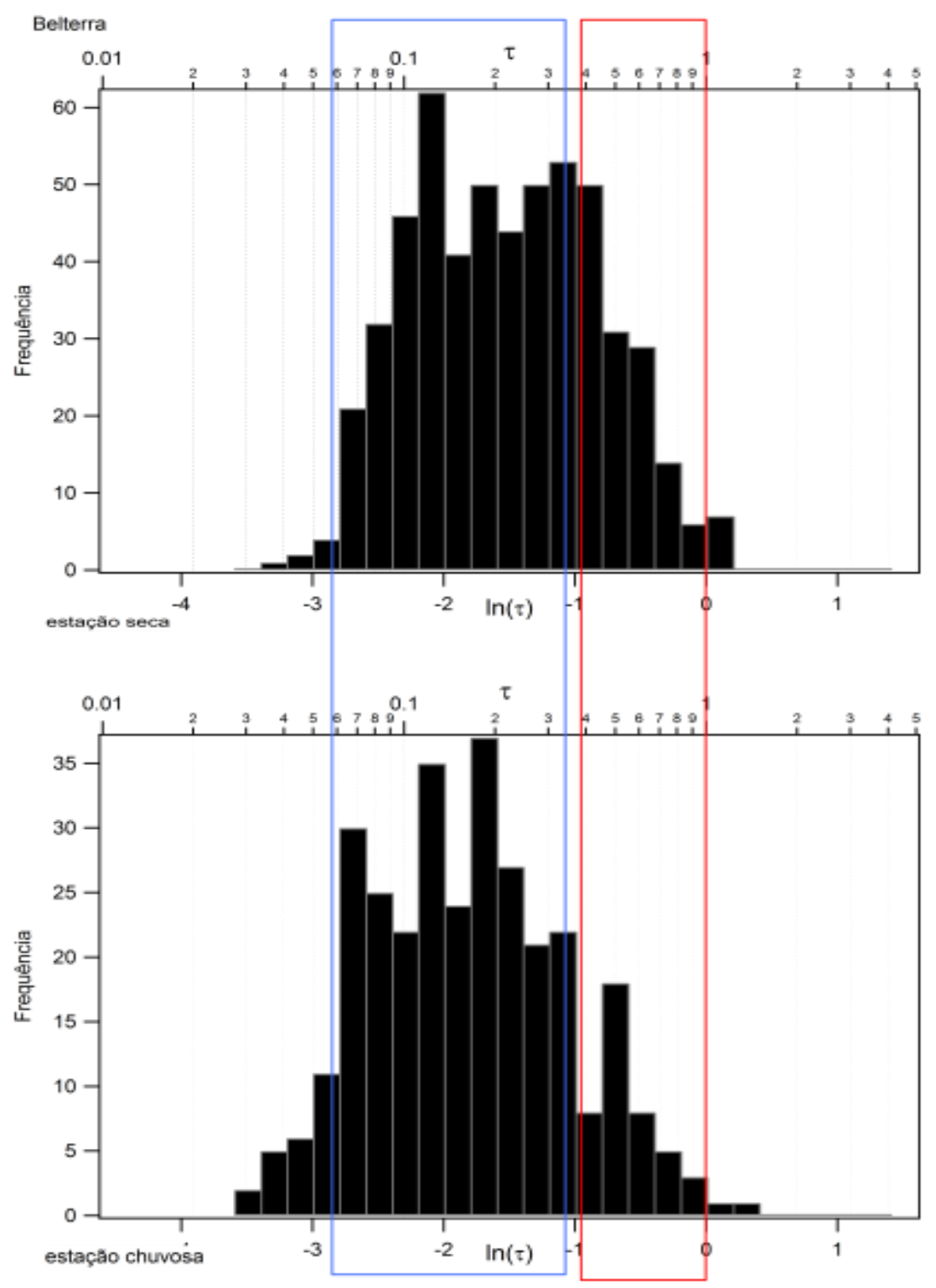

Figura 20. Histograma da frequência (número de medidas não normalizado) de $\tau_{500}$ durante a estação seca e chuvosa em Belterra. O sítio de Balbina apresenta comportamento similar. $O$ retângulo azul indica os valores de background, com $\tau_{500 \mathrm{~nm}}$ entre $\sim 0,06$ a 0,30 ; o retângulo vermelho mostra os valores mais altos, de $\tau_{500 \mathrm{~nm}}$ entre $\sim 0,4$ a 1,0 . 


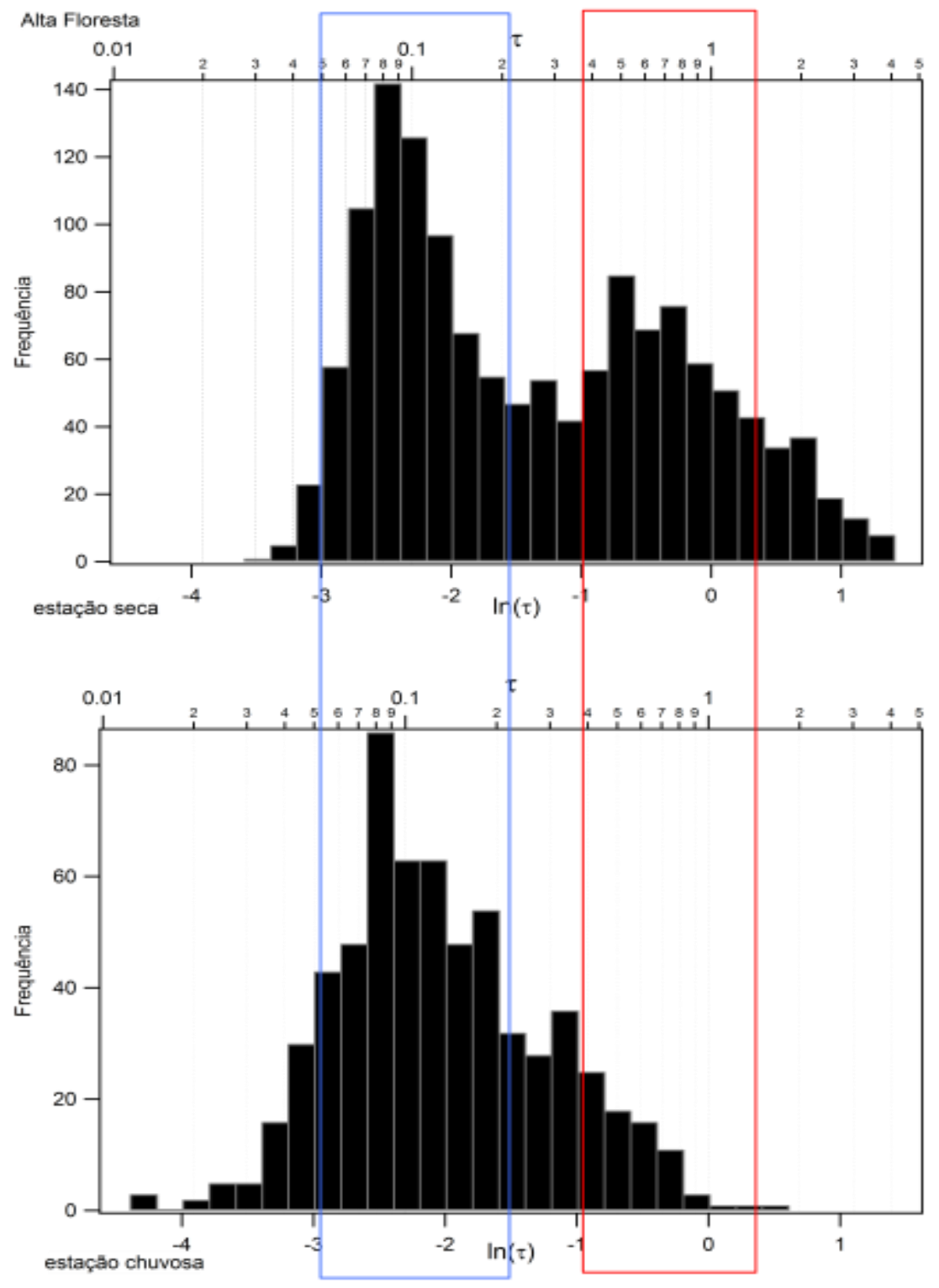

Figura 21. Histograma de frequência de $\tau_{500}$ durante a estação seca e chuvosa em Alta Floresta, representando a região do arco do desflorestamento. $O$ retângulo azul indica os valores de background, com $\tau_{500 \mathrm{~nm}}$ entre $\sim 0,06$ a 0,30; o retângulo vermelho indica os valores mais altos, de $\tau_{500 \mathrm{~nm}}$ entre $\sim 0,4$ a 1,0 . 


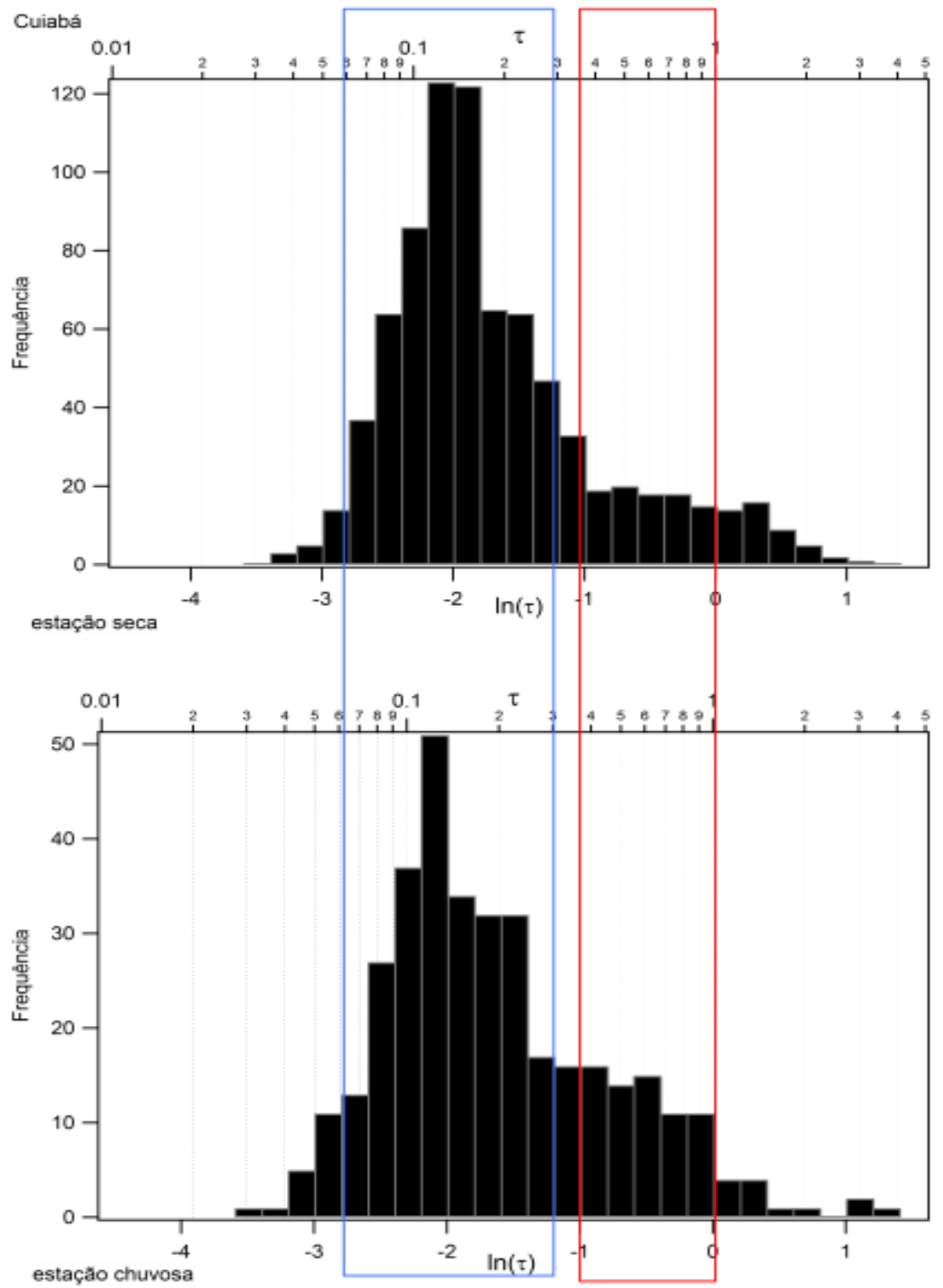

Figura 22. Histograma da frequência de $\tau_{500}$ durante a estação seca e chuvosa em Cuiabá, representando a região do arco do cerrado. $O$ retângulo azul indica os valores de background, com $\tau_{500 \mathrm{~nm}}$ entre $\sim 0,06$ a 0,30 ; o retângulo vermelho indica os valores mais altos, de $\tau_{500 \mathrm{~nm}}$ entre $\sim 0,4$ a 1,0 . 


\subsubsection{COEFICIENTE DE ÅNGSTRÖM}

O coeficiente de Ångström (definido na Equação (23), da Seção 2.3) é normalmente usado para caracterizar a dependência espectral do aerossol de uma determinada região. Neste trabalho foi estudada sua relação com a profundidade óptica do aerossol para caracterizar a carga e fonte de aerossóis para as diferentes regiões estudadas. Os valores de coeficiente de Ångström apresentados neste estudo são entre os comprimentos de onda 870 e 440 nm.

Na parte superior da Figura 23, nota-se que os sítios do Norte da Amazônia não apresentam dependência evidente entre o coeficiente de Ångström e $\tau$. Os valores são esparsos e não há correlação entre a espessura óptica e o tamanho de partícula. Isso mostra que para estas regiões o aerossol é dominado por partículas biogênicas da moda grossa e por produção secundária de aerossóis na moda fina, em um continuo de valores de Ångström de 0,2 a 1,0. Uma situação diferente ocorre para as demais 6 localidades estudadas. Quando o coeficiente de Ångström chega perto de 2,0, a profundidade óptica do aerossol cresce significativamente, indicando um forte domínio de aerossóis da moda fina, provavelmente vindo de emissões de queimadas. Percebe-se que para valores altos de $\tau$ o particulado é dominado pela fração fina, com valores de Ångström de 1,5 a 2,0. Os sítios de cerrado também recebem fortes cargas de aerossóis de queimada, sobretudo da região Amazônica, por transporte em altas altitudes. Nessa época de seca, o exponente Ångström também aumenta para cerca de 1,5 - 2,0 para valores altos de $\tau$, assim como na região do arco do desflorestamento. 
Observa-se em alguns lugares, Cuiabá, Alta Floresta, Rio Branco e Abracos Hill, medidas de Ångström entre 2,5 e 3,0 (quase no limite do regime Rayleigh), com $\tau$ menor que 0,4 ocorrem em algumas ocasiões. Essas observações ocorrem principalmente durante a estação chuvosa. Embora não haja inversões suficientes de outras propriedades, como raio efetivo do aerossol, esta condição indica a possibilidade de produção secundária de aerossóis a partir de precursores biogênicos naturais. São necessárias medidas complementares para que esta hipótese possa ser confirmada, mas é bastante provável que esta seja a explicação desta componente. É possível também notar pelo código de cores da Figura 23 que os valores altos de $\tau$, no eixo horizontal, sempre ocorrem na estação seca, de agosto a novembro. No período de janeiro a maio os valores de $\tau$ estão sempre abaixo de 0,4 , conforme indicado anteriormente na série temporal de profundidade óptica do aerossol da Figura 18. Os sítios do Norte da Amazônia não apresentaram relação significativa entre o coeficiente de Ångström e a profundidade óptica do aerossol. 

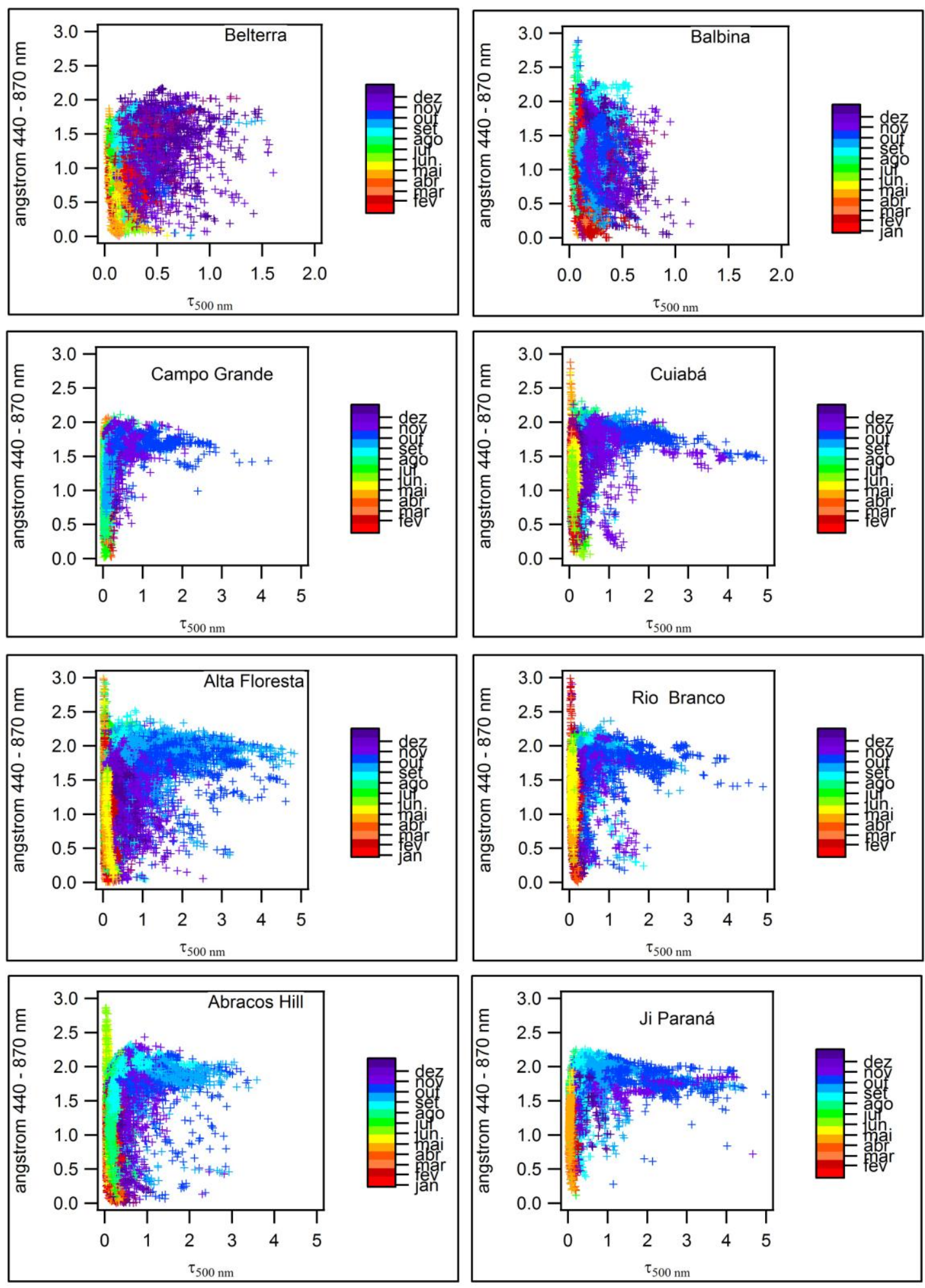

Figura 23. Coeficiente de Ångström entre os comprimentos de onda 870-440 nm versus a profundidade óptica do aerossol em $500 \mathrm{~nm}$. Os sítios de Belterra e Balbina não apresentam dependência significativa entre essas duas propriedades. 
O albedo de espalhamento único $\left(\omega_{0}\right)$ do aerossol caracteriza a natureza intrínseca do aerossol de espalhamento e absorção de radiação. Essa propriedade mede a razão entre o espalhamento e extinção (que é a soma do espalhamento e absorção) da radiação solar que interage com o aerossol. A Figura 24 mostra a série temporal das medidas da AERONET de albedo de espalhamento único de todas as estações estudadas.

Existe uma grande dificuldade em se obter medidas durante a estação chuvosa visto que para o cálculo das propriedades de absorção é necessário céu limpo, sem nuvens, e ainda que se obtenham medidas deste tipo em vários ângulos de espalhamento, o que não é requerido para medidas diretas de extinção óptica. Além disso, a incerteza do algoritmo é muito grande quando se tem pouco aerossol, a saber, $\tau_{440 \mathrm{~nm}}$ menor que 0,4 . Durante a estação chuvosa a média da profundidade óptica do aerossol fica em torno de 0,15 , e por isso as observações obtidas são principalmente durante a estação seca.

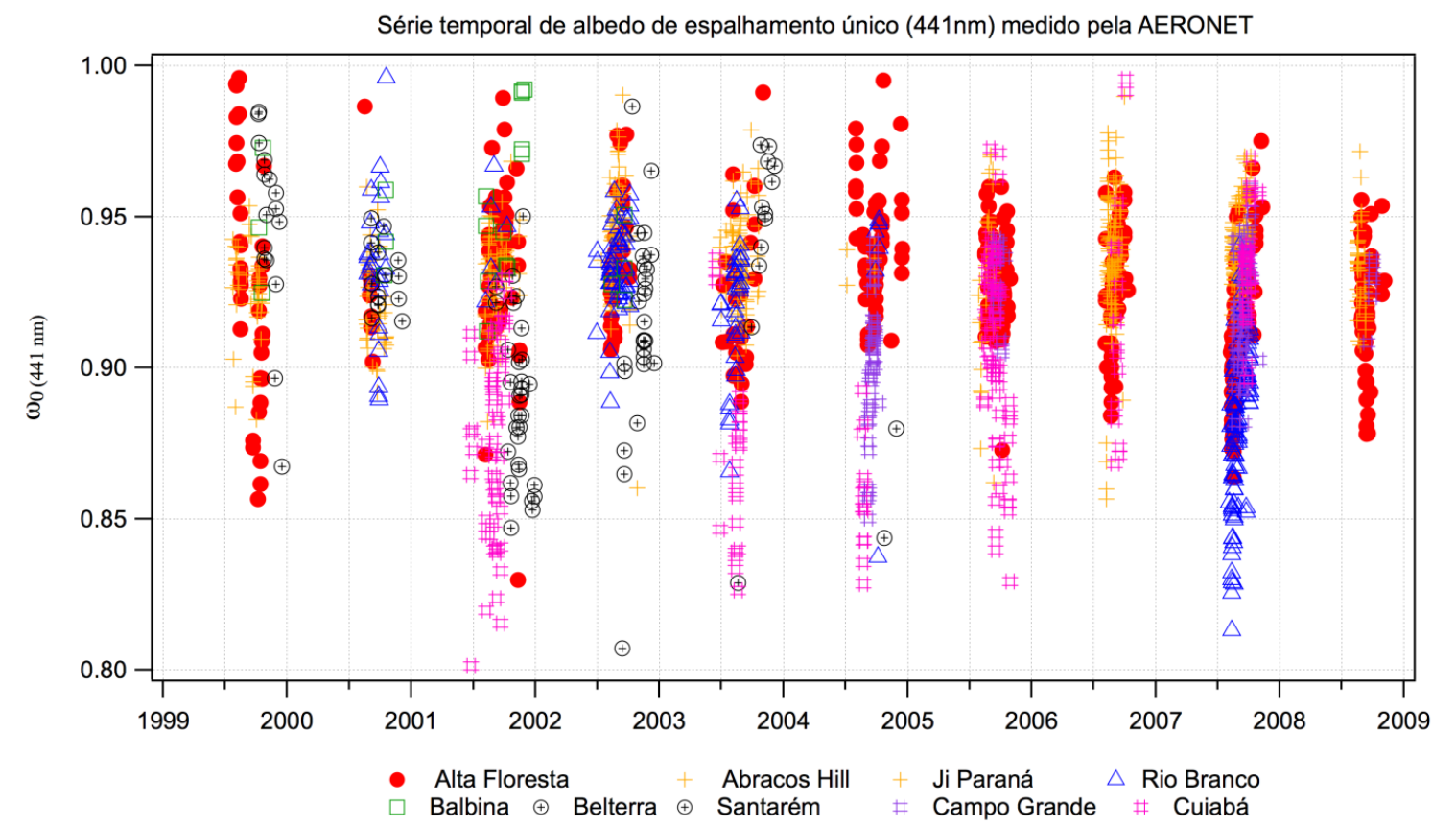

Figura 24. Série temporal de albedo de espalhamento único obtido pela AERONET para nove locais da Amazônia. 
O valor médio de $\omega_{0}(673 \mathrm{~nm})$ para as estações do arco do desflorestamento é de $0,92 \pm 0,03$, com exceção de Rio Branco que registrou valores baixos principalmente no ano de 2007,

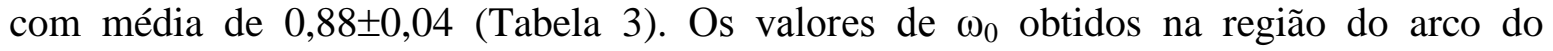
desflorestamento variaram entre 0,85 e 1,00. Em Alta Floresta, a mais longa série temporal, o número de medidas na estação seca é de 539, e apenas 26 na estação chuvosa, conforme mostrado na Tabela 3. Nesse caso, embora as médias da estação seca e chuvosa sejam compatíveis entre si deve se levar em conta que as medidas da estação chuvosa se referem a eventos com moderado valor de $\tau$ para a média da estação, sendo provavelmente devido a algum evento de queimada, e não de aerossol biogênico natural.

Nos sítios de Cerrado a variabilidade de $\omega_{0}$ é maior, com valores que vão de 0,80 até 1,00, ilustrado no histograma de frequências da Figura 25. A média do albedo de espalhamento

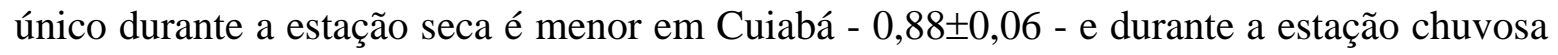
apenas 1 medida foi obtida em Campo Grande. Esse resultado de $\omega_{0}$ era esperado para o cerrado, que tem aerossol tipicamente mais absorvedor.

Em Cuiabá é possível é possível observar duas modas de valores de $\omega_{0}$ na Figura 25. Para o cálculo do albedo de espalhamento único típico do cerrado sem a influência de queimadas de longa distância, separaram-se os valores moderados de $\tau_{500}$, entre 0,4 e 0,7 , e com $\tau_{500}$ maior que 1,5. A média de $\omega_{0}$ para moderado $\tau_{500}$ ficou em $0,84 \pm 0,05$, compatível com a média para toda a estação. Já no caso de $\tau_{500}$ maior que 1,5 , a média de $\omega_{0}$ é de $0,92 \pm 0,03$, compatível com as estações do arco do desflorestamento. Em Alta Floresta, o valor encontrado de $\omega_{0}$ para $\tau_{500}$ moderado foi de $0,90 \pm 0,03$, e para $\tau_{500}$ maior que 1,5 foi de

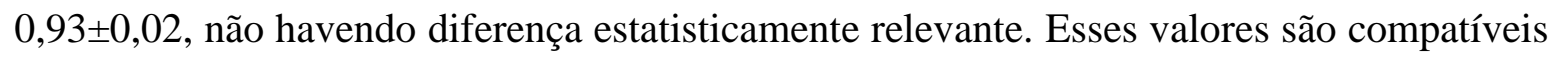
com o trabalho de [Schafer et al., 2008] que encontrou os valores de $\omega_{0} \mathrm{em} 550 \mathrm{~nm}$ de 0,86 e 0,91 em Cuiabá para $\tau_{500}$ moderado e $\tau_{500}$ maior que 1,0 , respectivamente; e 0,92 e 0,93 em Alta Floresta, interpolando os canais da AERONET durante os anos de 1999 - 2006. Este resultado mostra que a climatologia de $\omega_{0}$ não mudou significativamente ao longo dos anos.

O Norte da Amazônia tem o valor médio de albedo mais alto que os demais, de 0,98 $\pm 0,01$ em Balbina durante a estação chuvosa. Durante a estação seca o albedo diminui para 
$0,92 \pm 0,02$, porém mantendo ainda um valor mais alto que nos sítios do arco do desflorestamento, o que indica claramente um aerossol pouco absorvedor.

Tabela 3. Valores médios, desvio padrão e número de observações de albedo de espalhamento único em $673 \mathrm{~nm}$ pela AERONET.

\begin{tabular}{|l|ccc|ccc|}
\multirow{2}{*}{} & \multicolumn{3}{c}{ Estação Seca } & \multicolumn{3}{c|}{ Estação Chuvosa } \\
\cline { 2 - 7 } & Média & Desvio Padrão & $\mathrm{N}$ & Média & Desvio Padrão & $\mathrm{N}$ \\
\hline Abracos & 0.914 & 0.031 & 353 & 0.903 & 0.024 & 4 \\
\hline Alta Floresta & 0.915 & 0.033 & 539 & 0.920 & 0.047 & 26 \\
\hline Balbina & 0.924 & 0.023 & 17 & 0.979 & 0.014 & 5 \\
\hline Belterra & 0.902 & 0.055 & 46 & 0.899 & 0.033 & 57 \\
\hline Campo Grande & 0.907 & 0.026 & 137 & 0.858 & - & 1 \\
\hline Cuiabá & 0.875 & 0.056 & 229 & - & - & 0 \\
\hline Ji Paraná & 0.922 & 0.026 & 291 & - & - & 0 \\
\hline Rio Branco & 0.883 & 0.040 & 250 & - & - & 0 \\
\hline
\end{tabular}

A frequência de medidas de $\omega_{0}$ foi analisada, e é mostrada na Figura 25 para os diferentes locais. Exceto pelos sítios de Balbina e Belterra, em que o número total de medidas é baixo, não se verificou nenhum valor espúrio que indicasse que os valores médios não representassem a distribuição. 

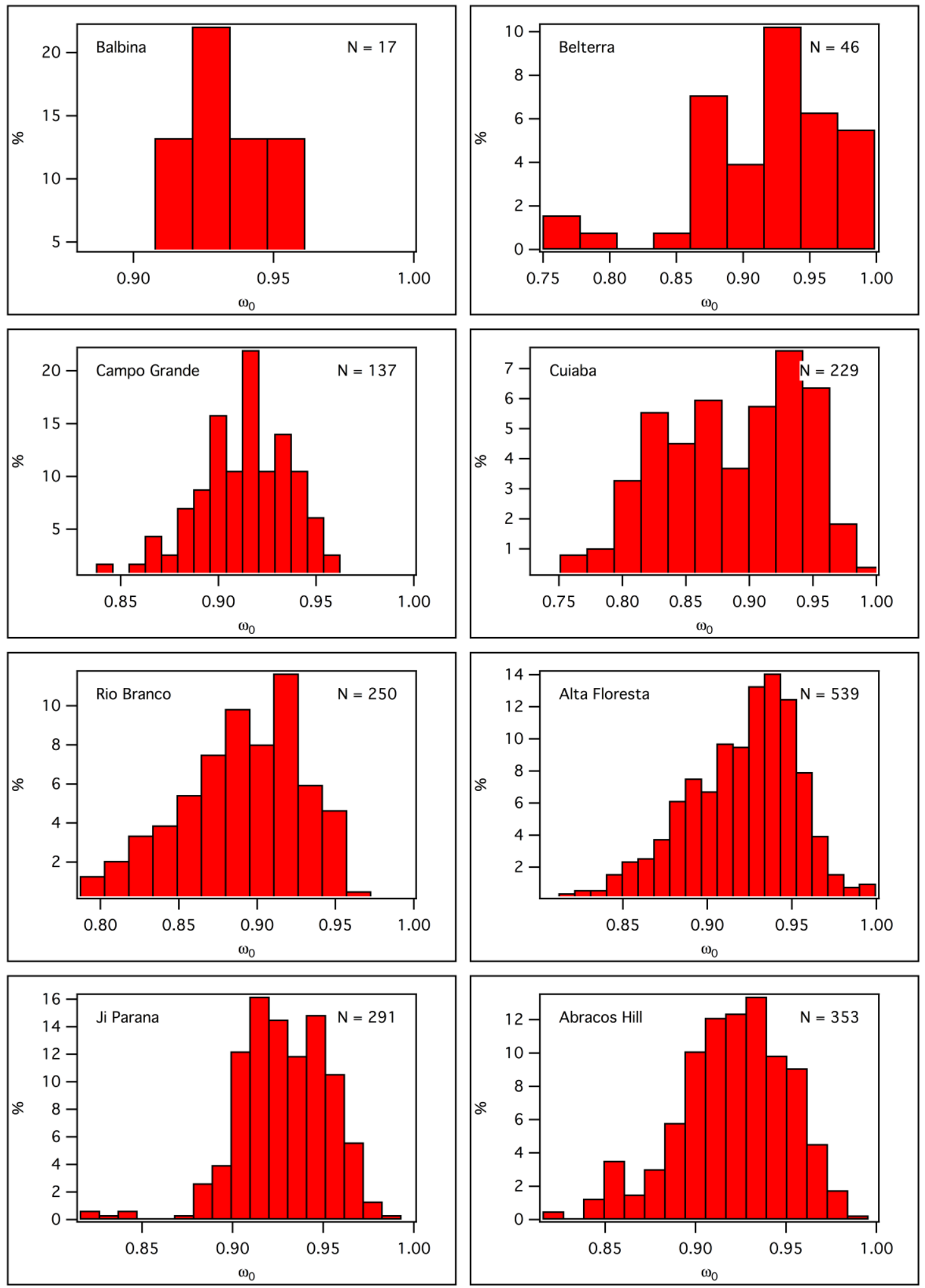

Figura 25. Histograma de frequência normalizada (\%) de medidas de albedo de espalhamento único em $673 \mathrm{~nm}$ entre maio e outubro pela AERONET para os vários locais estudados. 
A dependência espectral do albedo de espalhamento único do aerossol é mostrada na Figura 26. As barras de erro foram omitidas, pois como discutido na Tabela 3 são da ordem de 0,03 e denotam a variabilidade atmosférica das propriedades intrínsecas do aerossol e não incerteza de medidas. A característica importante desse gráfico é que o valor de $\omega_{0}$ diminui conforme aumenta o comprimento de onda, e é razoavelmente uniforme no comportamento para os diferentes locais, com exceção de Cuiabá e Rio Branco. Comportamento similar a esses dois últimos sítios foi encontrado por [Eck et al., 2000] em Etosha, Namibia, e Bethlehem, África do Sul, também utilizando a rede AERONET. O referido trabalho durante o experimento SAFARI2000 apresentou os valores de $\omega_{0}$ de 0,90 no canal $440 \mathrm{~nm}$, e de 0,84 no canal de 1020 nm, compatível com os valores encontrados em Cuiabá e Rio Branco. Uma hipótese para explicar esse comportamento é que devido a localização desses radiômetros próximo a zona rural eles sofrem a influência de aerossóis recém emitidos de queimadas locais, e por isso apresentam valores de $\omega_{0}$ mais baixos. No entanto não fica claro apenas pelas propriedades ópticas o completo motivo desse comportamento no sítio de Rio Branco. Essa questão requer um estudo mais aprofundado, provavelmente utilizando medidas locais ao nível do solo dos coeficientes de absorção e espalhamento. 


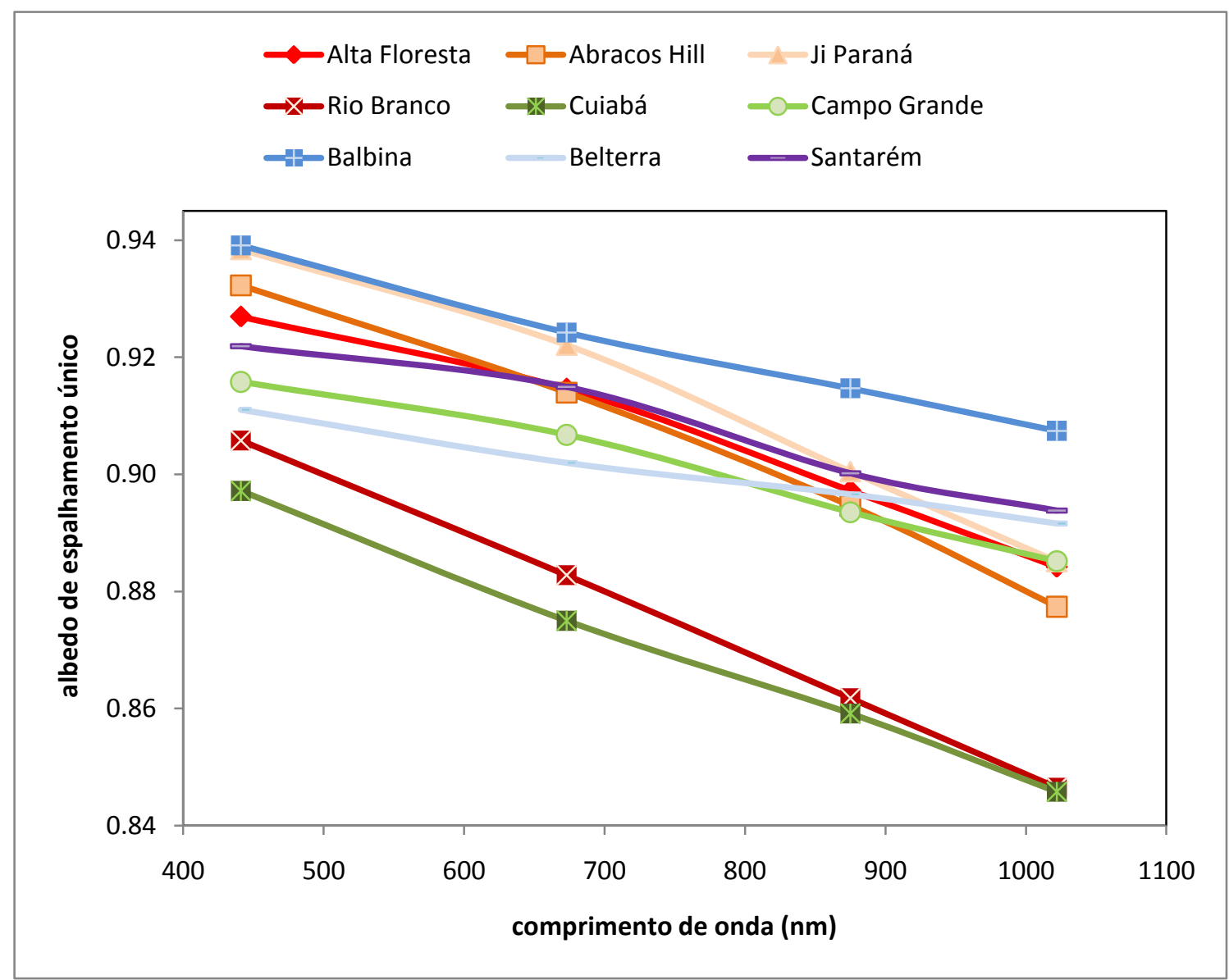

Figura 26. Dependência espectral do albedo de espalhamento único médio durante a estação seca para as diversas estações da AERONET.

\subsubsection{A DISTRIBUIÇÃO DE TAMANHO E RAIO EFETIVO DO AEROSSOL}

O algoritmo da AERONET deriva as propriedades de distribuição de tamanho em volume do aerossol, de raio efetivo de toda a população de aerossol, o raio efetivo da moda fina e o raio efetivo da moda grossa, como descrito na Seção 2.3. Essas propriedades microfísicas do aerossol indicam a dominância das fontes de emissão, diferentes em cada estação do ano.

Os valores médios e o desvio padrão do raio efetivo do aerossol e da largura da distribuição de tamanho dos aerossóis durante a estação seca são mostrados na Tabela 4 e Tabela 5, 
respectivamente, e durante a estação chuvosa na Tabela 6 e Tabela 7. Nota-se que entre a estação chuvosa e a estação seca há uma diminuição no raio efetivo total do aerossol, exceto em Campo Grande. No entanto, devido a dispersão dos valores não é possível distinguir dois regimes diferentes entre a estação seca e a estação chuvosa. Nos sítios do arco do desflorestamento a mudança é de $0,37 \pm 0,12 \mu$ m na estação chuvosa, para $0,27 \pm 0,08$ $\mu \mathrm{m}$ durante a estação seca. Esse comportamento é consistente com o aumento da emissão de aerossóis de queimada predominantemente na moda fina durante a estação seca apresentada por [Martin et al., 2010a]. O raio efetivo da moda fina é de 0,14 $\pm 0,41 \mu \mathrm{m}$ em toda a região Amazônica para a estação seca. Já o raio efetivo da moda grossa apresenta maior variabilidade, pois é mais susceptível às emissões locais.

Tabela 4. Valores médios e desvio padrão do raio efetivo das partículas de aerossol de toda a distribuição de tamanho e também da moda fina e da moda grossa, separadamente, durante a estação seca.

\begin{tabular}{|ccc|cc|}
\hline $\begin{array}{c}\text { Raio } \\
\text { Efetivo } \\
(\mu \mathrm{m})\end{array}$ & Total & $\begin{array}{c}\text { Moda } \\
\text { Fina }\end{array}$ & $\begin{array}{c}\text { Moda } \\
\text { Grossa }\end{array}$ & $\mathbf{N}$ \\
\hline $\begin{array}{c}\text { Abracos } \\
\text { Ji Paraná }\end{array}$ & $0.24 \pm 0.06$ & $0.4 \pm 0.01$ & $2.43 \pm 0.45$ & 790 \\
\hline $\begin{array}{c}\text { Alta } \\
\text { Floresta }\end{array}$ & $0.35 \pm 0.15$ & $0.14 \pm 0.01$ & $2.43 \pm 0.37$ & 1871 \\
\hline $\begin{array}{c}\text { Rio } \\
\text { Branco }\end{array}$ & $0.24 \pm 0.06$ & $0.14 \pm 0.01$ & $2.27 \pm 0.44$ & 749 \\
\hline Balbina & $0.27 \pm 0.09$ & $0.14 \pm 0.01$ & $1.74 \pm 0.35$ & 166 \\
\hline Belterra & $0.36 \pm 0.16$ & $0.14 \pm 0.02$ & $1.79 \pm 0.41$ & 287 \\
\hline $\begin{array}{c}\text { Campo } \\
\text { Grande }\end{array}$ & $0.49 \pm 0.20$ & $0.14 \pm 0.01$ & $2.59 \pm 0.28$ & 1109 \\
\hline Cuiabá & $0.32 \pm 0.11$ & $0.13 \pm 0.01$ & $2.50 \pm 0.27$ & 764 \\
\hline
\end{tabular}

Tabela 5. Valores médios e desvio padrão da largura da distribuição de tamanho das partículas durante a estação seca.

\begin{tabular}{|cccc|}
$\begin{array}{c}\text { Desvio } \\
\text { padrão } \\
(\mu \mathrm{m})\end{array}$ & Total & $\begin{array}{c}\text { Moda } \\
\text { Fina }\end{array}$ & $\begin{array}{c}\text { Moda } \\
\text { Grossa }\end{array}$ \\
\hline $\begin{array}{c}\text { Abracos } \\
\text { Ji Paraná }\end{array}$ & $1.45 \pm 0.17$ & $0.39 \pm 0.04$ & $0.68 \pm 0.06$ \\
\hline $\begin{array}{c}\text { Alta } \\
\text { Floresta }\end{array}$ & $1.47 \pm 0.14$ & $0.43 \pm 0.06$ & $0.67 \pm 0.05$ \\
\hline $\begin{array}{c}\text { Rio } \\
\text { Branco }\end{array}$ & $1.45 \pm 0.14$ & $0.41 \pm 0.04$ & $0.70 \pm 0.06$ \\
\hline Balbina & $1.40 \pm 0.11$ & $0.39 \pm 0.04$ & $0.71 \pm 0.05$ \\
\hline Belterra & $1.40 \pm 0.11$ & $0.42 \pm 0.05$ & $0.72 \pm 0.04$ \\
\hline $\begin{array}{c}\text { Campo } \\
\text { Grande }\end{array}$ & $1.42 \pm 0.15$ & $0.41 \pm 0.03$ & $0.65 \pm 0.04$ \\
\hline Cuiabá & $1.52 \pm 0.13$ & $0.41 \pm 0.04$ & $0.65 \pm 0.05$ \\
\hline
\end{tabular}


Tabela 6. Valores médios e desvio padrão do raio efetivo das partículas de aerossol de toda a distribuição de tamanho e também da moda fina e da moda grossa, separadamente, durante a estação chuvosa.

\begin{tabular}{|ccccc|}
\hline $\begin{array}{c}\text { Raio } \\
\text { Efetivo } \\
(\mu \mathrm{m})\end{array}$ & Total & $\begin{array}{c}\text { Moda } \\
\text { Fina }\end{array}$ & $\begin{array}{c}\text { Moda } \\
\text { Grossa }\end{array}$ & $\mathbf{N}$ \\
\hline $\begin{array}{c}\text { Abracos } \\
\text { Ji Paraná }\end{array}$ & $0.37 \pm 0.14$ & $0.15 \pm 0.01$ & $2.04 \pm 0.61$ & 30 \\
\hline $\begin{array}{c}\text { Alta } \\
\text { Floresta }\end{array}$ & $0.37 \pm 0.15$ & $0.14 \pm 0.01$ & $2.13 \pm 0.51$ & 104 \\
\hline $\begin{array}{c}\text { Rio } \\
\text { Branco }\end{array}$ & $0.29 \pm 0.11$ & $0.14 \pm 0.02$ & $1.94 \pm 0.40$ & 68 \\
\hline Balbina & $0.40 \pm 0.23$ & $0.14 \pm 0.01$ & $1.90 \pm 0.51$ & 4 \\
\hline Belterra & $0.38 \pm 0.16$ & $0.15 \pm 0.01$ & $1.92 \pm 0.53$ & 133 \\
\hline $\begin{array}{c}\text { Campo } \\
\text { Grande }\end{array}$ & $0.38 \pm 0.12$ & $0.14 \pm 0.02$ & $2.31 \pm 0.27$ & 468 \\
\hline Cuiabá & $0.34 \pm 0.10$ & $0.13 \pm 0.01$ & $2.15 \pm 0.25$ & 43 \\
\hline
\end{tabular}

Tabela 7. Valores médios e desvio padrão da largura da distribuição de tamanho das partículas durante a estação chuvosa.

\begin{tabular}{|cccc|}
$\begin{array}{c}\text { Desvio } \\
\text { padrão } \\
(\mu \mathrm{m})\end{array}$ & Total & $\begin{array}{c}\text { Moda } \\
\text { Fina }\end{array}$ & $\begin{array}{c}\text { Moda } \\
\text { Grossa }\end{array}$ \\
\hline $\begin{array}{c}\text { Abracos } \\
\text { Ji Paraná }\end{array}$ & $1.42 \pm 0.12$ & $0.44 \pm 0.08$ & $0.73 \pm 0.07$ \\
\hline $\begin{array}{c}\text { Alta } \\
\text { Floresta }\end{array}$ & $1.45 \pm 0.11$ & $0.42 \pm 0.06$ & $0.71 \pm 006$ \\
\hline $\begin{array}{c}\text { Rio } \\
\text { Branco }\end{array}$ & $1.44 \pm 0.12$ & $0.42 \pm 0.05$ & $0.70 \pm 0.06$ \\
\hline Balbina & $1.36 \pm 0.17$ & $0.42 \pm 0.06$ & $0.72 \pm 0.07$ \\
\hline Be terra & $1.39 \pm 0.44$ & $0.44 \pm 0.06$ & $0.71 \pm 0.07$ \\
\hline $\begin{array}{c}\text { Campo } \\
\text { Grande }\end{array}$ & $1.51 \pm 0.11$ & $0.40 \pm 0.03$ & $0.70 \pm 0.04$ \\
\hline Cuiabá & $1.53 \pm 0.10$ & $0.42 \pm 0.07$ & $0.70 \pm 0.05$ \\
\hline
\end{tabular}

A mudança mais significativa entre a estação seca e chuvosa é no volume de partículas principalmente as da moda fina, como ilustrado na Figura 27. Esse aumento é maior na região do arco do desflorestamento, e mais localizado no raio de $0,15 \mu \mathrm{m}$. A moda fina corresponde também ao aerossol formado secundariamente na atmosfera a partir da oxidação de compostos emitidos pela vegetação [Schneider et al., 2011] e é observada durante todo o ano. A moda grossa também está sempre presente, tanto na estação chuvosa quanto na seca, com valores similares. Ela corresponde ao aerossol biogênico natural, de partículas primárias, e tem valores compatíveis com os encontrados por [Schneider et al., 2011] durante a campanha AMAZE2008 em Manaus de 1,6 - 5,0 $\mu \mathrm{m}$ de raio aerodinâmico medido ao nível do solo.

Como veremos na próxima seção, o raio efetivo da população de aerossol é importante na forçante radiativa direta do aerossol, bem como o volume de partículas que também é caracterizado indiretamente pela profundidade óptica do aerossol. 

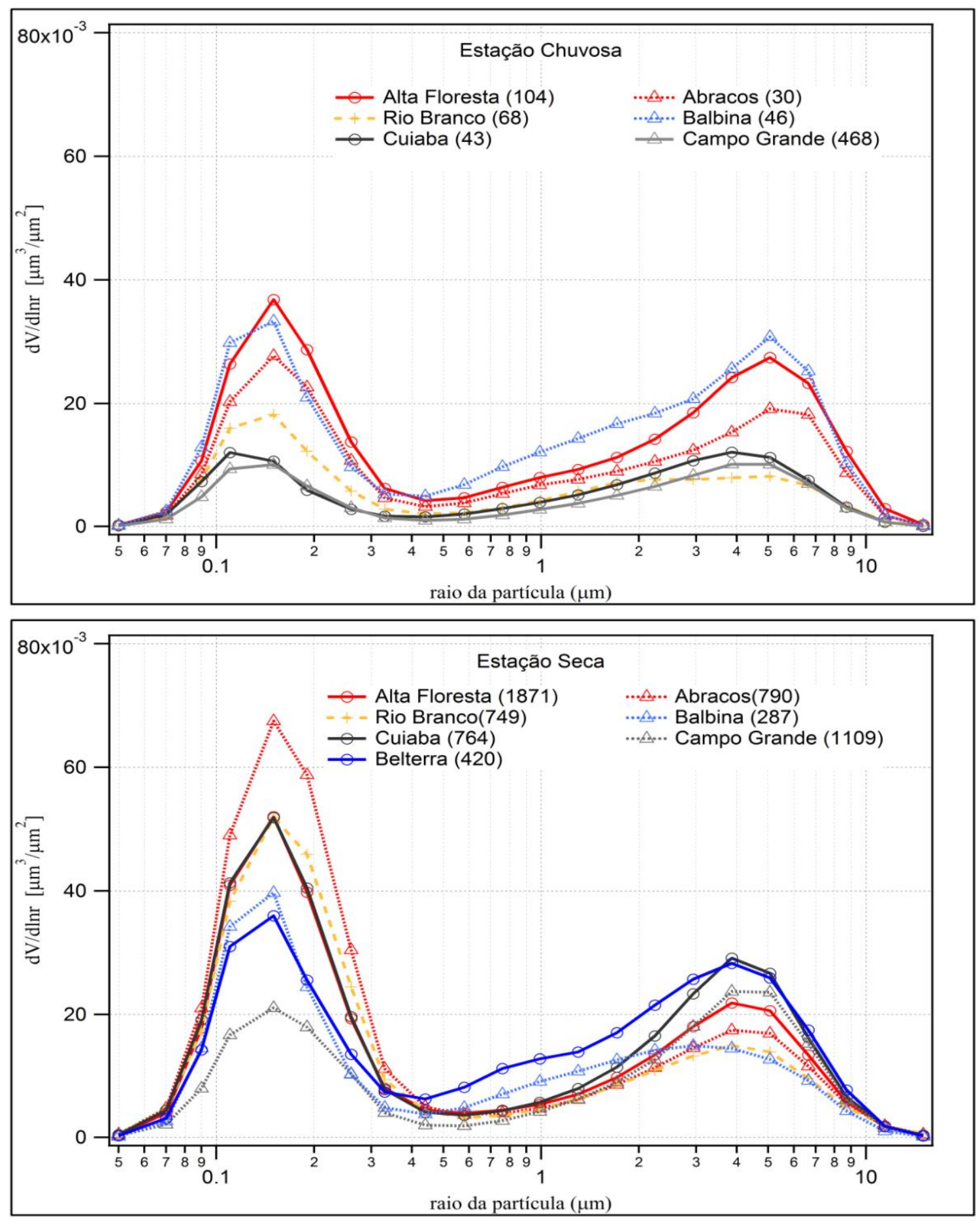

Figura 27. Média da distribuição de tamanho do aerossol durante a estação chuvosa (acima) e estação seca (abaixo), e o número de observações. Durante a estação seca o volume de partículas é bem maior que durante a estação chuvosa, e o pico da moda fina é bem pronunciado. Durante a estação chuvosa, é a moda grossa que predomina em termos de massa. 
4.1.6 FORÇANTE RADIATIVA DIRETA E EFICIÊNCIA DE FORÇANTE INSTANTÂNEAS DO AEROSSOL

A propriedade de forçante radiativa direta do aerossol (definida na Seção 2.3.1) é utilizada para quantificar o impacto climático das partículas de aerossol. Valores negativos de forçante estão relacionados com esfriamento na superfície, e valores positivos com o aquecimento. De maneira simples, quanto maior o número de partículas de aerossol, mais radiação solar incidente será refletida e absorvida. Desse modo, observa-se uma relação linear entre a forçante radiativa direta instantânea no topo da atmosfera $\left(\mathrm{FR}_{\mathrm{TOA}}\right)$ derivada pela AERONET e a profundidade óptica do aerossol $(\tau)$ em toda a região Amazônica, como mostrado nos gráficos à esquerda da Figura 28.

Observa-se que a forçante radiativa direta no topo da atmosfera, $\mathrm{FR}_{\mathrm{TOA}}$, possui relação com a carga total de aerossóis na atmosfera e com o raio efetivo do aerossol, tanto na região do arco do desflorestamento quanto no cerrado, conforme ilustrado nos gráficos da Figura 28. Em Alta Floresta, a $\mathrm{FR}_{\mathrm{TOA}}$ chega a cerca de $-100 \mathrm{~W} \cdot \mathrm{m}^{-2}$ para o aerossol de raio efetivo menor que $0,2 \mu \mathrm{m}$, correspondendo a valores de $\tau_{500}$ maiores que 1,5, conforme Figura 28. Ainda em Alta Floresta, para o aerossol de raio efetivo maior que cerca de $0,4 \mu \mathrm{m}$, a FR $\mathrm{FOA}_{\mathrm{TO}}$ não passa de $-20 \mathrm{~W} . \mathrm{m}^{-2}$, com $\tau_{500}$ correspondente abaixo de 0,5. Esses resultados são consistentes com as origens do aerossol na região do arco do desflorestamento conforme discutido anteriormente neste trabalho e por [Martin et al., 2010b], que indicam a predominância de aerossóis de origem natural (biogênico ou de ressuspensão do solo) durante a estação chuvosa (i.e. correspondentes aos mínimos de $\tau$ ao longo do ano, conforme [Martin et al., 2010b] e de aerossóis de queimadas durante a estação seca, aos quais correspondem os máximos anuais de $\tau$. A mesma tendência não é observada para as medidas na região do Norte da Amazônia. 

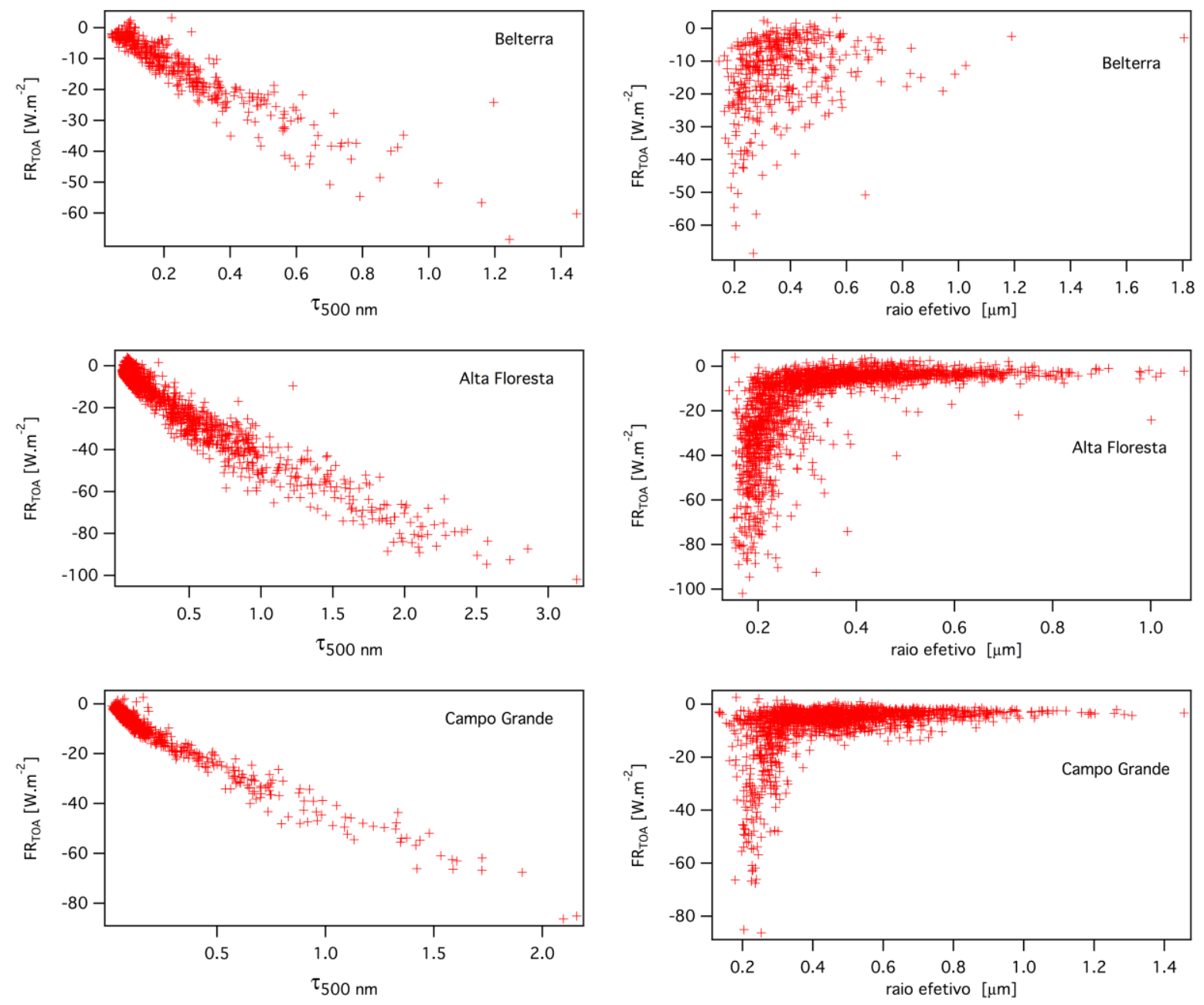

Figura 28. À esquerda, relação entre a forçante radiativa direta instantânea do aerossol no topo da atmosfera $\left(\mathrm{FR}_{\mathrm{TOA}}\right)$ e a profundidade óptica do aerossol em $500 \mathrm{~nm}$. À direita, a mesma forçante radiativa do aerossol versus o raio efetivo do mesmo.

Foi ajustada uma regressão linear aos valores de forçante radiativa do aerossol e $\tau_{500}$. Os coeficientes obtidos são mostrados na Tabela 8. A incerteza mostrada na tabela é a incerteza do ajuste, sendo que a todos os pontos foi dado o mesmo peso. A validação do produto de forçante radiativa do aerossol da AERONET é discutida no trabalho de [García et al., 2008b]. No referido trabalho, a irradiância solar na superfície foi modelada utilizando-se os mesmos procedimentos de cálculo da AERONET e comparada com as medidas de irradiância solar na superfície obtidas por piranômetros da rede SolRadNet/NASA. Globalmente, essas medidas concordaram em 99\% dos casos. Para a região Amazônica, composta pelas estações de Alta Floresta, Ji Paraná, Rio Branco e 
Belterra, [García et al., 2008a] encontrou discrepâncias de $6 \pm 13$ W.m ${ }^{-2}$ entre a FR obtida pela AERONET e a FR modelada a partir das observações do piranômetro.

$\mathrm{O}$ coeficiente angular da regressão linear da $\mathrm{FR}_{\mathrm{TOA}}$ versus profundidade óptica do aerossol nada mais é do que a eficiência de forçante do aerossol (definida na Seção 2.3.1), para $\tau$ medido em $500 \mathrm{~nm}$. Os coeficientes lineares encontrados foram bastante baixos, compatíveis com zero, o que era esperado visto que a forçante radiativa do aerossol deve ser nula quando $\tau$ é igual a zero. Embora tenha sido encontrada eficiência da forçante do aerossol maior em Belterra, os valores encontrados nas três estações são compatíveis dentro das incertezas das medidas. A eficiência de forçante encontrada na região Amazônica é compatível com a encontrada por [Patadia et al., 2008], que numa análise com metodologia independente a partir de sensoriamento remoto por satélite, foi encontrada a média de eficiência de forçante de $-44,2$ W.m ${ }^{-2}$ na Amazônia.

Tabela 8. Coeficiente angulares e lineares da regressão linear entre forçante radiativa direta do aerossol e profundidade óptica do mesmo.

\begin{tabular}{|l|ccc|ccc|c|c|}
\cline { 2 - 8 } \multicolumn{1}{c|}{} & \multicolumn{3}{c|}{ coef. angular } & \multicolumn{2}{c|}{ coef. linear } & R2 & N \\
\hline Belterra & $-50,9$ & \pm & 1,0 & $-0,3$ & \pm & 0,3 & 0,84 & 420 \\
Alta Floresta & $-38,6$ & \pm & 0,2 & $-2,4$ & \pm & 0,1 & 0,93 & 1924 \\
Campo Grande & $-41,5$ & \pm & 0,2 & $-2,0$ & \pm & 0,1 & 0,95 & 1577 \\
\hline
\end{tabular}




\subsubsection{ESTUDO DE CASO DE INFLUÊNCIA DE POEIRA DO DESERTO DO}

SAARA

Um caso interessante que foi possível observar através das medidas da AERONET é a influência do transporte de poeira mineral do deserto do Saara para a o Norte do Brasil, discutida por [Kaufman, 2005; Prospero et al., 1981]. As propriedades ópticas de poeira mineral são muito diferentes das encontradas no aerossol biogênico ou de queimadas da Amazônia. Para aerossóis de poeira do Saara, o albedo de espalhamento único tem uma dependência espectral característica por absorver fortemente a radiação de espectro do ultravioleta, mostrada na Figura 29, muito diferente do comportamento anual médio em Balbina discutido na anteriormente na Figura 26. Desse modo, foram separados os casos mostrados na Figura 29, dos dias 9 e 10 de fevereiro de 2000, e do dia 9 de fevereiro de 2001.

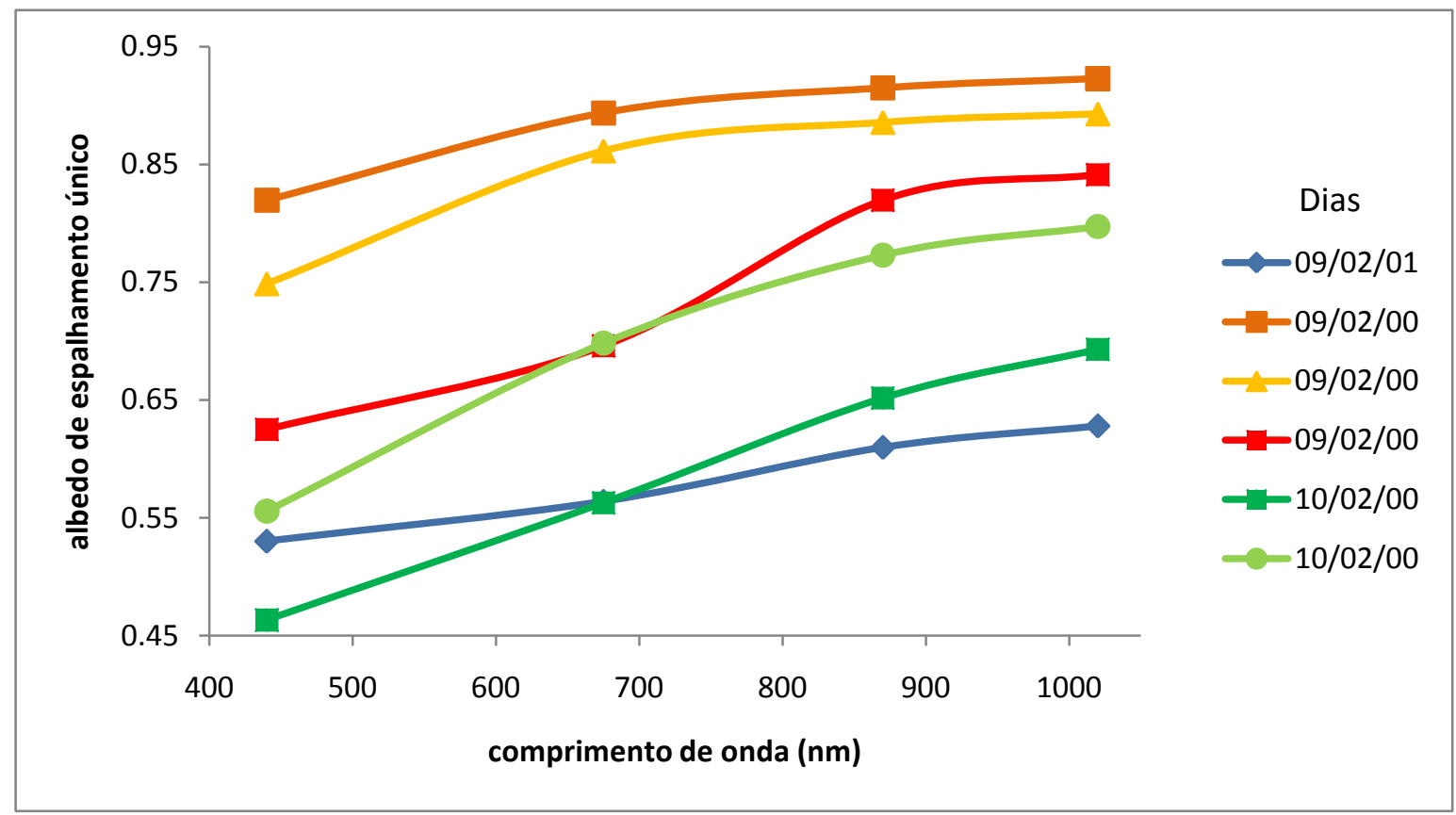

Figura 29. Dependência espectral do albedo de espalhamento único (441 nm) para 4 dias selecionados no sítio de Balbina/AM durante a estação chuvosa na Amazônia. 


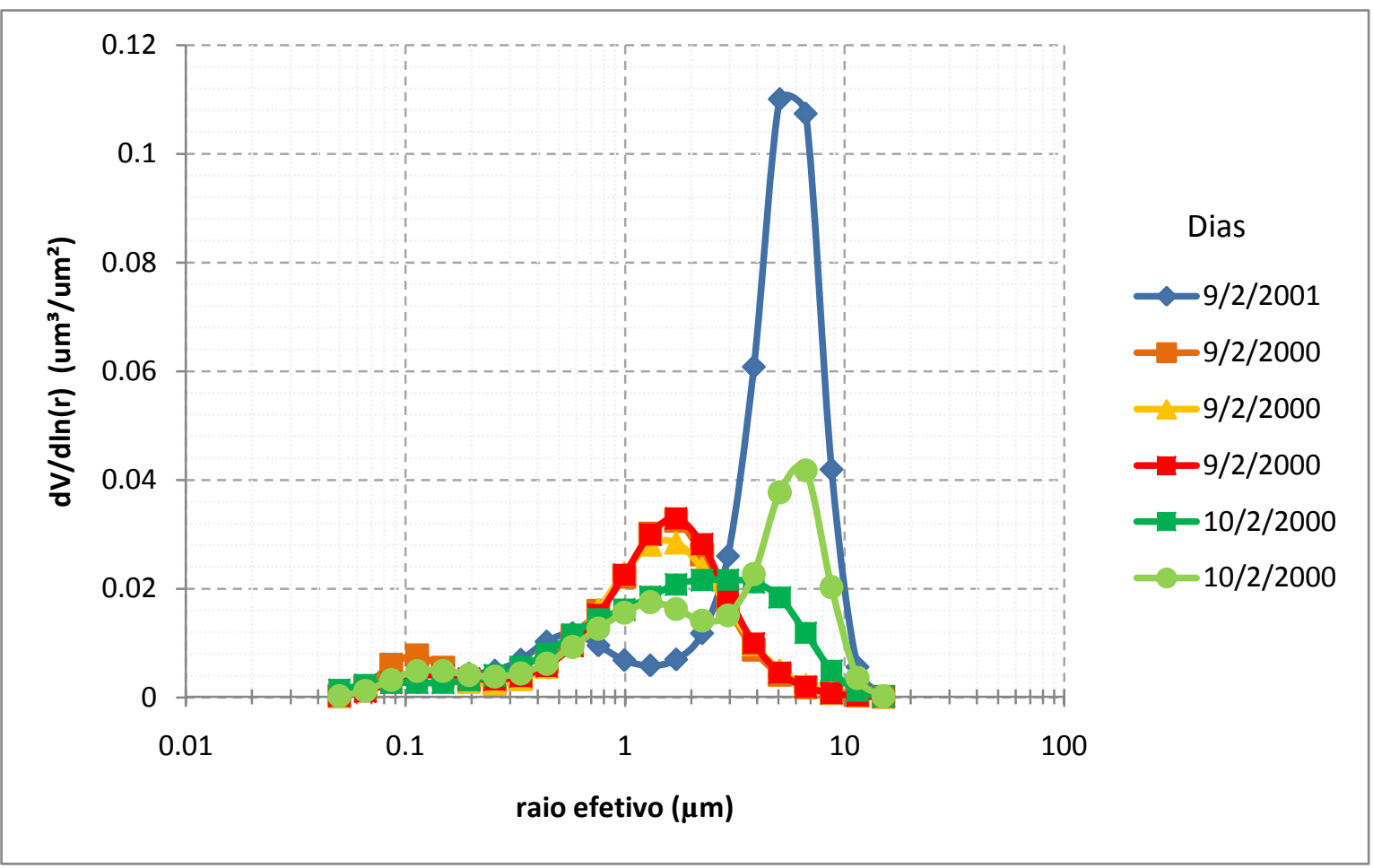

Figura 30. Distribuição de tamanho volumétrica do aerossol para os dias selecionados. 
A poeira mineral contribui majoritariamente para a moda grossa, e os valores encontrados para a distribuição de tamanho do aerossol, ilustrado na Figura 30, são consistentes com o obtido por outros autores [Ben-Ami et al., 2010b; Formenti et al., 2001; Prospero et al., 1981]. As retro-trajetórias da Figura 31, Figura 32 e Figura 33, obtidas pelo modelo de transporte lagrangiano HYSPLIT (Hybrid Single-Particle Lagrangian Integrated Trajectory) ilustram o caminho percorrido pelas massas de ar em vários níveis de altura até chegar a Balbina. Nos dias 9 de fevereiro de 2001 e 10 de fevereiro de 2000 a massa de ar é uma mistura de aerossóis proveniente do próprio continente Americano, e do oceano Atlântico. Essa mistura é caracterizada por um aerossol mais absorvedor, ilustrado nas cores azul e verde da Figura 29. Já o dia 9 de fevereiro de 2000 apresenta massas de ar vindo do continente Africano. Esse quadro é consistente com o estudo de caso apresentado por [Ansmann et al., 2009], que mediu poeira mineral do Saara em Manaus durante a campanha AMAZE2008. Com o perfil vertical de aerossóis medido por um Raman lidar, [Ansmann et al., 2009] encontrou aerossóis correspondente ao transporte de poeira mineral numa camada entre 2 - $4 \mathrm{~km}$ de altura, muito similar ao presente caso ilustrado na Figura 32.

Nesse estudo de caso pode ser identificado como diferentes tipos de aerossóis podem causar o aquecimento ou resfriamento da atmosfera. A profundida óptica do aerossol nesses casos selecionados foi aproximadamente constante, com o valor relativamente baixo de $0,12 \pm 0,01$. Isso mostra que a variação no valor da forçante radiativa direta do aerossol, mostrada na Figura 34, não é devido somente à quantidade absoluta de aerossóis. O caso de aerossol de albedo maior, correspondente a hipótese de poeira mineral, possui valor associado de forçante radiativa negativa. São as barras 2, 3 e 4 da Figura 34, referentes ao dia 9 de fevereiro de 2000, e estão relacionadas ao efeito de resfriamento da atmosfera. Os aerossóis mais absorvedores correspondem às barras 1 e 5 da Figura 34, dias 9 de fevereiro de 2001 e 10 de fevereiro de 2000. Esses aerossóis estão associados ao efeito de aquecimento da atmosfera, com forçante radiativa positiva, como mostrado na Figura 34. 


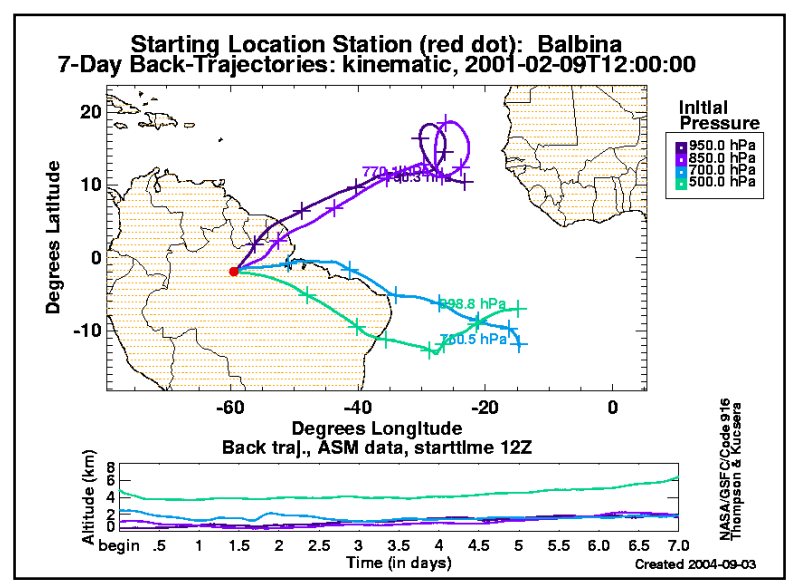

Figura 31. Retro-trajetórias de 7 dias em Balbina. 09/fev./2001.

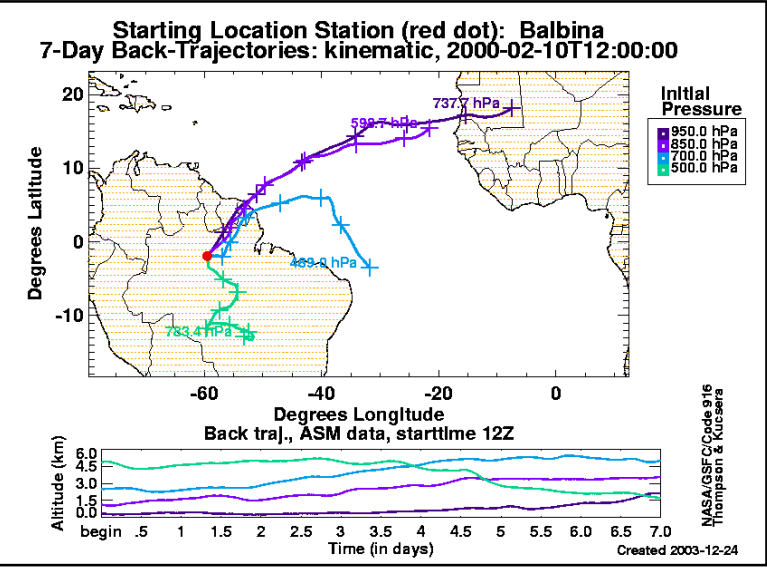

Figura 33. Retro-trajetórias de 7 dias em Balbina. 10/fev./2000.

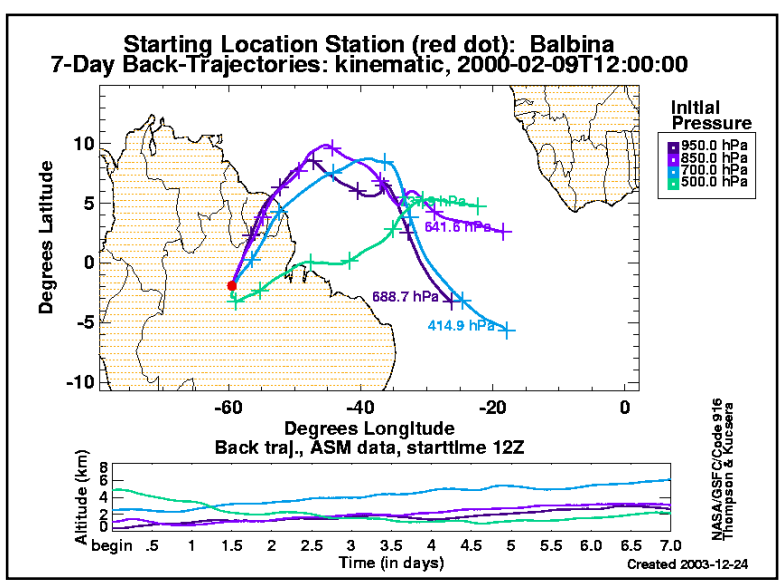

Figura 32. Retro-trajetórias de 7 dias em Balbina. 09/fev./2000. 


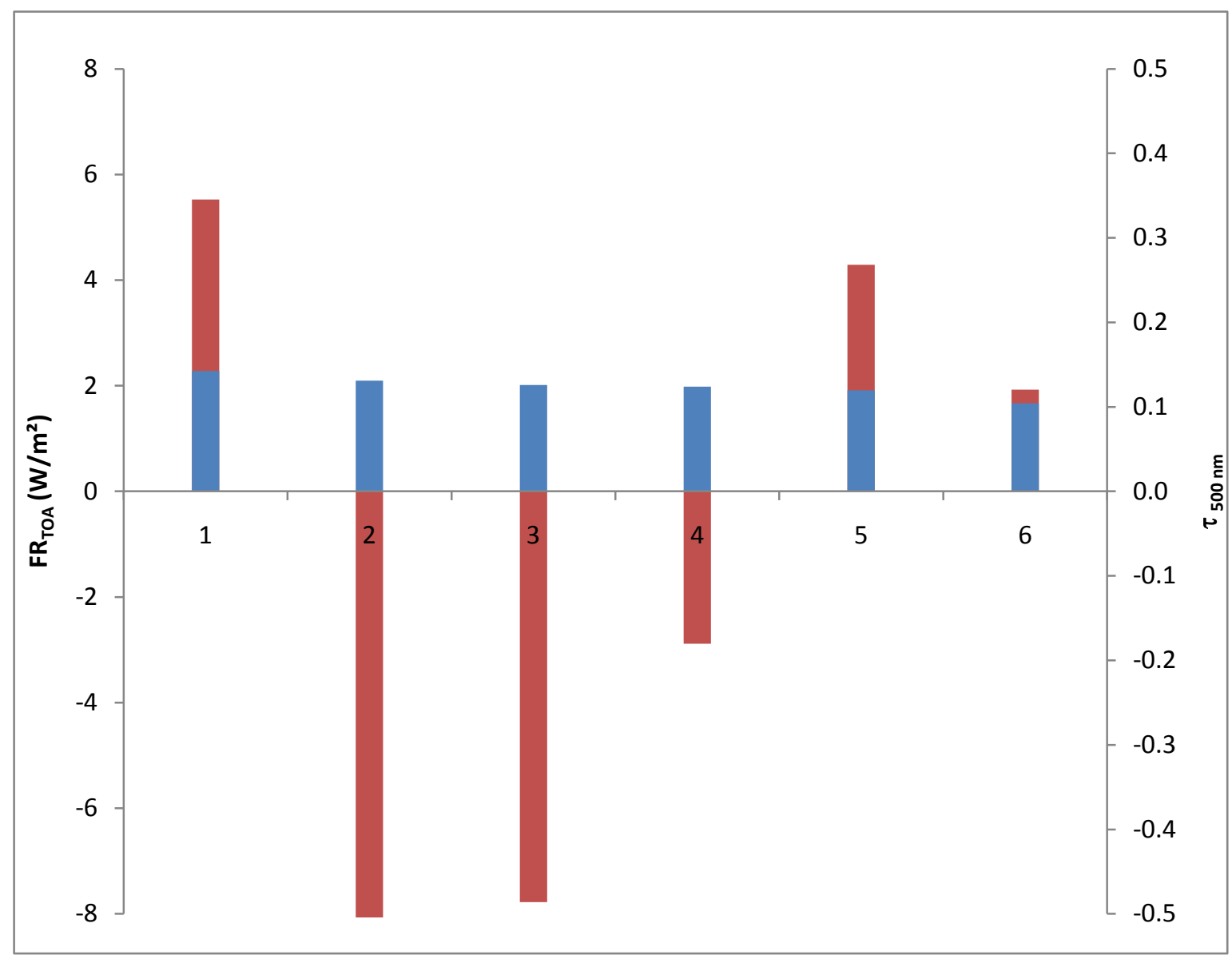

Figura 34. Forçante radiativa do aerossol no topo da atmosfera em vermelho e profundidade óptica do aerossol, em azul. A média de $\tau$ é 0,12 $\pm 0,01$. A barra 1 corresponde ao dia 9 -fev2001, as barras de 2 a 4 correspondem às observações feitas em 9-fev-2000, e as barras 5 e 6 ao dia 10-fev-2000.

Para essa análise, as propriedades ópticas obtidas pela AERONET utilizadas foram as de nível 1.5 de calibração. Isso porque a incerteza nas inversões de albedo de espalhamento único são maiores para $\tau_{440}$ menor que 0,4 , e não passam no controle de qualidade dos dados de nível 2.0. Pelo fato de as partículas de poeira contribuírem para a moda grossa, o algoritmo de inversão tende a classificá-las como contaminação por nuvem, além de as incertezas associadas serem maiores na região espectral do ultravioleta [Eck et al., 1999]. No entanto, pela persistência durante dois dias consecutivos e um total de 5 observações das propriedades de albedo de espalhamento único e distribuição de tamanho características de poeira mineral, pode-se conjecturar a influência do Saara nestes dias selecionados. 


\subsection{OBTENÇÃO DE UMA RELAÇÃO QUANTITATIVA ENTRE A CONCENTRAÇÃO DO MATERIAL PARTICULADO FINO À SUPERFÍCIE E A PROFUNDIDADE ÓPTICA DO AEROSSOL INTEGRADO NA COLUNA ATMOSFÉRICA}

A exposição humana a elevados níveis de concentração de material particulado inalável tem sido associada a várias doenças cardiopulmonares [Pope III, 2002], e por isso tem sido extensivamente estudada em termos de efeitos na saúde. Esses estudos requerem uma base de dados de longo termo tanto de medidas da saúde (mortalidade ou morbidade) quanto de material particulado, o que pode ser um empecilho para estudos em regiões remotas, ou que não tenham grade de instrumentação suficiente para tal como o caso da região Amazônica.

$\mathrm{O}$ uso de medidas de sensoriamento remoto para estudos de impactos de material particulado na saúde tem sido considerado uma alternativa para suprir a carência de informações em regiões remotas não cobertas por redes de observação em terra. No entanto é necessário cuidado ao se comparar medidas obtidas por satélite, que representam médias de toda a coluna atmosférica, e medidas instantâneas realizadas ao nível do solo. Especificamente para aerossóis pode-se utilizar o sensor MODIS, para o qual cada pixel tem resolução espacial nominal de $10 \mathrm{~km}$.

A abordagem utilizada neste trabalho foi de procurar uma relação linear entre profundidade óptica do aerossol medida na coluna atmosférica e concentração de material particulado na superfície medida independentemente. Estimativas deste relacionamento foram realizadas por vários autores e são comparados na Tabela 9, utilizando tanto medidas de sensores em satélites como o MODIS, quanto utilizando radiômetros da rede AERONET. Os coeficientes angulares e lineares são tão variados quanto os autores, e os coeficientes de correlação linear (R) variam significativamente dependendo da região, mesmo restringindo os dados em relação as condições em que pode ser aplicada, com informações do perfil vertical da atmosfera com LIDAR, horário do dia, ou condições de tempo e outros parâmetros. 
Outras abordagens utilizando modelos de transporte global químico [Chu, 2003; EngelCox, 2004; Engel-Cox et al., 2006; Schaap et al., 2008; Wang, 2003], e de relação não linear [van Donkelaar et al., 2010; 2006] melhoraram um pouco a relação entre $\tau$ e material particulado, mas não de maneira a justificar a sofisticação do cálculo. Mais recentemente, um grupo de Harvard [Liu et al., 2005] conseguiu melhorar significativamente a correlação entre ambos com um método estatístico de encontrar os coeficientes angular e linear dia por dia, sendo uma parte do coeficiente fixa e outra aleatória.

O presente estudo optou por uma abordagem simples de regressão linear, tomando vantagem da robustez da longa série temporal de medidas, com o mínimo de restrições. Foram utilizadas medidas de solo de concentração de material particulado fino $\left(\mathrm{MP}_{2,5}\right)$ obtidas através do TEOM e AFG, comparadas com medidas de profundidade óptica do aerossol no canal de $500 \mathrm{~nm}$ dos radiômetros da AERONET em Santarém (AFG 20002004), Alta Floresta (AFG 1992-2005; TEOM 2006) e Ji Paraná (TEOM, 2002), conforme descrito anteriormente no Capítulo 3 Materiais e Métodos. A partir do instrumento AFG foram calculados os valores médios diários $(24 \mathrm{~h})$ das medidas de concentração, e a partir do instrumento TEOM foram calculados as médias horárias, devido à alta resolução temporal desses equipamentos e também para não restringir a análise a um só tipo de relação entre a concentração de MP e profundidade óptica do aerossol. 
Tabela 9. Comparação entre as regressões lineares da literatura. $R$ é o coeficiente de correlação linear, $\mathrm{N}$ o número de observações e $\tau$ é a profundidade óptica do aerossol.

\begin{tabular}{|c|c|c|c|c|c|c|c|}
\hline $\begin{array}{l}\text { coef. } \\
\text { angular }\end{array}$ & $\begin{array}{l}\text { coef. } \\
\text { linear }\end{array}$ & $\mathbf{R}$ & $\mathbf{N}$ & $\tau$ & Local & Período & Referência \\
\hline \multicolumn{8}{|l|}{ diário } \\
\hline 124,5 & $-0,34$ & 0,63 a 0,85 & 864 & AERONET $^{2}$ & Holanda, Cabauw & Ago06 - Maio07 & Schaap et al., 2009 \\
\hline 18,66 & 7,54 & $-0,22$ a 0,94 & 35619 & MODIS & EUA & Abr - Set 2002 & Engel-Cox et al., 2004 \\
\hline 25,33 & 11,09 & 0,57 & $\sim 17$ & MODIS & EUA, Baltimore & Verão, 2004 & Engel-Cox et al., 2006 \\
\hline 40,56 & 3,96 & 0,75 & $\sim 15$ & $\mathrm{LIDAR}^{3}$ & EUA, Baltimore & Verão, 2004 & Engel-Cox et al., 2006 \\
\hline 64,84 & 1,75 & 0,76 & $\sim 15$ & $\mathrm{LIDAR}^{4}$ & EUA, Baltimore & Verão, 2004 & Engel-Cox et al., 2006 \\
\hline 71,43 & 0,86 & 0,7 & 1095 & MODIS & EUA, Alabama & 2002 & Wang e Christopher, 2003 \\
\hline 55 & 8 & 0,82 & 29 & AERONET $^{5}$ & Itália, Ispra & Ago - Out 2000 & Chu et al., 2003 \\
\hline 40 & 5 & 0,85 & 152 & AERONET & Alta Floresta & $2001-2005$ & Presente trabalho \\
\hline 30,07 & 0,08 & 0,77 & 385 & AERONET & Santarem & $2000-2004$ & Presente trabalho \\
\hline \multicolumn{8}{|l|}{ horário } \\
\hline 22,55 & 6,35 & 0,356 a 0,939 & 13967 & MODIS & EUA & Abr - Set 2002 & Engel-Cox et al., 2004 \\
\hline 31,06 & 5,22 & 0,65 & $\sim 17$ & MODIS & EUA, Baltimore & Verão, 2004 & Engel-Cox et al., 2006 \\
\hline 26,96 & 9,26 & 0,56 & $\sim 75$ & LIDAR $^{2}$ & EUA, Baltimore & Verão, 2004 & Engel-Cox et al., 2006 \\
\hline 48,51 & 5,2 & 0,65 & $\sim 75$ & $\mathrm{LIDAR}^{3}$ & EUA, Baltimore & Verão, 2004 & Engel-Cox et al., 2006 \\
\hline 40,6 & 1,9 & 0,87 & 153 & AERONET & Alta Floresta & Set - Nov 2006 & Presente trabalho \\
\hline 39,7 & 5,4 & 0,76 & 126 & AERONET & Ji Parana & Set - Nov 2004 & Presente trabalho \\
\hline
\end{tabular}

Os valores médios de concentração de material particulado fino $\left(\mathrm{MP}_{2,5}\right)$, profundidade óptica do aerossol ( $\left.\tau_{500 \mathrm{~nm}}\right)$ e exponente Ångström 870-440 nm são mostrados na Tabela 9.

\footnotetext{
${ }^{2}$ Média horária entre $11 \mathrm{~h}$ e $15 \mathrm{~h}$ UTC.

${ }^{3}$ Profundidade óptica do aerossol calculada com LIDAR para toda a coluna atmosférica.

${ }^{4}$ Profundidade óptica do aerossol calculada com LIDAR abaixo da camada limite planetária.

${ }^{5} \mathrm{MP}_{10}$
} 
De maneira geral, $\mathrm{MP}_{2,5}$ variou de $7-13 \mu \mathrm{g} / \mathrm{m}^{3}$ em média na estação chuvosa , e pelo menos dobrou a concentração durante a estação de queimadas. Santarém é um sítio com baixa carga de aerossóis na atmosfera, com média de $\mathrm{MP}_{2,5}$ de $2 \mu \mathrm{g} / \mathrm{m}^{3}$ durante a estação chuvosa, subindo para cerca de $11 \mu \mathrm{g} / \mathrm{m}^{3}$ no na estação seca.

Em Alta Floresta notam-se dois períodos diferentes no que diz respeito ao material particulado, conforme mostrado na [Hoelzemann et al., 2009a]. De 1992-2000 a 20012006, a concentração típica na estação de queimadas caiu pela metade, de $61 \mu \mathrm{g} / \mathrm{m}^{3}$ a 32 $\mu \mathrm{g} / \mathrm{m}^{3}$ em média. $\mathrm{O}$ interessante é que a média de $\tau$ não apresentou o mesmo comportamento, subindo de 0,74 para apenas 0,76 . Isso se deve, possivelmente, ao fato de o radiômetro medir o aerossol presente em toda a coluna atmosférica, o que pode ser traduzido por uma média espacial de uma área da ordem de quilômetros quadrados, segundo o trabalho de [Hoelzemann et al., 2009a]. Desse modo, a medida de profundidade óptica do aerossol é representativa da região do arco do desflorestamento, enquanto que a medida ao nível do solo é mais susceptível a mudanças locais de emissão de aerossóis.

O CONAMA (Conselho Nacional do Meio Ambiente), órgão nacional que estabelece os padrões nacionais de qualidade do ar, contempla apenas para o material particulado inalável, $\mathrm{MP}_{10}$, sem restrição específica ao particulado fino, $\mathrm{MP}_{2,5}$. No período de 1992 a 2000, o sítio de Alta Floresta teve 88 dias em que a média de 24 horas foi superior ao padrão estabelecido para $\mathrm{MP}_{10}$ de $50 \mu \mathrm{g} / \mathrm{m}^{3}$. A média anual de material particulado fino e inalável é mostrada na Tabela 11, mas deve-se ter em conta que o período de amostragem se refere principalmente à estação seca, como mostrado no histograma da Figura 35. 
Tabela 10. Valores típicos de concentração de material particulado fino $\left(\mathrm{MP}_{2.5}\right)$, profundidade óptica do aerossol $\left(\tau_{500 \mathrm{~nm}}\right)$, e coeficiente de Ångström para alguns dos sítios de medidas da Amazônia.

\begin{tabular}{|c|c|c|c|}
\hline ALTA FLORESTA 1992-2000 & Estação chuvosa & Estação seca & Queimadas \\
\hline $\mathbf{M P}_{2.5}\left(\mu \mathrm{g} / \mathrm{m}^{3}\right)$ AFG & $7.12 \pm 6.53(\mathrm{~N}=213)$ & $10.06 \pm 7.30(\mathrm{~N}=44)$ & $61.36 \pm 63.40(\mathrm{~N}=432)$ \\
\hline$\tau_{500 \mathrm{~nm}}$ & $0.18 \pm 0.14(\mathrm{~N}=150)$ & $0.14 \pm 0.07(\mathrm{~N}=149)$ & $0.74 \pm 0.54(\mathrm{~N}=144)$ \\
\hline Ångström 870-440 & $0.82 \pm 0.42$ & $1.38 \pm 0.34$ & $1.73 \pm 0.37$ \\
\hline ALTA FLORESTA 2001-2006 & Estação chuvosa & Estação seca & Queimadas \\
\hline $\mathbf{M P}_{2.5}\left(\mu \mathrm{g} / \mathrm{m}^{3}\right)$ TEOM & $13.69 \pm 7.62(\mathrm{~N}=902)$ & & $26.04 \pm 23.54(\mathrm{~N}=723)$ \\
\hline $\mathbf{M P}_{2.5}\left(\mu \mathrm{g} / \mathrm{m}^{3}\right)$ AFG & $6.03 \pm 5.09(\mathrm{~N}=119)$ & $10.22 \pm 3.53(\mathrm{~N}=19)$ & $32.27 \pm 25.82(\mathrm{~N}=166)$ \\
\hline$\tau_{500 \mathrm{~nm}}$ & $0.17 \pm 0.12(\mathrm{~N}=251)$ & $0.16 \pm 0.12(\mathrm{~N}=247)$ & $0.76 \pm 0.54(\mathrm{~N}=376)$ \\
\hline Ångström 870-440 & $1.07 \pm 0.46$ & $1.53 \pm 0.39$ & $1.76 \pm 0.31$ \\
\hline JI PARANÁ & Estação chuvosa & Estação seca & Queimadas \\
\hline $\mathbf{M P}_{2.5}\left(\mu \mathrm{g} / \mathrm{m}^{3}\right)$ AFG & $6.5 \pm 2.9(\mathrm{~N}=422)$ & & $43.6 \pm 40.5(\mathrm{~N}=2200)$ \\
\hline$\tau_{500 \mathrm{~nm}}$ & $0.17 \pm 0.13(\mathrm{~N}=401)$ & $0.15 \pm 0.10(\mathrm{~N}=396)$ & $0.75 \pm 0.54(\mathrm{~N}=520)$ \\
\hline Ångström 870-440 & $0.97 \pm 0.46$ & $1.47 \pm 0.38$ & $1.75 \pm 0.33$ \\
\hline SANTARÉM & Estação chuvosa & & Poluído \\
\hline $\mathbf{M P}_{2.5}\left(\mu \mathrm{g} / \mathrm{m}^{3}\right)$ AFG & $2.10 \pm 7.52(\mathrm{~N}=381)$ & & $11.0 \pm 1.7(\mathrm{~N}=281)$ \\
\hline$\tau_{500 \mathrm{~nm}}$ & $0.11 \pm 0.05(\mathrm{~N}=363)$ & & $0.36 \pm 0.22(\mathrm{~N}=522)$ \\
\hline Ångström 870-440 & $0.89 \pm 0.34$ & & $1.21 \pm 0.33$ \\
\hline
\end{tabular}


Tabela 11. Média anual de concentração de material particulado fino $\left(\mathrm{MP}_{2,5}\right)$, inalável $\left(\mathrm{MP}_{10}\right)$, e número de dias em que o padrão nacional de $\mathrm{MP}_{10}$ de $50 \mu \mathrm{g} / \mathrm{m}^{3} \mathrm{em} 24 \mathrm{~h}$ foi excedido no sítio de Alta Floresta.

\begin{tabular}{cccc}
\hline Ano & $\mathbf{M P}_{\mathbf{2 , 5}}\left(\boldsymbol{\mu g} / \mathbf{m}^{\mathbf{3}}\right)$ & $\mathbf{M P}_{\mathbf{1 0}}\left(\boldsymbol{\mu g} / \mathbf{m}^{\mathbf{3}}\right)$ & \# dias em que $\mathbf{M P}_{\mathbf{1 0}} \mathbf{2 4 h}$ foi excedido \\
\hline 1993 & 48.9 & 85.6 & 15 \\
1994 & 22.6 & 41.8 & 6 \\
1995 & 176.2 & 292.5 & 21 \\
1996 & 59.0 & 93.2 & 21 \\
1997 & 29.3 & 47.4 & 4 \\
1998 & 76.1 & 106.8 & 18 \\
1999 & 18.1 & 30.5 & 3 \\
2000 & 5.1 & 9.5 & 0 \\
2001 & 1.2 & 2.2 & 0 \\
2002 & 26.7 & 42.4 & 1 \\
2003 & 7.9 & 12.0 & 0 \\
2004 & 6.6 & 11.1 & 0 \\
$* 2006$ & 10.6 & 52.8 & - \\
\hline
\end{tabular}

*Período de setembro a novembro de 2006, média horária. 


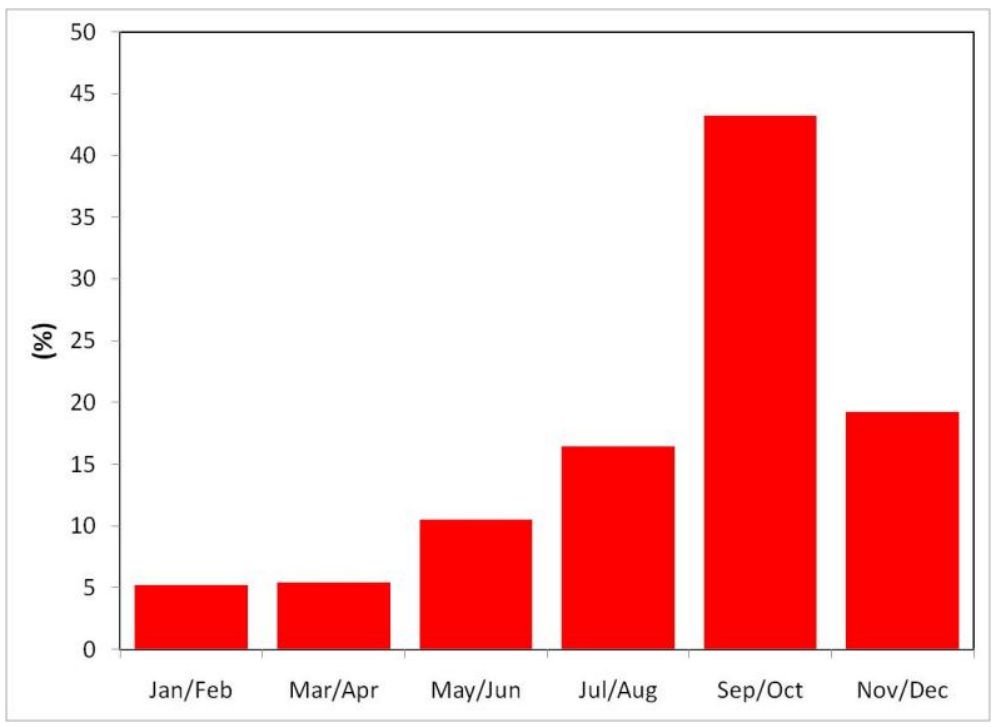

Figura 35. Histograma normalizado de frequência dos dados de $\mathrm{MP}_{2,5}$ no ano. Mais de $\mathbf{5 0 \%}$ das medidas foram tomadas durante a estação seca.

Em Santarém, na análise de $\mathrm{MP}_{2,5}$ versus $\tau$ foi obtida uma regressão linear com coeficiente angular de $(30,7 \pm 1,3) \mu \mathrm{g} / \mathrm{m}^{3}$, e coeficiente linear de $(0,08 \pm 0,40) \mu \mathrm{g} / \mathrm{m}^{3}$, sendo o coeficiente de correlação de 0,59, conforme pode ser visto na Figura 36. Esse valor de coeficiente de regressão é compatível com os valores da literatura (Tabela 9), e mostra que a relação entre material particulado na superfície funciona para sítios pouco poluídos.

Em Ji Paraná, a regressão linear obtida com médias horárias de $\mathrm{MP}_{2,5}$ teve um coeficiente angular de $(35,8 \pm 2,7) \mu \mathrm{g} / \mathrm{m}^{3}$, Figura 37, e coeficiente linear de $(5,2 \pm 2,3) \mu \mathrm{g} / \mathrm{m}^{3}$. O coeficiente de correlação foi compatível com o de Santarém, no valor de 0,58.

Embora a análise de regressão em Santarém tenha sido obtida com médias diárias de $\mathrm{MP}_{2,5}$, e em Ji Paraná com médias horárias, os coeficientes angulares de ambos são da mesma ordem, 30,7 e 35,8 $\mu \mathrm{g} / \mathrm{m}^{3}$. Essa comparação é importante, pois indica que o período noturno pouco influencia a relação, o que é esperado visto que a emissão de material particulado em queimadas ocorre principalmente durante o dia, em geral no período da tarde. 


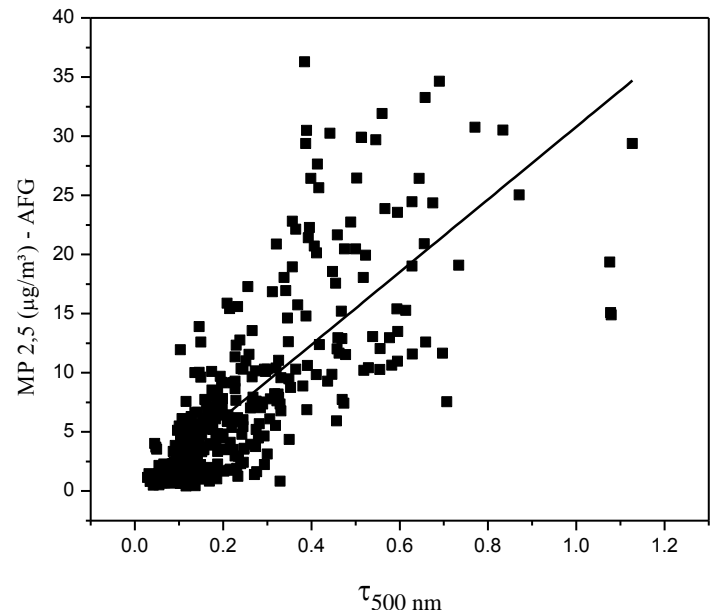

Figura 36. Gráfico de regressão entre $\mathrm{MP}_{2,5} \mathrm{e}$ profundidade óptica do aerossol em Santarém durante o período de 2000 a 2004. $\mathrm{MP}_{2,5}=(30,7 \pm 1,3) \tau+(0,08 \pm 0,40) ; R=0,59 ;$ $\mathbf{N}=385$.

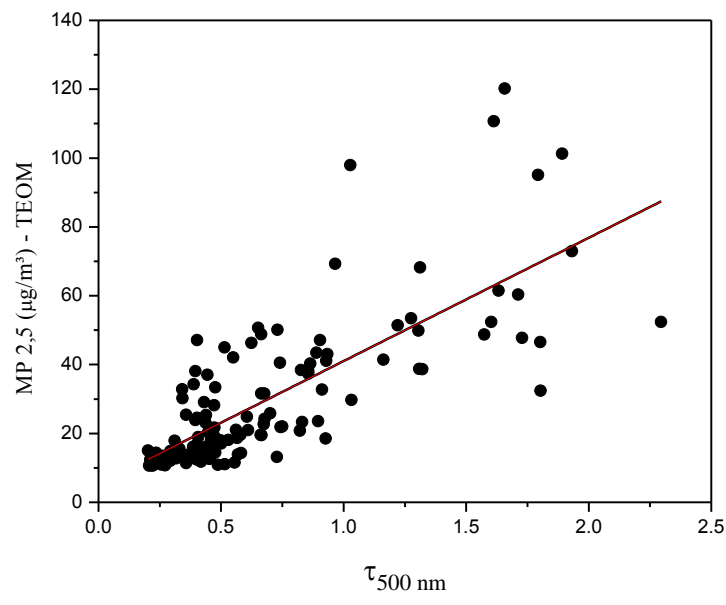

Figura 37. Gráfico de regressão entre $\mathrm{MP}_{2,5} \mathrm{e}$ profundidade óptica do aerossol em Ji Paraná durante o período de setembro a dezembro de 2002.

$\mathrm{MP}_{2,5}=(35,8 \pm 2,7) \tau+(5,2 \pm 2,3) ; \quad R=0,58$ $\mathrm{N}=126$.

Em Alta Floresta, a regressão entre $\mathrm{MP}_{2,5}$ e profundidade óptica foi obtida separadamente para dois períodos caracterizados pela carga de aerossóis. No período de 1995; 1999-2000 foi obtido um coeficiente angular de $(88,6 \pm 5,9) \mu \mathrm{g} / \mathrm{m}^{3}$, e o coeficiente linear foi compatível com zero $(6,4 \pm 5,3) \mu \mathrm{g} / \mathrm{m}^{3}$ (Figura 38-a). $\mathrm{O}$ instrumento medindo $\mathrm{MP}_{2,5}$ à superfície nesse período foi o AFG com médias diárias (24h), e o coeficiente de correlação encontrado foi de 0,67, com 111 observações coincidentes. Já para o período de 2001-2005 (Figura 38-b) o coeficiente angular foi praticamente a metade $(40,4 \pm 2,0) \mu \mathrm{g} / \mathrm{m}^{3}$, com R de 0,72 , sendo essa média também de $24 \mathrm{~h}$, obtida pelo AFG.

Em 2006 o método para medida de $\mathrm{MP}_{2,5}$ utilizado foi o TEOM (Figura 38-c), e a regressão linear teve coeficiente angular consistente com o método gravimétrico dos filtros do AFG de $(36,7 \pm 1,7) \mu \mathrm{g} / \mathrm{m}^{3}$. É reforçado, novamente, que não foi encontrada diferença entre as comparações de médias diárias e horárias. O coeficiente linear foi compatível com zero $(3,6 \pm 1,6) \mu \mathrm{g} / \mathrm{m}^{3}$, e o coeficiente de correlação encontrado foi de 0,75 . 
Para validar o método, a profundidade óptica do aerossol obtida de maneira independente pelo sensor MODIS foi utilizada para estimar a concentração de material particulado fino através dos coeficientes obtidos anteriormente. Como a medida de satélite ocorre no máximo duas vezes por dia (satélites Terra e Aqua), a correlação com as médias horárias (fornecida pelo TEOM) se mostrou a mais adequada.

Como mostra a Figura 39, em Ji Paraná foi encontrada a regressão linear de o coeficiente angular encontrado para a comparação entre valores medidos e modelados foi de $(0,35 \pm 0,05)$, enquanto que o coeficiente linear foi incompatível com zero $(19 \pm 3) \mu \mathrm{g} / \mathrm{m}^{3}$. O valor do coeficiente de correlação foi compatível com o encontrado na comparação com a AERONET: 0,60. Em Alta Floresta, como ilustrado na Figura 40, o coeficiente angular ficou próximo da unidade $(1,18 \pm 0,06)$, o coeficiente linear é compatível com zero $(1 \pm 2)$ $\mu \mathrm{g} / \mathrm{m}^{3}$, e o coeficiente de correlação foi de 0,96. O número de observações foi de 29 em Alta Floresta e 27 em Ji Paraná. 
a)

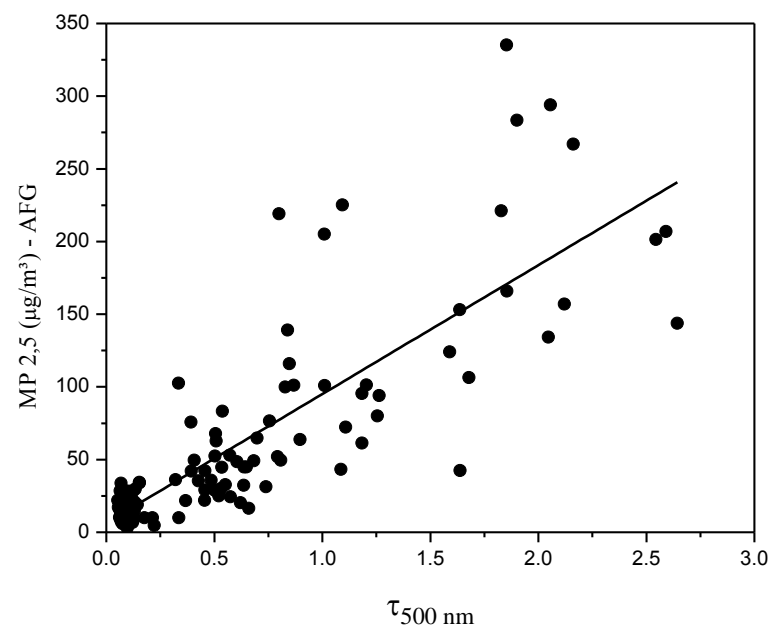

c)

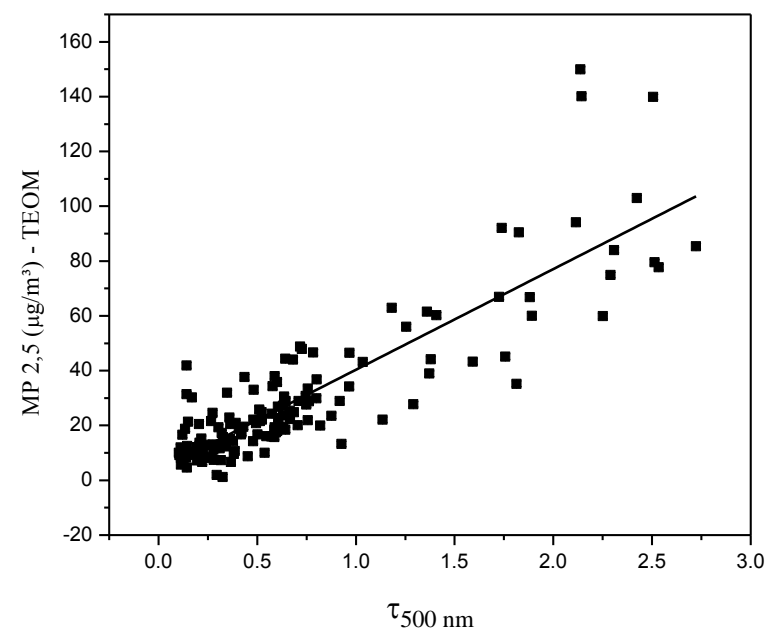

Figura 38. Gráfico de regressão entre $\mathrm{MP}_{2,5}$ e profundidade óptica do aerossol da AERONET em Alta Floresta. a) Com $\mathrm{MP}_{2,5}$ medido pelo AFG, no período de 1995; 1999-2000: $\mathrm{MP}_{2,5}=(88,6 \pm 5,9) \tau+(6,4 \pm 5,3) ; \mathrm{R}=0,67 ; \mathrm{N}=111$.

b) Com $\mathrm{MP}_{2,5}$ medido pelo AFG, no período de 2001-2005: $\mathrm{MP}_{2,5}=(40,4 \pm 2,0) \tau+(5,0 \pm 1,3)$ $\mathrm{R}=\mathbf{0 , 7 2 ;} \mathrm{N}=\mathbf{1 5 2}$.

c) Com $\mathrm{MP}_{2,5}$ medido pelo $\mathrm{TEOM}$, no período de 2006: $\mathrm{MP}_{2,5}=(36,7 \pm 1,7) \tau+(3,6 \pm 1,6) \mathrm{R}=0,75$; $\mathbf{N}=153$.

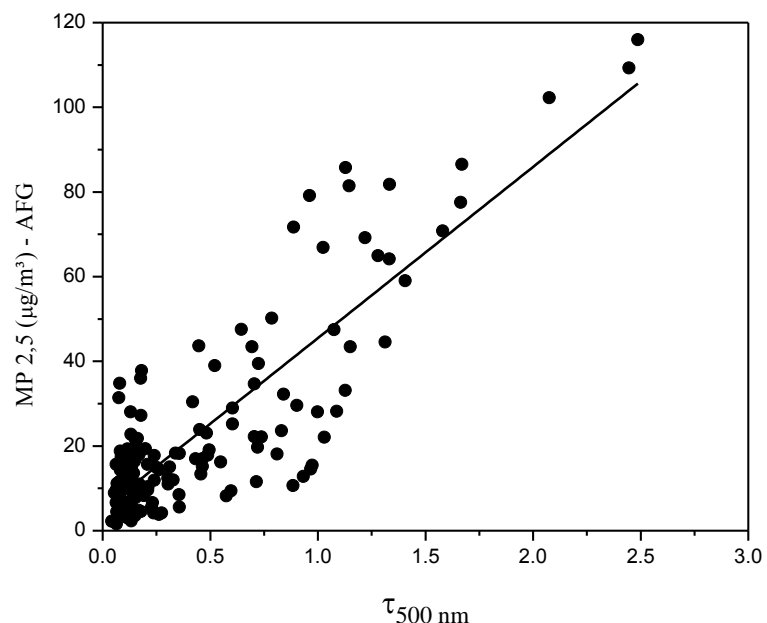




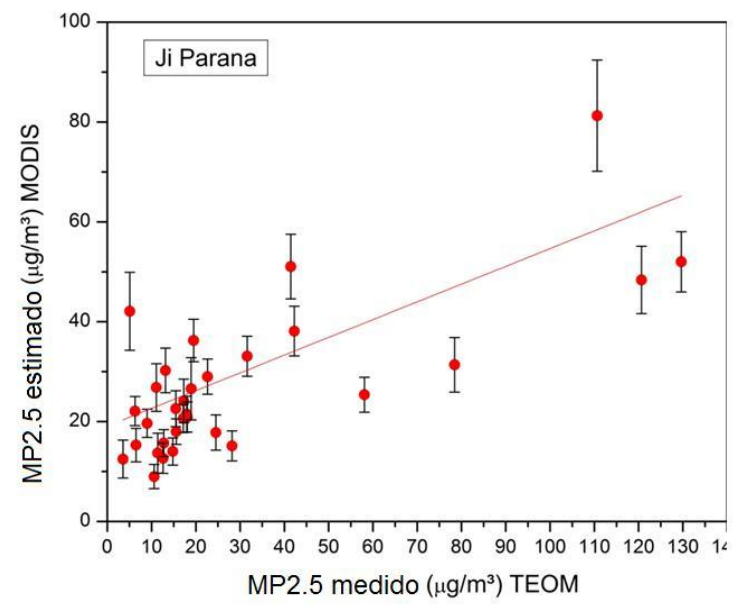

Figura 39. Comparação entre $\mathrm{MP}_{2,5}$ estimado pelo $\tau$ obtido pelo MODIS e $\mathrm{MP}_{2,5}$ medido pelo TEOM em Ji Paraná.

$y=(0,35 \pm 0,05) x+(19 \pm 3) . R=0,764 . N=27$.

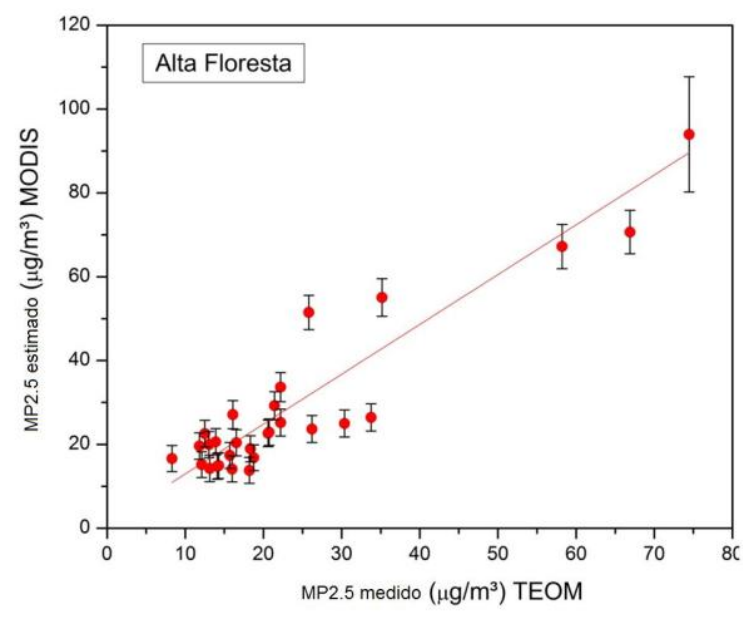

Figura 40. Comparação entre $\mathrm{MP}_{2,5}$ estimado pelo $\tau$ obtido pelo MODIS e $\mathrm{MP}_{2,5}$ medido pelo TEOM em Alta Floresta.

$y=(1,18 \pm 0,06) x+(1 \pm 2) . R=0,962 . ~ N=29$.

Embora grande parte das medidas tenha sido obtida durante a estação seca nenhum dado foi excluído, ou seja, a estação chuvosa também está presente nesta análise. As medidas utilizadas na correlação abrangem um total de 9 anos, utilizando 2 métodos independentes de medidas in situ (AFG e TEOM) e também de sensoriamento remoto (AERONET e MODIS). Nesse contexto, considera-se que tais comparações entre valores medidos e previstos para o $\mathrm{MP}_{2,5}$ são adequados e recomenda-se a regressão linear de $\mathrm{MP}_{2,5}=$ $(37 \pm 2) \tau_{500}+(5 \pm 2)$ em unidades de $\left[\mu \mathrm{g} . \mathrm{m}^{-3}\right]$ para a região do arco do desflorestamento, e $\mathrm{MP}_{2,5}=(30,7 \pm 1,3) \tau_{500}+(0,08 \pm 0,40)$ nas mesmas unidades, para a região de Belterra. Esta análise é tema de um artigo em fase final de revisão cujo resumo encontra-se no Apêndice I. 


\section{CONCLUSÕES}

O presente trabalho analisou as principais propriedades do aerossol atmosférico através de longa série temporal de medidas com radiômetros da rede AERONET, realizadas na Amazônia com medidas constantes de 1999 a 2010. O algoritmo de processamento dos dados da AERONET passou por uma reformulação em 2006 e conta com um novo controle de qualidade dos dados que resultou em mais observações de nível 2.0 de calibração. $O$ estudo foi divido em três regiões de interesse: o Norte da Amazônia, compreendendo os sítios de Balbina, AM, e Belterra, PA, representando a floresta Amazônica o aerossol biogênico natural; o arco do desflorestamento que compreende os sítios de Alta Floresta, MT, Ji Paraná, RO, e Rio Branco, AC, e abrange os três estados de região de desmatamento impactados pelas práticas agropecuárias de queimadas. Por fim, a região do cerrado foi representada pelos sítios de Cuiabá, MT, e Campo Grande, MS, que ocasionalmente recebe transporte de massas de ar da região Amazônica com aerossol envelhecido proveniente principalmente de queimadas.

A profundidade óptica do aerossol $\left(\tau_{500}\right)$ encontrada durante a estação chuvosa nas três regiões é de cerca de 0,15 , e corresponde ao aerossol de fundo, também chamado de background. Durante a estação de queimadas a coluna atmosférica recebe alta carga de aerossóis, com valores de profundidade óptica do aerossol que chegam a 5,5 em medidas instantâneas em Alta Floresta, enquanto que na região do cerrado o pico de profundidade óptica fica em torno de 1,5 em média.

A dependência espectral da profundidade óptica dada pelo coeficiente de Ångström, indicativa do tamanho da partícula de aerossol, aumenta significativamente durante a estação de queimadas. Isso indica a predominância de partículas finas nessa época do ano, o que é corroborado pelas medidas de distribuição de tamanho na região do arco do desflorestamento. Essas medidas mostram um aumento no volume da moda fina com um pico no raio de $0,15 \mu \mathrm{m}$. Essa moda fina está presente durante todo o ano, e corresponde também ao aerossol produzido secundariamente na atmosfera, pela oxidação de compostos emitidos pela vegetação, presentes tanto na região do arco do desflorestamento como no Norte da Amazônia. Os sítios do Norte da Amazônia não apresentam dependência evidente 
entre o coeficiente de Ångström e $\tau$. Nessas regiões o aerossol é dominado por partículas biogênicas da moda grossa, e tem valores compatíveis com os encontrados por [Schneider et al., 2011] durante a campanha AMAZE2008 em Manaus de 1,6 - 5,0 $\mu \mathrm{m}$ de raio aerodinâmico medido ao nível do solo. Essa moda grossa também está presente na distribuição de tamanho da região do arco do desflorestamento, correspondente a emissões primárias de partículas pela vegetação. Os sítios de cerrado também recebem fortes cargas de aerossol de queimada, sobretudo da região Amazônica, por transporte. Na época da seca, o exponente Ångström também aumenta para valores de cerca de 1,5 a 2,0 para valores altos de $\tau$, assim como na região do arco do desflorestamento, indicando impacto maior das partículas da moda fina.

Também foram analisadas as medidas de propriedade intrínseca do aerossol como o albedo de espalhamento único $\left(\omega_{0}\right)$. O valor médio de $\omega_{0}(673 \mathrm{~nm})$ para as estações do arco do

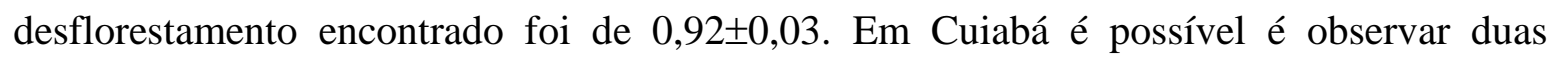
modas de valores de $\omega_{0}$, correspondentes ao aerossol natural do cerrado e a influência de queimadas de longa distância. Para a obtenção dos valores dessas duas modas foram separadas as medidas de $\omega_{0}$ com valores moderados de $\tau_{500}$, entre 0,4 e 0,7 , e com $\tau_{500}$ maior que 1,5. A média de $\omega_{0}$ para moderado $\tau_{500}$ ficou em $0,84 \pm 0,05$, enquanto que no caso de $\tau_{500}$ maior que 1,5 , a média de $\omega_{0}$ encontrada foi de $0,92 \pm 0,03$, compatível com as estações do arco do desflorestamento. O Norte da Amazônia foi caracterizado por aerossol

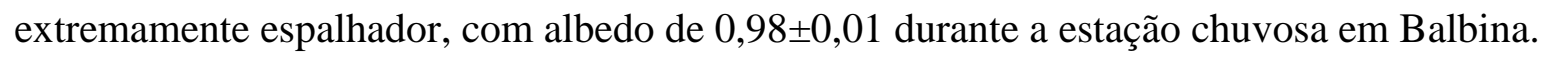

O impacto climático dos aerossóis é quantificado através das inversões de forçante radiativa direta do aerossol pelo algoritmo da AERONET. A forçante radiativa instantânea no topo da atmosfera chegou a -100 W.m ${ }^{-2}$ no arco do desflorestamento para partículas finas associadas à emissão de queimadas. Verificou-se que a forçante possui relação com o raio efetivo do aerossol nas regiões do arco do desflorestamento e do cerrado. O valor de eficiência de forçante do aerossol na Amazônia, obtido através de regressão linear entre a forçante radiativa e a profundidade óptica do aerossol em $500 \mathrm{~nm}$, variou entre $-38,6 \mathrm{~W} . \mathrm{m}^{-}$ ${ }^{2} \cdot \tau^{-1}$ em Alta Floresta, a $-50,9 \mathrm{~W} \cdot \mathrm{m}^{-2} \cdot \tau^{-1}$ em Belterra. A incerteza do produto de forçante da AERONET é de $9 \pm 12 \mathrm{~W} . \mathrm{m}^{-2}$. Esses valores são compatíveis ao encontrado por [Patadia et al., 2008]. 
Uma análise importante foi a comparação entre as medidas de sensoriamento remoto de aerossol integradas na coluna atmosférica com medidas físicas ao nível do solo. Estudou-se a relação da profundidade óptica do aerossol obtida pelos radiômetros da AERONET e a concentração de material particulado fino, $\mathrm{MP}_{2,5}$ obtida ao nível do solo por duas técnicas independentes: o método de microbalança oscilante do TEOM e o amostrador de filtros AFG. As medidas utilizadas neste estudo abrangem um total de 9 anos de medidas. Nesse contexto, considera-se que tais comparações entre valores medidos e previstos para o $\mathrm{MP}_{2,5}$ são adequados e recomenda-se a regressão linear de $\mathrm{MP}_{2,5}=(37 \pm 2) \tau_{500}+(5 \pm 2) \mathrm{em}$ unidades de $\left[\mu \mathrm{g} \cdot \mathrm{m}^{-3}\right]$ para a região do arco do desflorestamento, e $\mathrm{MP}_{2,5}=(30,7 \pm 1,3) \tau_{500}+$ $(0,08 \pm 0,40)$ nas mesmas unidades, para a região de Belterra. A validação feita com $\tau$ obtido independentemente pelo sensor MODIS, a bordo dos satélites Terra e Aqua, mostrou que a relação funciona para o arco do desflorestamento e a profundidade óptica do aerossol obtida por ambos os métodos pode ser usada alternativamente para estudos de efeitos de material particulado na saúde humana. 


\section{RECOMENDAÇÕES PARA TRABALHOS FUTUROS}

O algoritmo da AERONET está sendo cada vez mais aprimorado, e recentemente foi disponibilizada a separação entre as profundidades ópticas de absorção e espalhamento. Uma exploração contínua e detalhada dos produtos de profundidade óptica de absorção e profundidade óptica de espalhamento da rede de radiômetros da AERONET é recomendada. Essas propriedades são calculadas a partir das medidas diretas de radiância e não estão restringidas às medidas de almucantar e de plano principal, que ocorrem somente em ângulos solares zenital maiores que $45^{\circ}$. Esse fato confere um número maior de observações em relação às inversões da função de fase e albedo de espalhamento único, o que possibilita uma análise climatológica mais detalhada, principalmente durante a estação chuvosa na região Amazônica. Também recomenda-se a comparação dessas propriedades com medidas físicas independentes, ao nível do solo, de seção de choque de espalhamento medidas pelo nefelômetro, e de seção de choque de absorção medidas pelo fotômetro de absorção MAAP, por exemplo. 


\section{REFERÊNCIAS BIBLIOGRÁFICAS}

Andreae, M. O. et al. (2001), Transport of biomass burning smoke to the upper troposphere by deep convection in the equatorial region, Geophysical Research Letters, 28(6), 951.

Andreae, M. O., D. Rosenfeld, P. Artaxo, A. A. Costa, G. P. Frank, K. M. Longo, and M. A. F. Silva-Dias (2004), Smoking rain clouds over the Amazon., Science (New York, N.Y.), 303(5662), 1337-42.

Ångström, A., (1929) On the atmospheric transmission of Sun radiation and on dust in the air, Geogr. Ann., 12, 130-159.

Ansmann, A., H. Baars, M. Tesche, D. Müller, D. Althausen, R. Engelmann, T. Pauliquevis, and P. Artaxo (2009), Dust and smoke transport from Africa to South America: Lidar profiling over Cape Verde and the Amazon rainforest, Geophysical Research Letters, 36(11), L11802.

Artaxo, P., F. Gerab, M. A. Yamasoe, and J. V. Martins (1994), Fine mode aerosol composition at three long-term atmospheric monitoring sites in the Amazon Basin, Journal of Geophysical Research, 99(D11), 22857-22868.

Artaxo, P., L. V. Rizzo, M. Paixao, S. de Lucca, P. H. Oliveira, L. L. Lara, K. T. Wiedemann, M. O. Andreae, B. Holben, and J. Schafer (2009), Aerosol Particles in Amazonia: Their Composition, Role in the Radiation Balance, Cloud Formation, and Nutrient Cycles, in Amazonia and global change, p. 233, American Geophysical Union.

Artaxo, P., P. H. Oliveira, L. L. Lara, T. M. Pauliquevis, L. V. Rizzo, C. P. Junior, M. PAIXÃO, and K. M. Longo (2006), Efeitos climáticos de partículas de aerossóis biogênicos e emitidos em queimadas na Amazônia, Revista Brasileira de Meteorologia, 21(3a), 168-22. 
Ben-Ami, Y., I. Koren, Y. Rudich, P. Artaxo, S. T. Martin, and M. O. Andreae (2010a), Transport of North African dust from the Bodélé depression to the Amazon Basin: a case study, Atmospheric Chemistry and Physics, 10(16), 7533-7544, doi:10.5194/acp10-7533-2010.

Ben-Ami, Y., I. Koren, Y. Rudich, P. Artaxo, S. T. Martin, and M. O. Andreae (2010b), Transport of Saharan dust from the Bodélé Depression to the Amazon Basin: a case study, Atmospheric Chemistry and Physics Discussions, 10(2), 4345-4372.

Ben-Ami, Y., I. Koren, Y. Rudich, P. Artaxo, S. T. Martin, and M. O. Andreae (2010c), Transport of Saharan dust from the Bodélé Depression to the Amazon Basin: a case study, Atmospheric Chemistry and Physics Discussions, 10(2), 4345-4372.

Brunekreef, B., and S. T. Holgate (2002), Air pollution and health., Lancet, 360(9341), 1233-42.

Castanho, A., Propriedades ópticas das partículas de aerossol e uma nova metodologia para a obtenção de espessura óptica via satélite sobre São Paulo. Tese de Doutorado defendida no Instituto de Física da Universidade de São Paulo, 2005.

Chu, D. A. (2003), Global monitoring of air pollution over land from the Earth Observing System-Terra Moderate Resolution Imaging Spectroradiometer (MODIS), Journal of Geophysical Research, 108(D21), 1-18.

COX, C., and W. MUNK (1954), Measurement of the Roughness of the Sea Surface from Photographs of the Sun's Glitter, Journal of the Optical Society of America, 44(11), 838.

Dias (2002), Cloud and rain processes in a biosphere-atmosphere interaction context in the Amazon Region, JOURNAL OF GEOPHYSICAL RESEARCH-ATMOSPHERES, 107(D20), 8072. 
Donkelaar, A. van, R. V. Martin, and R. J. Park (2006), Estimating ground-level PM 2.5 using aerosol optical depth determined from satellite remote sensing, Journal of Geophysical Research, 111(D21).

Donkelaar, A. van, R. V. Martin, M. Brauer, R. Kahn, R. Levy, C. Verduzco, and P. J. Villeneuve (2010), Global estimates of ambient fine particulate matter concentrations from satellite-based aerosol optical depth: development and application., Environmental health perspectives, 118(6), 847-55.

Dubovik, O. et al. (2006a), Application of spheroid models to account for aerosol particle nonsphericity in remote sensing of desert dust, Journal of Geophysical Research, 111(D11), 1-34.

Dubovik, O. et al. (2006b), Application of spheroid models to account for aerosol particle nonsphericity in remote sensing of desert dust, Journal of Geophysical Research, 111(D11), 1-34.

Dubovik, O., A. Smirnov, B. N. Holben, M. D. King, Y. J. Kaufman, T. F. Eck, and I. Slutsker (2000), Accuracy assessments of aerosol optical properties retrieved from Aerosol Robotic Network (AERONET) Sun and sky radiance measurements, Journal of Geophysical Research, 105(D8), 9791-9806.

Dubovik, O., and M. D. King (2000), A flexible inversion algorithm for retrieval of aerosol optical properties from Sun and sky radiance measurements, Journal of Geophysical Research, 105(D16), 20673-20696.

Dubovik, O., B. N. Holben, T. F. Eck, A. Smirnov, Y. J. Kaufman, M. D. King, D. Tanré, and I. Slutsker (2002), Variability of Absorption and Optical Properties of Key Aerosol Types Observed in Worldwide Locations, Journal of the Atmospheric Sciences, 59(3), 590-608. 
Dubuisson, P., J. C. Buriez, and Y. Fouquart (1996), High spectral resolu- tion solar radiative transfer in absorbing and scattering media, application to the satellite simulation, J. Quant. Spectrosc. Radiat. Transfer, 55(1), 103-126.

Eck, T. F., B. N. Holben, J. S. Reid, O. Dubovik, A. Smirnov, N. T. O’Neill, I. Slutsker, and S. Kinne (1999), Wavelength dependence of the optical depth of biomass burning, urban, and desert dust aerosols, Journal of Geophysical Research, 104(D24), 3133331349.

Engel-Cox, J. (2004), Qualitative and quantitative evaluation of MODIS satellite sensor data for regional and urban scale air quality, Atmospheric Environment, 38(16), 24952509.

Engel-Cox, J. a, R. M. Hoff, R. Rogers, F. Dimmick, A. C. Rush, J. J. Szykman, J. AlSaadi, D. A. Chu, and E. R. Zell (2006), Integrating lidar and satellite optical depth with ambient monitoring for 3-dimensional particulate characterization, Atmospheric Environment, 40(40), 8056-8067.

Fearnside, P. M. (1986), Human carrying capacity of the Brazilian rainforest, Columbia University Press.

Formenti, P., M. O. Andreae, L. Lange, G. Roberts, J. Cafmeyer, I. Rajta, W. Maenhaut, B. N. Holben, P. Artaxo, and J. Lelieveld (2001), Saharan dust in Brazil and Suriname during the Large-Scale Biosphere-Atmosphere Experiment in Amazonia (LBA) Cooperative LBA Regional Experiment (CLAIRE) in March 1998, Journal of Geophysical Research, 106(D14), 14919-14934.

Forster, P., V. Ramaswamy, P. Artaxo, T. Berntsen, R. Betts, and D. W. Fahey (2007), Changes in Atmospheric Constituents and in Radiative Forcing, in Climate Change 2007: The Physical Science Basis. Contribution of Working Group I to the Fourth Assessment Report of the Intergovernmental Panel on Climate Change, edited by H. L. Milleredited by, with M.Tignor, Cambridge University Press, Cambridge, United Kingdom and New York, NY, USA. 
Freitas, S. R., K. M. Longo, M. a F. Silva Dias, P. L. Silva Dias, R. Chatfield, E. Prins, P. Artaxo, G. a Grell, and F. S. Recuero (2005), Monitoring the transport of biomass burning emissions in South America, Environmental Fluid Mechanics, 5(1-2), 135167.

García, O. E. et al. (2008a), Validation of AERONET estimates of atmospheric solar fluxes and aerosol radiative forcing by ground-based broadband measurements, Journal of Geophysical Research, 113(D21), 1-16.

Gash, J. H. C., and C. A. Nobre (1996), Amazonian Deforestation and Climate, John Wiley.

Hoelzemann, J. J., K. M. Longo, R. M. Fonseca, N. M. E. do Rosário, H. Elbern, S. R. Freitas, and C. Pires (2009a), Regional representativity of AERONET observation sites during the biomass burning season in South America determined by correlation studies with MODIS Aerosol Optical Depth, Journal of Geophysical Research, 114(D13), 120.

Holben, B. N., T. F. Eck, and R. S. Fraser (1991), Temporal and spatial variability of aerosol optical depth in the Sahel region in relation to vegetation remote sensing, International Journal of Remote Sensing, 12(6), 1147-1163.

Holben, B. N., T. F. Eck, I. Slutsker, A. Smirnov, A. Sinyuk, J. Schafer, D. Giles, and O. Dubovik (2006), Aeronet's Version 2.0 quality assurance criteria, SPIE.

Hopke, P. K., Y. Xie, T. Raunemaa, S. Biegalski, S. Landsberger, W. Maenhaut, P. Artaxo, and D. Cohen (1997), Characterization of the Gent Stacked Filter Unit PM10 Sampler, Aerosol Science and Technology, 27(6), 726-735.

Ichoku, C. (2003), MODIS observation of aerosols and estimation of aerosol radiative forcing over southern Africa during SAFARI 2000, Journal of Geophysical Research, 108(D13), 1-13. 
Kauffman, J. B., D. L. Cummings, and D. E. Ward (1994), Relationships of Fire, Biomass and Nutrient Dynamics along a Vegetation Gradient in the Brazilian Cerrado, The Journal of Ecology, 82(3), 519.

Kaufman, Y. J. (2005), Aerosol anthropogenic component estimated from satellite data, Geophysical Research Letters, 32(17), 3-6.

Koren, Ilan, Lorraine A Remer, and Karla Longo. "Reversal of trend of biomass burning in the Amazon." Geophysical Research Letters 34, no. 20 (October 18, 2007): 2-5.

Kuhn, U. et al. (2010), Impact of Manaus City on the Amazon Green Ocean atmosphere: ozone production, precursor sensitivity and aerosol load, Atmospheric Chemistry and Physics Discussions, 10(5), 13091-13178.

Levy, R. C., L. a Remer, R. G. Kleidman, S. Mattoo, C. Ichoku, R. Kahn, and T. F. Eck (2010), Global evaluation of the Collection 5 MODIS dark-target aerosol products over land, Atmospheric Chemistry and Physics, 10(21), 10399-10420.

Liou, K.-N. (2002), An Introduction to Atmospheric Radiation, Academic Press.

Liousse, C. et al. (2004), Deriving global quantitative estimates for spatial and temporal distributions of biomass burning emissions, in Emissions of atmospheric trace compounds, edited by C. Granier, P. Artaxo, and C. E. Reeves, pp. 71-113, Springer.

Liu, Y., J. a Sarnat, V. Kilaru, D. J. Jacob, and P. Koutrakis (2005), Estimating groundlevel PM2.5 in the eastern United States using satellite remote sensing., Environmental science \& technology, 39(9), 3269-78.

Marengo, J. a (2004), Interdecadal variability and trends of rainfall across the Amazon basin, Theoretical and Applied Climatology, 78(1-3), 1-18, doi:10.1007/s00704-0040045-8.

Martin, R. (2008), Satellite remote sensing of surface air quality, Atmospheric Environment, 42(34), 7823-7843. 
Martin, S. T. et al. (2010b), Sources and properties of Amazonian aerosol particles, Reviews of Geophysics, 48(2).

Martins, J. V., P. Artaxo, C. Liousse, J. S. Reid, P. V. Hobbs, and Y. J. Kaufman (1998a), Effects of black carbon content, particle size, and mixing on light absorption by aerosols from biomass burning in Brazil, Journal of Geophysical Research, 103(D24), 32041-32050.

Martins, J. V., P. Artaxo, C. Liousse, J. S. Reid, P. V. Hobbs, and P. Artaxo (1998b), Sphericity and morphology of smoke particles from biomass burning in Brazil, Journal of Geophysical Research, 103(D24), 32051-32057.

Nakajima, T. et al., Use of sky brightness measurements from ground for remote sensing of particulate polydispersion. Applied Optics, 35, 2672-2686, 1996.

Nakajima, T., Tanaka, M., Algorithm for radiative intensity calculations in moderately thick atmosphere using a truncation approximation. Journal of Quantitative Spectroscopy \& Radiative Transfer, 40, 51-69, 1998.

Nakajima, T., Tanaka, M., Yamauchi, T., Retrieval of the optical properties of aerosols from aureole and extinction data. Applied Optics, 22, 2951-2959, 1983.

Oliveira, P. H. F., P. Artaxo, C. Pires, S. de Lucca, A. Procopio, B. Holben, J. Schafer, L. F. Cardoso, S. C. Wofsy, and H. R. Rocha (2007), The effects of biomass burning aerosols and clouds on the CO 2 flux in Amazonia, Tellus B, 59(3), 338-349.

Patadia, F., P. Gupta, S. A. Christopher, and J. S. Reid (2008), A Multisensor satellitebased assessment of biomass burning aerosol radiative impact over Amazonia, Journal of Geophysical Research, 113(D12), 1-14.

Pokrovsky, O. (2003), Land surface albedo retrieval via kernel-based BRDF modeling: I. Statistical inversion method and model comparison, Remote Sensing of Environment, 84(1), 100-119. 
Pope III, C. A. (2002), Lung Cancer, Cardiopulmonary Mortality, and Long-term Exposure to Fine Particulate Air Pollution, JAMA: The Journal of the American Medical Association, 287(9), 1132-1141.

Pope, C. A., R. T. Burnett, G. D. Thurston, M. J. Thun, E. E. Calle, D. Krewski, and J. J. Godleski (2004), Cardiovascular mortality and long-term exposure to particulate air pollution: epidemiological evidence of general pathophysiological pathways of disease., Circulation, 109(1), 71-7.

Procópio, A. S. (2003b), Modeled spectral optical properties for smoke aerosols in Amazonia, Geophysical Research Letters, 30(24).

Prospero, J. M., R. A. Glaccum, and R. T. Nees (1981), Atmospheric transport of soil dust from Africa to South America, Nature, 289(5798), 570-572.

Remer, L. A (2002), Validation of MODIS aerosol retrieval over ocean, Geophysical Research Letters, 102(12), 16,971.

Roger, J. C., M. Mallet, P. Dubuisson, H. Cachier, E. Vermote, O. Dubovik, and S. Despiau (2006), Asynergetic approach for estimating the local direct aerosol forcing: Application to an urban zone during the ESCOMPTE experiment, J. Geophys. Res., 111, D13208.

Schaap, M., A. Apituley, R. M. a Timmermans, R. B. a Koelemeijer, and G. de Leeuw (2008), Exploring the relation between aerosol optical depth and PM2.5 at Cabauw, the Netherlands, Atmospheric Chemistry and Physics Discussions, 8(5), 17939-17986.

Schafer, J. S., T. F. Eck, B. N. Holben, P. Artaxo, and a F. Duarte (2008), Characterization of the optical properties of atmospheric aerosols in Amazônia from long-term AERONET monitoring (1993-1995 and 1999-2006), Journal of Geophysical Research, 113(D4), 1-16.

Schmid, B. et al. (2001), Comparison of Columnar Water-Vapor Measurements from Solar Transmittance Methods, Applied Optics, 40(12), 1886. 
Schneider, J., F. Freutel, S. R. Zorn, Q. Chen, D. K. Farmer, J. L. Jimenez, P. Artaxo, A. Wiedensohler, and S. Borrmann (2011), Mass-spectrometric identification of primary biological particle markers : indication for low abundance of primary biological material in the pristine submicron aerosol of Amazonia, Atmospheric Chemistry and Physics Discussions, (March), 1-32.

Seinfeld, J. H., and S. N. Pandis (2006), Atmospheric chemistry and physics: from air pollution to climate change, Wiley.

Sinyuk, A., O. Dubovik, B. Holben, T. Eck, F. Breon, J. Martonchik, R. Kahn, D. Diner, E. Vermote, and J. Roger (2007), Simultaneous retrieval of aerosol and surface properties from a combination of AERONET and satellite data, Remote Sensing of Environment, 107(1-2), 90-108.

Solomon, S., G.-K. Plattner, R. Knutti, and P. Friedlingstein (2009), Irreversible climate change due to carbon dioxide emissions., Proceedings of the National Academy of Sciences of the United States of America, 106(6), 1704-9.

Stamnes, K., Tsay, S.C., Wiscombe, W., Jayaweera, K, Numerically stable algorithm for discrete ordinate method radiative transfer in multiple scattering and emitting layered media, Applied Optics, 27, 2502-2509, 1998.

Wang, J. (2003), Intercomparison between satellite-derived aerosol optical thickness and PM 2.5 mass: Implications for air quality studies, Geophysical Research Letters, $30(21), 2-5$.

Ward, D. E., J. B. Susott, J. B. Kauffman, R. E. Babbit, D. L. Cummings, B. Dias, B. N. Holben, Y. J. Kaufman, R. A. Rasmussen, and A. Setzer (1992), Smoke and Fire Characteristics for Cerrado and Deforestation Burns in Brazil: BASE-B Experiment, Journal of Geophysical Research, 97(D13), 14601-14619. 
Yamasoe, M. (2000), Chemical composition of aerosol particles from direct emissions of vegetation fires in the Amazon Basin: water-soluble species and trace elements, Atmospheric Environment, 34(10), 1641-1653.

Yamasoe, M.A., Estudo de propriedades ópticas de partículas de aerossóis a partir de uma rede de radiômetros. Tese de Doutorado defendida no Instituto de Física da Universidade de São Paulo, 1999. 


\title{
8 APÊNDICE I
}

Resumo de artigo em fase final de revisão sobre a relação entre profundidade óptica do aerossol medida por sensoriamento remoto e concentração de material particulado fino, a ser submetido à revista $A C P$ - Atmospheric Chemistry and Physics.

Quantitative and qualitative relationship between AOD obtained by AERONET and MODIS and $\mathbf{P M}_{2.5}$ from in situ measurements in Brazilian Amazonia over several years

\author{
M. Paixão', D. Mourao², A. Correia', S. Hacon², P. Artaxo ${ }^{1}$ \\ [1]\{Institute of Physics, University of Sao Paulo, Sao Paulo, Brazil $\}$ \\ [2]\{Escola de Saúde Pública da Fundação Oswaldo Cruz, Rio de Janeiro, Brazil \} \\ Abstract
}

It was used long-term AERONET aerosol optical depth measurements to find a relationship with in situ PM2.5 concentrations obtained by several intensive sampling campaigns since 1995 to 2006 performed in the Amazon Basin. Aerosol optical thickness was measured using CIMEL radiometers to derive aerosol optical thickness (AOT) as part of the NASA/AERONET network. AERONET level 2 AOT with the latest inversion procedures was used to guarantee good cloud screening and aerosol physical properties. Additionally AOT was also derived from the MODIS sensor on Terra and Aqua satellites, with a resolution of $10 \mathrm{Km}$ around the ground based sampling site. Looking at the time series, aerosol concentrations varied significantly, and it was possible to notice a change in the PM2.5 aerosol load in Alta Floresta about the year 2000, but the optical properties were not affected. It was found a statistically significant correlation and an average linear regression of $\mathrm{PM}_{2.5}=(37 \pm 2)$ AOD500 + $(5 \pm 2)$ in $\mu \mathrm{g} / \mathrm{m}^{3}$ in the deforestation arc evaluated from $2001-$ 2006 is proposed. Estimates from MODIS aerosol optical depth was used to calculate ground based PM2.5 concentrations, with statistically significant agreement. This technique is very useful to assess health effects of aerosols in Amazonia, or in sites affected by biomass burning aerosols were no ground based measurements exists. 